

This work is licensed under the Creative Commons License 3.0 "by-nd", allowing you to download, distribute and print the document in a few copies for private or educational use, given that the document stays unchanged and the creator is mentioned. You are not allowed to sell copies of the free version. 
erschienen als Band 38 der Reihe „Göttinger Bibliotheksschriften“ im Universitätsverlag Göttingen 2011 


\section{Bücher unter Verdacht}

NS-Raub- und Beutegut

an der SUB Göttingen

Katalog der Ausstellung vom

13. Mai - 10. Juli 2011

Bearbeitet von Nicole Bartels, Juliane Deinert, Wilfried Enderle und Helmut Rohlfing (mit einem Beitrag von Frank Möbus zur Bibliothek des Seminars für Deutsche Philologie)

Göttinger Bibliotheksschriften Band 38

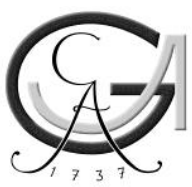

Universitätsverlag Göttingen 2011 


\section{Bibliographische Information der Deutschen Nationalbibliothek}

Die Deutsche Nationalbibliothek verzeichnet diese Publikation in der Deutschen Nationalbibliographie; detaillierte bibliographische Daten sind im Internet über $<$ http://dnb.ddb.de $>$ abrufbar.

Göttinger Bibliotheksschriften

herausgegeben von

Prof. Dr. Norbert Lossau

Niedersächsische Staats- und Universitätsbibliothek Göttingen

Platz der Göttinger Sieben 1

D - 37073 Göttingen

Dieses Buch ist auch als freie Onlineversion über die Homepage des Verlags sowie über den OPAC der Niedersächsischen Staats- und Universitätsbibliothek (http://www.sub.uni-goettingen.de) erreichbar und darf gelesen, heruntergeladen sowie als Privatkopie ausgedruckt werden. Es gelten die Lizenzbestimmungen der Onlineversion. Es ist nicht gestattet, Kopien oder gedruckte Fassungen der freien Onlineversion zu veräußern.

Satz und Layout: SUB Göttingen (Lena Kietzmann)

Umschlaggestaltung: SUB Göttingen (Kathrin Overesch, Jutta Pabst)

(C) 2011 Universitätsverlag Göttingen http:/ / univerlag.uni-goettingen.de

ISBN: 978-3-86395-027-9

ISSN: 0943-951X 


\section{Inhaltsverzeichnis}

$\begin{array}{ll}\text { Vorwort } & 7\end{array}$

Einführung 9

A. NS-Raub- und Beutebücher und die Universitätsbibliothek Göttingen 1933-1945

1. NS-Raub- und Beutebücher in wissenschaftlichen Bibliotheken 11

2. Zur Geschichte der Universitätsbibliothek Göttingen im Dritten Reich 14

3. NS-Raubgut in der Universitätsbibliothek Göttingen 21

4. Wie findet man NS-Raubgut? - Die Projektarbeit an der SUB Göttingen 27

B. NS-Raubgut aus den Jahren 1933-1945

1. Verbotene Literatur aus Volksbüchereien und Leihbuchhandlungen 33

2. Bücher aus Arbeiterbibliotheken und sozialdemokratischen Vereinen 41

3. Die Deutsche Arbeitsfront 47

4. Bücher von politisch und rassisch Verfolgten: Walter Heise 50

5. Bücher von politisch und rassisch Verfolgen: Dr. Heinrich Tröger 56

6. Bücher von politisch und rassisch Verfolgten: Dr. Friedrich Fischl und Dr. Hanns Fischl 61

C. NS-Beutebücher 1939-1945

1. Bücher aus deutschen Kriegsgefangenenlagern 67

2. Bücher aus den besetzten Gebieten $\quad 72$

D. Verdachtsfälle und ungeklärte Fälle: Unlösbarkeiten bei der Suche nach NS-Raub- und Beutegut

E. Raubgut am Seminar für Deutsche Philologie der Universität Göttingen

F. Restitutionen und die Provenienzforschung an der SUB Göttingen nach Abschluß des Projektes 


\section{Vorwort}

Die Niedersächsische Staats- und Universitätsbibliothek Göttingen hat vom 13. Mai bis 10. Juli 2011 im Foyer der Zentralbibliothek am Platz der Göttinger Sieben eine Ausstellung unter dem Titel Bücher unter Verdacht. NS-Raub-und Beutegut an der SUB Göttingen gezeigt. Zum ersten Mal hat die SUB Göttingen damit öffentlich dokumentiert, wie und in welchem Umfang NS-verfolgungsbedingt entzogene Kulturgüter, wie es in juristischer Formulierung heißt, in ihre Bestände gekommen waren. Diese Ausstellung basiert auf einem Forschungsprojekt zur Ermittlung und Restitution von NS-Raub- und Beutebüchern an der SUB Göttingen, das vom 1. Juni 2009 bis 31. August 2011 an der Niedersächsischen Staats- und Universitätsbibliothek Göttingen durchgeführt wurde. Nicht möglich gewesen wäre dieses Projekt ohne die Aufstockung der eigenen Mittel durch die finanzielle Unterstützung über die Arbeitsstelle für Provenienzrecherche/-forschung am Institut für Museumsforschung der Staatlichen Museen zu Berlin - Stiftung Preußischer Kulturbesitz, aus Mitteln des Beauftragten der Bundesregierung für Kultur und Medien. Vorangegangen war ein zum 1. September 2008 begonnenes, initiierendes Vorprojekt, das anteilig vom Präsidium der Universität Göttingen und der SUB Göttingen finanziert worden war. Die Ausstellung selbst erhielt maßgebliche Unterstützung durch den Universitätsbund Göttingen e.V. Allen Drittmittelgebern ist die SUB Göttingen dafür zu Dank verpflichtet.

Dass die SUB Göttingen vor einigen Jahren begonnen hat, ihre eigene Raubgutgeschichte zu rekonstruieren, hat sie dem Interesse und der Neugier eines ihrer Referendare, Arno Barnert, zu verdanken, der sich begleitend zu seiner Ausbildung für dieses Thema interessierte und die ersten Fälle verdächtiger Bücher entdeckte. Einige Ergebnisse seiner Arbeit wurden im Mai 2008 im Rahmen einer von Frank Möbus im Alten Rathaus der Stadt Göttingen organisierten Ausstellung zum 75. Jahrestag der Bücherverbrennung vom 10.5.1933 öffentlich gemacht. Für die Durchführung der ersten Vor-Untersuchungen konnten die Historikerinnen Nicole Bartels und Juliane Deinert gewonnen werden, die in der Folge das von Wilfried Enderle und Helmut Rohlfing, SUB Göttingen, geleitete Hauptprojekt verantwortlich durchführten.

Der Online-Katalog der SUB Göttingen dokumentiert heute umfassend und auf Dauer die Ergebnisse des Projektes. Jeder Leser kann die aufgezeigten Raubgutfälle finden und etwas über die individuelle Geschichte dieses Buches lernen. Um die Ergebnisse des Projektes auch erstmals der interessierten Öffentlichkeit bekannt zu machen, hat das Projektteam der SUB Göttingen zum Ende des Projektes mit Unterstützung von Silke Glitsch und Katharina Overesch, Stabsstelle Öffentlichkeitsarbeit der SUB, die genannte Ausstellung erarbeitet. Der vorliegende Katalog macht somit die Ausstellung und die Ergebnisse des Projekts gleichsam auf Dauer zugänglich. Die Ausstellung haben dankenswerterweise unterstützt: 
Archiv der Friedrich Ebert-Stiftung Bonn; Kreisarchiv Göttingen; Museum Nienburg/Weser; Staatsarchiv Hamburg; Staatsarchiv Stade; Stadtarchiv Göttingen; Stadtarchiv Hann. Münden; Universitätsarchiv Göttingen. Für die Herstellung der Druckvorlage des Kataloges ist Lena Kietzmann zu danken; für die Unterstützung der Druckvorbereitung beim Göttinger Universitätsverlag Jutta Pabst. Prof. Trude Maurer danken wir für Korrekturhinweise bei der Ausstellung.

Norbert Lossau 


\section{Einführung}

Die Geschichte von Raub- und Beutebüchern im Bestand wissenschaftlicher Bibliotheken ist eine Geschichte des Verdrängens und Vergessens. In der unmittelbaren Nachkriegszeit wollte man sich daran nicht erinnern - daher wurde auch nicht darüber geschrieben. Ausgerechnet Bibliotheken, die mitunter gerne als Schatzhäuser der Erinnerung, als Orte kultureller Überlieferung apostrophiert werden, hätten somit einen - wenn auch nicht gerade einen ruhmvollen Teil - ihrer eigenen Geschichte verloren, obwohl zugleich die Spuren des Geschehens in ihren eigenen Beständen sichtbar vorhanden waren und sind - aber vielfach nicht beachtet und übersehen wurden. Dass es soweit nicht kam, hat sicherlich mehrere Gründe: Es hat nicht zuletzt mit der Entwicklung der geschichtswissenschaftlichen wie der bibliothekshistorischen Forschung zu tun. Im Laufe der 1980er Jahre haben sich die Bibliothekshistoriker erstmals etwas intensiver der Zeit des Dritten Reiches zugewandt. Gleichzeitig begann sich die Geschichtswissenschaft ausführlicher als zuvor mit dem Thema der „Arisierungen“ im Dritten Reich, den Enteignungen und der Beraubung der Juden, zu beschäftigten. Hinzu kam, dass sich nach 1989 auch die Frage nach der Restitution jüdischen Besitzes aus dem Gebiet der ehemaligen DDR neu stellte. Die Suche nach den legitimen Besitzern international bekannter Kunstwerke gab der Provenienzforschung sowie überhaupt der Erforschung des Raubs von Kulturgütern im Dritten Reich neuen Anschub. Dass Bibliothekare seit Anfang der 1990er Jahre erstmals begannen, sich mit dem Thema NS-Raubgut in ihren Beständen zu beschäftigen, hängt aber wohl auch damit zusammen, dass nach der Generation der Bibliothekare, die noch in der NS-Zeit tätig waren und nach der Generation derjenigen, die von diesen Bibliothekaren ausgebildet worden waren, mittlerweile eine dritte Generation sich diesem Thema unbefangener und frei von persönlicher Beteiligung und Verantwortung nähern konnte. In Deutschland waren es die Staats- und Universitätsbibliothek Bremen sowie die Universitätsbibliothek Marburg, die als erste ihre Bestände genauer untersuchten. Mit den seit 1992 in regelmäßigen Abständen stattfindenden Hannoveraner Symposien zum Thema NS-Raubgut hat die GottfriedWilhelm-Leibnizbibliothek in Hannover ein wissenschaftliches Forum geschaffen, welches das Thema im Blick der Bibliothekare hielt und den Austausch darüber förderte.

Bei der Konzeption des Kataloges wurde bewusst darauf verzichtet, einen neuen, in sich konsistenten Text zu schreiben. Der Katalog dokumentiert also Stellwand- und Objekttexte der Ausstellung, wobei in einzelnen Fällen Texte etwas erweitert und um Literaturhinweise ergänzt wurden. Außerdem werden einige der ausgestellten Objekte ganz oder im Ausschnitt in Abbildungen gezeigt. Diese Beschränkung des Katalogs auf eine reine Dokumentation der Ausstellung hängt natürlich auch mit den begrenzten Mitteln und Möglichkeiten des Projektes zu- 
sammen, vor allem aber damit, dass es noch kaum Literatur zur Geschichte der Göttinger Universitätsbibliothek im Dritten Reich gibt. Diese Phase der Geschichte, wie generell die Geschichte der Bibliothek im 20. Jahrhundert, ist noch nicht gründlich erforscht worden. Der vorliegende Katalog kann und will in dieser Hinsicht nicht mehr als ein erster Baustein, gleichsam eine Vorstudie für eine notwendige, umfangreichere Darstellung der Geschichte der Göttinger Universitätsbibliothek im Dritten Reich sein. Vor allem und zunächst aber soll er dazu dienen, die Ergebnisse des Projektes und damit die Geschichte der NS-Raub- und Beutebücher der Universitätsbibliothek Göttingen auf Dauer im Gedächtnis der Bibliothekare und der Öffentlichkeit zu halten. Und vielleicht kann er aber auch dazu beitragen, weitere Informationen zu den vorgestellten Büchern, insbesondere zu den Beispielen ungelöster Fälle, durch Leser zu bekommen. Denn Provenienzrecherchen sind ein Puzzlespiel, bei dem erst durch das Zusammenkommen vieler Einzelinformationen eindeutige Aussagen über die Geschichte eines Buches zu erzielen sind. Nutzer der SUB Göttingen, die also ältere, vor 1945 erschienene Bücher der Bibliothek lesen, in denen sich auffällige Besitzstempel oder Eintragungen befinden, mögen also mitunter kurz innehalten und über die Geschichte des Buches, das sie gerade gelesen haben, nachdenken. Die Bibliothek ist für Hinweise auf möglicherweise interessante Provenienzeinträge dankbar. Auch wenn in dem durchgeführten Projekt systematisch nach Raubgut recherchiert und eine beträchtliche Anzahl von Raub- und Beutebüchern ermittelt wurden, so können, wie in dem Katalog auch gezeigt wird, damit nicht alle einzelnen Fälle, insbesondere antiquarische Erwerbungen nach 1945, abgedeckt werden.

$\mathrm{HR} / \mathrm{WE}$ 


\section{A. NS-Raub- und Beutebücher und die Universitätsbibliothek Göttingen 1933 - 1945}

\section{NS-Raub- und Beutebücher in wissenschaftlichen Bibliotheken}

Das nationalsozialistische Deutschland hat nicht nur systematisch Kunstwerke, sondern in großem Umfang auch Bücher geraubt - ein historischer Vorgang, der im öffentlichen Gedächtnis bislang kaum präsent ist. ${ }^{1}$ In Deutschland beschlagnahmte Bücher von Institutionen und Privatpersonen werden als NS-Raubbücher bezeichnet, Bücher, die während des Zweiten Weltkrieges in den besetzten Gebieten geraubt wurden, als Beutebücher.

Woher kamen die Bücher aber genau? In den ersten Jahren der NS-Herrschaft war es zunächst sogenannte „verbotene“ Literatur, die in Buchhandlungen, bei Verlagen und in Büchereien beschlagnahmt wurde. Dazu kamen aber rasch auch größere Mengen von Büchern aus Bibliotheken von Einrichtungen verbotener Organisationen, wie Parteien, Gewerkschaften, Freimaurerlogen und Vereinen. Dabei handelte es sich dann nicht mehr nur um sogenannte „verbotene“ Literatur, sondern, je nach dem Umfang und Sammlungsprofil einer beschlagnahmten Bibliothek, um ein breites Spektrum unterschiedlichster Literatur von der Belletristik bis zum Fachbuch. Auch Privatbibliotheken politisch Verfolgter blieben vor dem Zugriff der NS-Behörden nicht verschont. Das gilt insbesondere auch für jüdische „Staatsangehörige“ - seit den Nürnberger Rassegesetzen vom 15.9.1935 waren Juden keine Reichsbürger mehr. Einen ersten, traurigen Höhepunkt bei der Beschlagnahmung von Büchern aus jüdischem Besitz markierte die Reichspogromnacht vom 9. November 1938 als SS und Gestapo eine erhebliche Anzahl jüdischer Gemeindebibliotheken beschlagnahmten (insgesamt ca. 300.000 Bände aus 71 Bibliotheken). ${ }^{2}$ Während des Krieges wurde der Bücherraub - unter anderem

${ }^{1}$ Einen guten Überblick gibt Bernd Reifenberg: NS-Raubgut in deutschen Bibliotheken. In: Raub und Restitution. Kulturgut aus jüdischem Besitz von 1933 bis heute, hrsg. von Inka Bertz und Michael Dormann, Berlin 2008, S. 157-171.

2 Werner Schroeder: Beschlagnahme und Verbleib jüdischer Bibliotheken in Deutschland vor und nach dem Novemberpogrom 1938. Der Kampf nationalsozialistischer und staatlicher Institutionen im Deutschen Reich um die jüdischen Bücher. In: Jüdischer Buchbesitz als Raubgut. Zwei- 
durch spezielle Einheiten wie den Einsatzstab Reichsleiter Rosenberg ${ }^{3}$, das Sonderkommando Künsberg ${ }^{4}$ oder durch verschiedene SS-Organisationen, aber auch durch die Wehrmacht - in weitaus größerem Stil in den besetzten Gebieten fortgeführt. Insbesondere in Osteuropa wurde dabei nicht nur hemmungslos geraubt, sondern es wurden vielfach auch vorhandene Büchereien zerstört, um bewusst den slawischen Völkern die Grundlage ihrer kulturellen Identität zu entziehen. Allein in Polen sollen 71\% der vor 1939 bestandenen Büchersammlungen zerstört worden sein. ${ }^{5}$

Wohin gingen die Bücher? In den ersten Jahren des Dritten Reiches waren häufig Universitäts- und Landesbibliotheken die Nutznießer. Kommunale Behörden, Bürgermeister- oder Landratsämter hatten keinen Raum und kein Interesse an den Büchern und gaben sie an wissenschaftliche Bibliotheken weiter. Oftmals wurden Bücher aber auch einfach zerstört. Mit einem Erlass vom 27. März 1934 versuchte das Reichsfinanzministerium das Verfahren etwas zu systematisieren, indem es anordnete, dass die beschlagnahmenden Behörden Listen der Bücher an die Preußische Staatsbibliothek melden sollten. Diese konnte dann Bücher für sich aussuchen, die übrigen wurden an andere Bibliotheken im Reich verteilt. So kamen ab 1934 Bücher aus beschlagnahmten Bibliotheken vermehrt über die PreuBische Staatsbibliothek sowie die bei ihr angesiedelte Reichstauschstelle, aber daneben immer auch noch über lokale Behörden in den Besitz wissenschaftlicher Bibliotheken, wo sie in der Regel unter der Rubrik „Geschenk/Tausch“ eingearbeitet wurden. ${ }^{6}$ Wie viele Bände bis 1945 an Universitätsbibliotheken verteilt wurden, ist beim derzeitigen Forschungsstand schwer zu sagen. Es könnten zwischen 300.000 und 700.000 (ohne die österreichischen Bibliotheken) gewesen sein. ${ }^{7}$

tes Hannoversches Symposium, hrsg. von Regine Dehnel (=Zeitschrift für Bibliothekswesen und Bibliographie, Sonderh. 88) Frankfurt/Main 2006, S. 36.

${ }^{3}$ Donald E. Collins / Herbert P. Rothfeder: The Einsatzstab Reichsleiter Rosenberg and the Looting of Jewish and Masonic Libraries during World War II. In: The Journal of Library History, Bd. 18, 1983, S. 21-36.

${ }^{4}$ Ulrike Hartung: Raubzüge in der Sowjetunion. Das Sonderkommando KÜNSBERG 1941-1943, Bremen 1997; Anja Heuss: Die "Beuteorganisation" des Auswärtigen Amtes. Das Sonderkommando Künsberg und der Kulturgutraub in der Sowjetunion. In: Vierteljahrshefte für Zeitgeschichte, Bd. 45, 1997, S. 535-556.

5 Andrzej Mezynski: Polnische Bibliotheken in den Jahren 1939 bis 1945. Die Politik der Besatzungsmächte und der Verlust von Büchersammlungen in Polen. In: Stefan Alker / Christina Köster / Markus Stumpf (Hrsg.): Bibliotheken in der NS-Zeit. Provenienzforschung und Bibliotheksgeschichte, Göttingen 2008, S. 301.

${ }^{6}$ Cornelia Briel: Zum Verhältnis zwischen Reichstauschstelle und Preußischer Staatsbibliothek in den Jahren 1934 bis 1945. In: Hans-Erich Bödeker / Gerd-Josef Bötte (Hrsg.): NS-Raubgut, Reichstauschstelle und Preußische Staatsbibliothek. Vorträge des Berliner Symposiums am 3. und 4. Mai 2007, München 2008, S. 45-83.

${ }^{7}$ Dies kann man vermuten, wenn man einerseits die bisherigen Ergebnisse der Provenienzforschung an Universitätsbibliotheken berücksichtigt, und andererseits die Zugänge über Tausch- und Geschenke auf der Basis der statistischen Daten des Jahrbuchs der deutschen Bibliotheken auswertet. Berücksichtigen muss man, dass alle Bibliotheken nach 1945 und ggf. bis heute über anti- 
Auch selbständige Seminar- und Institutsbibliotheken an Universitäten gelangten in den Besitz geraubter Bücher. Die in quantitativer Hinsicht größten Nutznießer des NS-Bücherraubs, insbesondere von den Beutezügen im Krieg, waren indes verschiedene NS-Organisationen, von denen einige bereits vor dem Krieg begonnen hatten, Bibliotheken aufzubauen. 1936 wurde zum Beispiel am Arbeitswissenschaftlichen Institut der Deutschen Arbeitsfront (DAF) eine sozial- und volkswirtschaftliche Zentralbibliothek gegründet, die ca. 300.000 Bände aus beschlagnahmten Gewerkschaftsbibliotheken übernahm. ${ }^{8}$ Auch der Sicherheitsdienst (SD) der NSDAP begann eine große Bibliothek zur sogenannten „Gegnerforschung“ aufzubauen, die vor allem Literatur zum Judentum, Marxismus und zu den Freimaurern umfasste. 1942 sollen so bereits 700.000 Bände zusammengekommen sein. In großem Stil wurden auch für die Zentralbibliothek der Hohen Schule der NSDAP, einer geplanten Parteiuniversität, die nach dem Krieg am Chiemsee eröffnet werden sollte, Bücher geraubt. Allein das Institut zur Erforschung der Judenfrage, das einzige bereits begründete Institut der Hohen Schule, soll 1943 in Frankfurt eine Bibliothek von ca. 550.000 Bänden besessen haben. ${ }^{9}$

Wie umfangreich die Plünderungen durch das NS-Regime gewesen waren, zeigt schon der Umstand, dass die Alliierten nach Kriegsende in Offenbach ein Archival Depot anlegten, wo sie geraubte Bücher aus Bergungsorten sammelten. Über 3 Millionen Bände konnten darüber nach 1945 restituiert werden. Hierbei handelte es sich weitgehend um Bücher, die von NS-Organisationen für ihre Bibliotheken geraubt worden waren. Man muss sich dabei im Klaren sein, dass von den Institutionen, die aus dem Offenbach Archival Depot Bücher zurückerhielten, keine ihre gesamte Bibliothek, sondern meist nur einen kleinen Teil bekam. ${ }^{10}$ Dies zeigt eindrücklich, wie groß die Menge der geraubten Bücher war - und wie viele davon bereits unmittelbar nach dem Raub oder in den Wirren des Krieges vernichtet wurden.

Nicht restituiert wurden in der Nachkriegszeit in der Regel diejenigen Bücher, die die bereits existierenden wissenschaftlichen Bibliotheken, also Universitäts-, Landes- und Staatsbibliotheken, in ihre Bestände aufgenommen hatten. Das gilt auch für die damalige Universitätsbibliothek Göttingen. Ehe nun genauer dargestellt werden soll, inwieweit und in welchem Umfang die Göttinger Bibliothek NS-Raub- und Beutebücher übernommen hat, soll ein kurzer Blick auf die Geschichte der Bibliothek in der NS-Zeit geworfen werden.

WE

quarische Käufe weiterhin NS-Raubbücher in ihren Besitz übernommen haben. In welchem Umfang dies erfolgt war, lässt sich beim derzeitigen Forschungsstand nicht abschätzen.

8 Vgl. dazu Kap. B 3 im Katalog.

9 Evelyn Adunka: Der Raub der Bücher. Plünderung in der NS-Zeit und Restitution nach 1945, Wien 2002, S. 15-51.

10 Veronica Albrink: Von Büchern, Depots und Bibliotheken. In: Bernd Reifenberg (Hrsg.): Die Suche nach NS-Raubgut in Bibliotheken. Recherchestand, Probleme, Lösungswege, Marburg 2006, S. 110-149. 


\section{Zur Geschichte der Universitätsbibliothek Göttingen im Dritten Reich}

Als 1933 die Nationalsozialisten die Macht übernahmen, befand sich die Universitätsbibliothek Göttingen, wie alle wissenschaftlichen Bibliotheken des Reiches, in einer krisenhaften Situation. Infolge der Weltwirtschaftskrise war der Etat gekürzt worden; zeitweise konnten keine neuen Monographien mehr erworben werden, umfassende Abbestellungen von Zeitschriften drohten. ${ }^{11}$ Unter den deutschen Bibliotheken zählte Göttingen trotzdem immer noch zu den Stützen der nationalen wissenschaftlichen Literaturversorgung. Keine Universitätsbibliothek gab zwischen 1925 und 1942 mehr Bücher in die nationale Fernleihe als Göttingen. Nur die Preußische Staatsbibliothek lag hier noch um das Zweieinhalbfache vorn. ${ }^{12}$

Der von 1933 bis 1935 amtierende Direktor, Prof. Dr. Josef Becker (Objekt A 2), versuchte - freilich ohne Erfolg - durch Anpassung an das neue Regime den Etat der Universitätsbibliothek Göttingen zu verbessern, ehe er 1935 zum Stellvertreter des Generaldirektors der Preußischen Staatsbibliothek befördert wurde und Göttingen verließ. Sein Nachfolger wurde 1935 der aus Münster versetzte Bibliotheksdirektor Dr. Karl Julius Hartmann (Objekt A 3). Ihm gelang es zumindest, das 200jährige Jubiläum der Universität Göttingen 1937 zu nutzen, um von der Hannoverschen Klosterkammer eine größere, einmalige finanzielle Zuwendung zu erhalten. ${ }^{13}$

Mit dem Sieg des Nationalsozialismus kam es in den ersten Jahren zu Spannungen unter den Bibliothekaren (Objekt A 4), da es neben erklärten Nationalsozialisten auch einige dezidierte Gegner des Regimes gab. Mit der Entlassung der jüdischen Bibliotheksräte Prof. Dr. Alfred Hessel (Objekt A 5) und Dr. Fritz Löwenthal Ende 1935 sowie der Zwangspensionierung der politisch nicht opportunen Bibliotheksräte Dr. Kurt Schellenberg 1937, Dr. Wilhelm Vogt 1938 und Dr. Gerda Krüger 1940 waren indes die profiliertesten Vertreter der Gegner aus der Bibliothek hinausgedrängt worden. ${ }^{14}$ Von der Mehrzahl der Bibliothekare ist über ihre politische Einstellung nichts bekannt. Was man den Akten entnehmen kann, ist, dass 193612 Mitarbeiter (von insgesamt 48) der NSDAP angehörten, darunter

11 Universitätsarchiv Göttingen, Kur. 1857, 11.1.1934, Memorandum von Becker; 4.6.1934, Becker an den Vorsitzenden des Preuß. Beirats für Bibliotheksangelegenheiten.

12 Auf der Grundlage der Daten des Jahrbuchs der Deutschen Bibliotheken, Bd. 17, 1926 bis Bd. 33, 1943.

13 Universitätsarchiv Göttingen, Kur. 1857, 7.7.1937, Präsident der Klosterkammer an Kurator.

14 Vgl. Wilfried Enderle: Karl Julius Hartmann als Direktor der Universitätsbibliothek in Göttingen (1935-1958). In: Bibliothekare im Nationalsozialismus. Handlungsspielräume, Kontinuitäten, Deutungsmuster, hrsg. von Michael Knoche u. Wolfgang Schmitz (=Wolfenbütteler Schriften zur Geschichte des Buchwesens, Bd. 46) Wiesbaden 2011, S. 210-214. 
zwei wissenschaftliche Bibliothekare einschließlich des Direktors (von insgesamt 10), wobei 6 der Parteimitglieder bereits vor 1933 eingetreten waren. ${ }^{15}$

Mit dem Ausbruch des Zweiten Weltkrieges wurde die Organisation des Bibliotheksbetriebs zunehmend schwieriger (Objekt A 8). Zahlreiche Bibliothekare wurden zur Wehrmacht eingezogen; Hartmann amtierte seit 1941 zugleich als kommissarischer Direktor der Bibliothek der Reichsuniversität Straßburg und war pro Monat immer nur für eine Woche in Göttingen. Am 24. November 1944 wurde das Gebäude der Universitätsbibliothek Göttingen von einer Luftmine schwer getroffen. Es gelang aber, die im Keller und im Erdgeschoss gelagerten Bücher zu retten. Die Bewahrung ihrer Bestände bildete den Grundstock für den Wiederaufbau der Universitätsbibliothek Göttingen nach dem Zweiten Weltkrieg, die bis 1958 weiterhin und mit großem Erfolg von Hartmann geleitet wurde.

\section{A 1}

\section{Historische Ansicht des Lesesaals der Universitätsbibliothek Göttingen}

Fotografie Lesesaal der Universitätsbibliothek Göttingen

SUB Göttingen: Fotoarchiv

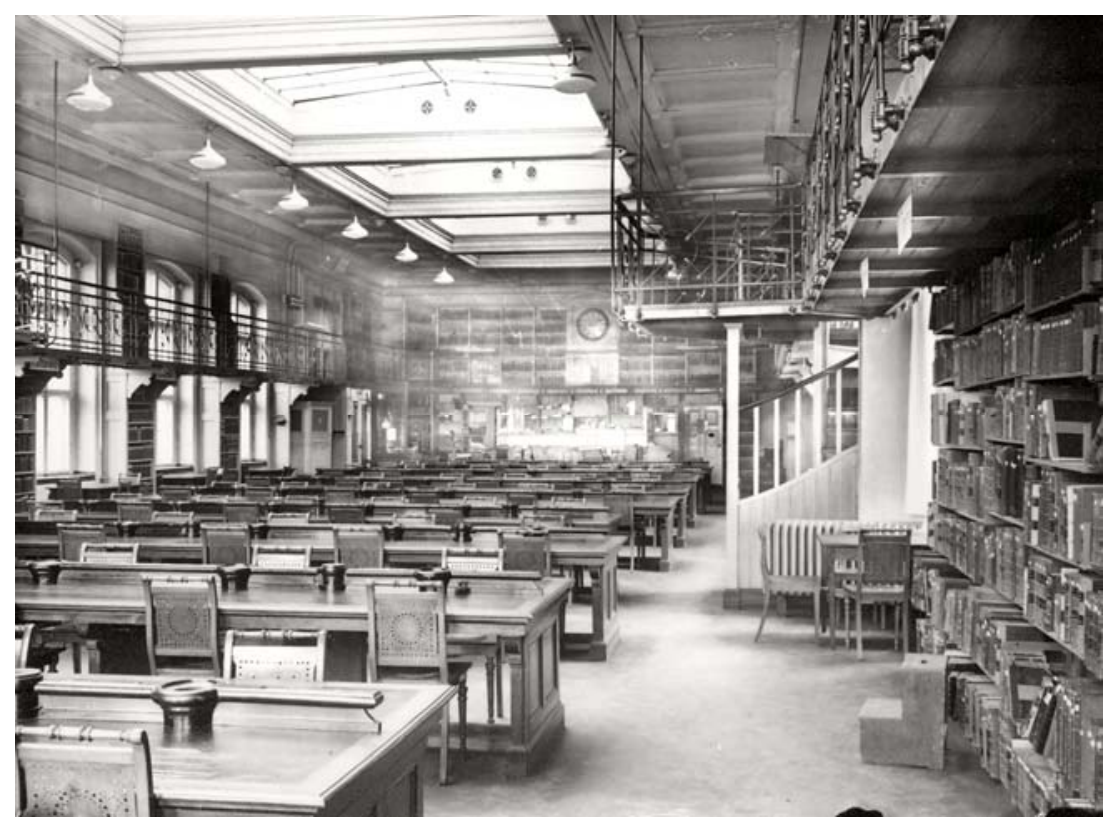

15 SUB Göttingen, Bibl.Arch. C 7,5, 30.11.1936, Hartmann an den Universitätskurator. 
Das Foto zeigt den Lesesaal im Historischen Bibliotheksgebäude am Papendiek 14. Die Einrichtung stammt aus dem 19. Jahrhundert. Beeindruckend war das Glasdach, durch das der Saal eine besondere Ausleuchtung erhielt. Nach der Zerstörung im Zweiten Weltkrieg wurde es durch eine massive Decke ersetzt.

\section{A 2}

Josef Becker - Direktor der Universitätsbibliothek Göttingen 1933-1935

Fotografie Dr. Josef Becker

SUB Göttingen: Sammlung Voit: Becker, Josef

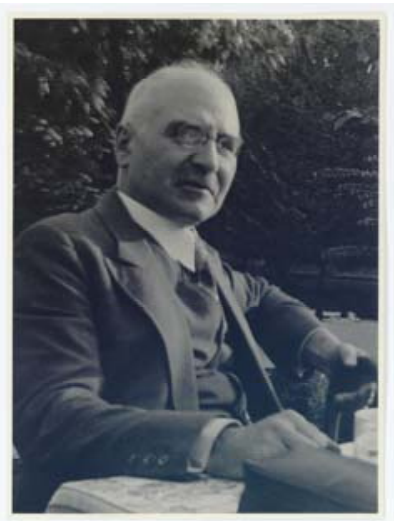

Josef Becker (1883-1949) hatte sich nach seiner Promotion in Geschichte 1906 und einer Tätigkeit als Lehrer 1915 als Kriegsfreiwilliger gemeldet. 1919 begann er mit der Ausbildung zum höheren Bibliotheksdienst und wurde 1920 zum Bibliotheksrat an der Preußischen Staatsbibliothek ernannt, wechselte aber bereits 1921 als Direktionsassistent an die Universitätsbibliothek Göttingen. Becker avancierte rasch. 1925 ging er als stellvertretender Direktor an die Staats- und Universitätsbibliothek Breslau, wurde 1929 Direktor der dortigen Stadtbibliothek und kam 1933 als Direktor an die Universitätsbibliothek Göttingen zurück. Im Zentrum seiner Arbeit stand die - freilich vergebliche - Bemühung, die katastrophale Etatsituation der Bibliothek zu verbessern. In seine Amtszeit fielen die ersten Aufnahmen beschlagnahmter Bücher in den Bestand der Göttinger Universitätsbibliothek. Bereits zum 1. April 1935 wurde er zum Ersten Bibliotheksrat, also dem Stellvertreter des Generaldirektors, an der Preußischen Staatsbibliothek ernannt und nahm damit eine Funktion ein, die er bis Kriegsende innehatte. Während des Zweiten Weltkrieges war er unter anderem kommissarischer Direktor der National- und Universitätsbibliothek in Prag. Nach Kriegsende leitete er bis zu seinem Tod für kurze Zeit die Bibliothek der Technischen Hochschule in Berlin.

(Lit.: Carl Wehmer: Josef Becker zum Gedenken. In: Bibliothek und Wissenschaft, Bd. 1, 1964, S. 266-282) 


\section{A 3 \\ Karl Julius Hartmann - Direktor der Universitätsbibliothek Göttingen 1935- 1958}

Fotografie Prof. Dr. Karl Julius Hartmann

SUB Göttingen: Sammlung Voit: Hartmann, Karl Julius

Karl Julius Hartmann (1893-1965) war nach seiner Promotion in Philosophie 1914, dem Kriegsdienst 1914 bis 1918 und einer medizinischen Promotion 1919 erst 1923 in Münster in den Bibliotheksdienst eingetreten. Zum Bibliotheksrat wurde er 1927 an der Staats- und Universitätsbibliothek Königsberg ernannt. Dort trat der nationalkonservative Hartmann zum 1. Mai 1933 als „Märzgefallener“ der NSDAP bei. Er wurde 1934 als Bibliotheksrat nach Göttingen und nur wenige Monate später als Direktor an die Universitätsbibliothek Münster versetzt. Von dort kam er 1935 als Nachfolger Josef Beckers wieder zurück nach Göttingen, wo er 1938 zum Honorarprofessor ernannt wurde. Während des Zweiten Weltkrieges amtierte er zudem als kommissarischer Direktor der damaligen Universitäts- und Landesbibliothek der Reichsuniversität Straßburg; darüber hinaus war er von 1939 bis 1964 zugleich auch

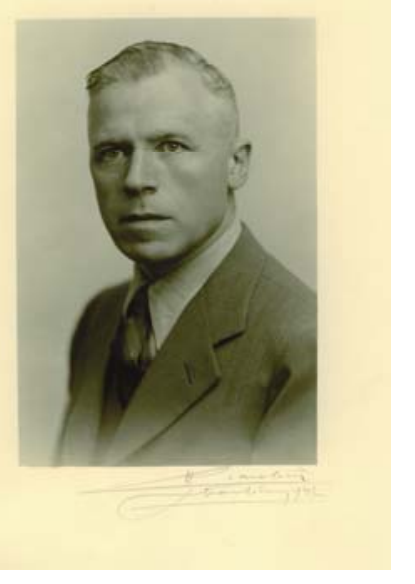

Sekretär, also Verwaltungsleiter, der Akademie der Wissenschaften zu Göttingen. Von 1942 bis 1945 gehörte er als Mitglied dem seit 1936 existierenden Reichsbeirat für Bibliotheksangelegenheiten an.

Hartmann war ein versierter Bibliotheksmanager, der nach nur sechswöchiger Beurlaubung im Sommer 1945 und erfolgreicher Entnazifizierung 1947 wesentlich dazu beitrug, dass die Universitätsbibliothek Göttingen, seit 1949 Niedersächsische Staats- und Universitätsbibliothek Göttingen, ihre Stellung als eine der führenden deutschen wissenschaftlichen Bibliotheken behaupten und ausbauen konnte. Als einziges Mitglied des ehemaligen Reichsbeirats gehörte er von 1949 bis 1958 dem Bibliotheksausschuss der Deutschen Forschungsgemeinschaft (DFG) an, einem der bibliothekspolitisch wichtigsten Gremien der Nachkriegszeit. Unter seiner Ägide bekam die SUB Göttingen in dem seit 1949 von der DFG organisierten Sondersammelgebietssystem von allen beteiligten Bibliotheken die meisten Sondersammelgebiete zugesprochen, so dass die Bibliothek ihre herausragende Funktion für die nationale Fernleihe kontinuierlich fortsetzen konnte. 
(Lit.: Wilfried Enderle: Karl Julius Hartmann als Direktor der Universitätsbibliothek in Göttingen (1935-1958). In: Bibliothekare im Nationalsozialismus. Handlungsspielräume, Kontinuitäten, Deutungsmuster, hrsg. von Michael Knoche u. Wolfgang Schmitz (=Wolfenbütteler Schriften zur Geschichte des Buchwesens, Bd. 46) Wiesbaden 2011, S. 193-223).

WE

\section{A 4 \\ Verbot politischer Debatten in den Diensträumen der Universitätsbiblio- thek Göttingen}

Umlauf vom 17.10.1935.

SUB Göttingen: Bibl. Arch. C 2,4

Der Direktor der Universitätsbibliothek Göttingen, Karl Julius Hartmann, machte in diesem hausinternen Rundschreiben seine Mitarbeiter darauf aufmerksam, dass „eine Haltung“ unabdingbar sei, „die nicht den geringsten Zweifel daran“ ließe, „dass es jeder Bibliotheksangehörige mit dem Treueid auf den Führer ernst“ nehme. In diesem Sinne untersagte der Bibliotheksleiter „politische Debatten in den Diensträumen“. Auf den ersten Blick stellt sich Hartmann hier offensichtlich ganz hinter das neue Regime. Liest man indes weiter, so verändert sich der Tenor seiner Aussage ein wenig. Denn er schrieb weiter: „Andererseits sind nachteilige Aeusserungen über Bibliotheksangehörige oder Bibliotheksangelegenheiten gegenüber aussenstehenden Personen oder Stellen als ein schwerer Verstoss gegen den Kameradschaftsgeist und gegen das Ansehen der Bibliothek anzusehen. Ein solcher liegt auch vor, wenn ohne stichhaltigen Grund Zweifel in die politische Haltung der Mitarbeiter gesetzt werden. Unbegründetes Misstrauen und Gesinnungsschnüffelei untergraben den Gemeinschaftsgeist und verhindern vertrauensvolle Zusammenarbeit. Beanstandungen sind ausnahmslos zuerst dem allein verantwortlichen Direktor vorzutragen. Ich appelliere an das Verantwortungsbewusstsein jedes Bibliotheksangehörigen zur aktiven Pflege des Gemeinschaftsgeistes nach innen und zur Hochachtung des äusseren Ansehens seiner Bibliothek." Hartmann nutzte zwar das Vokabular des Nationalsozialismus, betonte zugleich aber, dass bibliothekarische Kollegialität und Solidarität Vorrang hat. Alle Beschäftigten hatten das Schriftstück zu lesen und die Kenntnisnahme mit ihrer Unterschrift zu bestätigen.

Aus heutiger Sicht lässt sich kaum noch feststellen, was der Anlass für die Aufsetzung eines solchen Schreibens war. Insgesamt ist die tatsächliche politische Einstellung der Bibliothekare im Einzelnen nur schwer zu erfassen. Was sich den Akten entnehmen lässt, ist, dass es unter den Bibliothekaren eine kleine Gruppe 
nationalsozialistisch aktiver Parteimitglieder gab und einige wenige Gegner des Regimes. Über die politische Haltung der Mehrzahl ist indes nichts bekannt.

JD/WE

\section{A 5}

\section{Entlassung des jüdischen Bibliotheksrats Alfred Hessel}

Schreiben des Kurators der Universität Göttingen vom 13.12.1935.

SUB Göttingen: Bibl. Arch. C 2,4

Wegen seiner jüdischen Abstammung wurde der Historiker Prof. Dr. Alfred Hessel (1877-1939) im Jahr 1935 von seinen Lehrverpflichtungen entbunden und als Bibliotheksrat aus dem Amt gedrängt. Im Dezember 1935 erfuhr er durch ein Schreiben des Kurators der Universität Göttingen von seiner endgültigen Entlassung zum Jahreswechsel. Hessel war als Wissenschaftler unter den Göttinger Bibliothekaren zweifelsohne der Qualifizierteste, da er vor dem Ersten Weltkrieg als Privatgelehrter mehrere Jahre u.a. für die Monumenta Germaniae Historica gearbeitet hatte, ehe er sich an der Universität Straßburg habilitierte. Nach dem Krieg habilitierte er sich an die Universität Göttingen um, wo er als außerordentlicher Professor im Alter von 46 Jahren auf eine Stelle an die Bibliothek wechselte. In dieser Funktion war er nicht nur weiter wissenschaftlich tätig - unter anderem als Mitdirektor des Diplomatischen Apparates (neben Karl Brandi) und als Universitätslehrer -, sondern ordnete auch das Archiv der Bibliothek neu und legte damit den Grundstock für die umfangreiche Geschichte der Universitätsbibliothek, die 1937 zum 200jährigen Jubiläum der Universität erscheinen sollte. Hessel wurde auch nach seiner Entlassung insgeheim noch weiter zur Mitarbeit herangezogen. Obwohl er ca. 60\% des Manuskriptes verfasst hatte, blieb sein Name bei der Herausgabe des Buches unerwähnt. Erst 1986 legte Christiane Kind-Doerne in ihrer Geschichte der Göttinger Universitätsbibliothek diesen Sachverhalt offen. Hessel verstarb am 18. Mai 1939 in Göttingen.

(Lit.: Wolfgang Petke: Alfred Hessel (1877-1939), Mediävist und Bibliothekar in Göttingen. In: Armin Kohnle / Frank Engehausen (Hrsg.): Zwischen Wissenschaft und Politik. Studien zur deutschen Universitätsgeschichte. Festschrift für Eike Wolgast zum 65. Geburtstag, Stuttgart 2001, S. 387-414)

JD/WE 
A 6 „Das Judentum ist Deutschlands Unheil“

Aushang in der Universitätsbibliothek Göttingen aus den 1930er Jahren. SUB Göttingen: Bibl. Arch. C 2,9

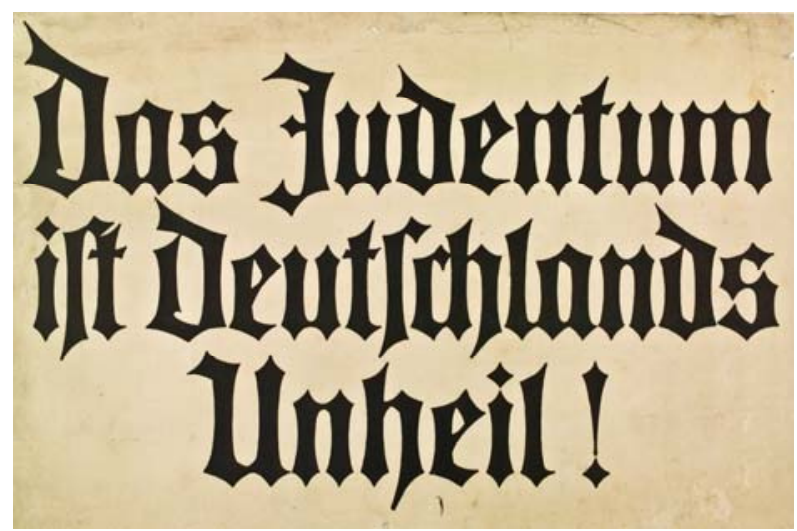

Bibliothek aufbewahrt werden, die Zeit überdauerte.

Das Plakat wurde vermutlich innerhalb des Gebäudes der Universitätsbibliothek Göttingen ausgehängt. Der genaue Platz seiner Anbringung lässt sich nicht mehr feststellen. Ebenso wenig ist bekannt, wann und von wem der Aushang verfasst wurde. Klar ist nur, dass das Plakat in einer Akte, in der sämtliche Aushänge der

\section{A 7}

Zutrittsverbot zu den Magazinen für „Volljuden“ an der Universitätsbibliothek Göttingen

Umlauf vom 15.11.1937.

SUB Göttingen: Bibl. Arch. C 2,5

Der Direktor der Universitätsbibliothek Göttingen, Karl Julius Hartmann, setzte zur Kenntnisnahme aller Beschäftigten in Umlauf, dass es „Volljuden“ nicht mehr gestattet sei, die Magazinräume zu betreten. In den Bibliotheksmagazinen sind die Medien, also die Bücher und Zeitschriften einer Bibliothek, aufbewahrt. Zugang zu den Magazinen hatten in der Regel die Mitarbeiter der Bibliothek sowie Benutzer mit einer entsprechenden Sondererlaubnis. 


\section{A 8 \\ Schließung der Universitätsbibliothek Göttingen wegen Kohlemangels}

Umlauf vom 5.1.1940.

SUB Göttingen: Bibl. Arch. C 2,5

Nach Ausbruch des Zweiten Weltkrieges im September 1939 verschlechterten sich die Arbeitsbedingungen an der Universitätsbibliothek Göttingen in erheblichem Maße. Bereits im Januar 1940 musste die Bibliothek „bis auf weiteres“ wegen Kohlenmangels geschlossen werden. Der Betrieb war seit Ausbruch des Krieges bis zur Wiederaufnahme am 1. April 1940 ohnehin nur im beschränkten Maße aufrechterhalten worden. Vor allem in den letzten Jahren des Krieges wurde die Kohlenknappheit zur wiederkehrenden Belastungsprobe für die Beschäftigten und Nutzer der Bibliothek.

\section{NS-Raubgut in der Universitätsbibliothek Göttingen}

Bereits seit 1933 wurden beschlagnahmte Bücher aus verschiedenen Quellen in den Bestand der Universitätsbibliothek Göttingen aufgenommen. Eine aktive Rolle könnte in den ersten Jahren der Leiter der Erwerbungsabteilung, Dr. Josef Wilhelm Kindervater, ein als stellvertretender Ortsgruppenleiter aktives NSDAPMitglied, eingenommen haben, ehe er 1935 als Direktor an die Universitätsbibliothek Münster versetzt wurde. ${ }^{16}$ Aus Sicht der Provenienzforschung ist an der Erwerbungspolitik der Universitätsbibliothek Göttingen interessant, dass ihre Haltung zum Thema beschlagnahmte und geraubte Bücher insgesamt durchschnittlich war und dem entsprochen haben dürfte, was die Mehrheit der damaligen Universitätsbibliotheken praktizierten. Das Gros der Raubgutfälle kam über offizielle Kanäle, meistens von der Preußischen Staatsbibliothek, der Reichstauschstelle oder von kommunalen Behörden, in wenigen Fällen auch von Privatpersonen. Nur in Einzelfällen ist nachzuweisen, dass Bibliothekare von sich aus aktiv wurden, um an beschlagnahmte Bücher zu gelangen. Von den Universitätsbibliotheken Freiburg und Heidelberg weiß man, dass Bücher deportierter Juden übernommen wurden; ${ }^{17}$ der Direktor der Universitäts- und Stadtbibliothek Köln

\footnotetext{
${ }^{16}$ Hinweise auf das Engagement Kindervaters für die NSDAP und seine positive Einstellung gegenüber dem Dritten Reich finden sich in seinem Briefwechsel mit dem Tübinger Bibliotheksdirektor Georg Leyh (Staatsbibliothek zu Berlin, Nachlass Leyh: Briefwechsel mit Kindervater, v.a. 5.1.1934 und 26.1.1934, Kindervater an Leyh).

${ }_{17}$ Reifenberg: NS-Raubgut in deutschen Bibliotheken (wie Anm. 1), S. 159.
} 
bemächtigte sich gezielt und mit massivem Druck der Privatbibliothek zweier jüdischer Wissenschaftlerinnen, Elise und Helene Richter. ${ }^{18}$ Vergleichbare Vorgänge sind für Göttingen nicht bekannt.

Ähnlich wie an der ebenfalls preußischen Universitätsbibliothek Marburg ${ }^{19}$ begnügte man sich in Göttingen mit den Einlieferungen von Raubgut aus offiziellen Kanälen. Ein Prozent der Erwerbungen von 1933 bis 1945, ca. 1.000 Bände, konnten bislang als Raubgut oder als Raubgutverdacht nachgewiesen werden. Rechnet man noch Bücher hinzu, bei denen aufgrund fehlender Quellen ein Verdacht nicht begründet werden kann, so könnten zwei bis drei Prozent der zeitgenössischen Erwerbungen unrechtmäßig in den Bestand aufgenommen worden sein.

Das scheinbar formaljuristisch korrekte Verhalten mag auch mit dazu beigetragen haben, dass die Göttinger Bibliothekare - wie auch generell ihre Kollegen in Deutschland (Objekt A 9) - nach 1945 ihr Verhalten nicht als Unrecht empfunden und selbstkritisch reflektiert haben (Objekt A10). So wurde in Göttingen nach 1945 keines der geraubten Bücher zurückgegeben. Eine Ausnahme bildeten 33.000 Bände, die unter der Ägide Hartmanns als kommissarischer Direktor der Universitäts- und Landesbibliothek Straßburg dort bis Herbst 1944 erworben worden waren und die er vor dem Einmarsch der Alliierten in Straßburg nach Göttingen verlagert hatte. Diese Bände wurden 1946 - mit Ausnahme eines umfangreichen Kartenwerkes - auf Druck des 1944 wieder zurückgekehrten französischen Direktors der Bibliothèque Nationale et Universitaire de Strasbourg, Dr. Ernest Wickersheimer, zurückerstattet, obwohl Hartmann noch versucht hatte, die Bände in Göttingen zu halten (Objekt A 13). ${ }^{20}$ Während hier der Druck der Besatzungsmacht keinen Ausweg ließ, galt dies nicht für Einzelpersonen oder kleinere deutsche Institutionen, wie die Stadtbücherei Hamburg-Harburg, die 1946 vergeblich Bücher zurückforderte, die sie nach 1933 aus ihren Beständen hatte aussondern müssen. ${ }^{21}$ Generell leugnete Hartmann in der unmittelbaren Nachkriegszeit ab, dass in größerem Umfang beschlagnahmte Literatur in die Bestände der Bibliothek aufgenommen worden sei (Objekte A 11 und A 12) und versuchte auf diesem Wege, die ungeliebte Geschichte in den Hintergrund zu drängen.

WE

\footnotetext{
${ }^{18}$ Christiane Hoffrath: Bücherspuren. Das Schicksal von Elise und Helene Richter und ihrer Bibliothek im „Dritten Reich“ (=Schriften der Universitäts- und Stadtbibliothek Köln, Bd. 19) Köln 2009.

19 Eckart Conze / Bernd Reifenberg (Hrsg.): Displaced Books. NS-Raubgut in der Universitätsbibliothek Marburg (=Schriften der Universitätsbibliothek Marburg, Bd. 127) Marburg 2006.

${ }^{20}$ SUB Göttingen, Bibl..Arch. D, Slg. ungeordneter Akten UB Straßburg; Bibliotheque Nationale et Universitaire de Strasbourg: Archive, AL 54 II A.

${ }^{21}$ Vgl. Kap. B 1 im Katalog.
} 


\section{A 9}

\section{Generelle Verharmlosung des Bücherraubs in der Nachkriegszeit}

Georg Leyh (Herausgeber):

Handbuch der Bibliothekswissenschaft, begr. von Fritz Milkau,

2. Auflage, Band 3,2: Geschichte der Bibliotheken.

Wiesbaden: Harrassowitz, 1957.

SUB Göttingen: $4^{\circ}$ Gen. 298: 3,2

In der zweiten, 1957 erschienenen und durchgängig überarbeiteten Auflage des Handbuchs der Bibliothekswissenschaft, dem damals maßgeblichen bibliothekarischen Standardwerk in Deutschland, hat Georg Leyh das Kapitel über die „Geschichte der Bibliotheken von der Aufklärung bis zur Gegenwart“" aktualisiert und ihre Geschichte im Dritten Reich und in der Nachkriegszeit thematisiert. Während er ausführlich auf die Kriegsverluste deutscher Bibliotheken eingeht, thematisiert er nur beiläufig das Thema Raubgut und leitet es lapidar mit dem Satz ein: „Die aus deutschen Beschlagnahmungen gelegentlich überwiesene Literatur war wissenschaftlich fast ausnahmslos wertlos" (Band 3.2, Seite 471), um dann weitgehend kommentarlos einige Beispiele geraubter Bibliotheken anzufügen. Restitutionen durch Universitätsbibliotheken gab es daher in der Nachkriegszeit kaum, das Thema selbst wurde im Großen und Ganzen weitgehend verdrängt. Allein aus den Büchersammlungen der NS-Organisationen wurden durch die Alliierten Bücher in größerem Umfang restituiert; ein großer Teil der Bücher war freilich bis Kriegsende vernichtet oder verschollen.

Die Bibliotheksgeschichtsschreibung näherte sich überhaupt erst in den 1980er Jahren der Zeit des Nationalsozialismus, um den Mythos von der politikfreien Sphäre der wissenschaftlichen Bibliotheken kritisch zu hinterfragen. Erst seit den 1990er Jahren begann allmählich die Erforschung des bis dahin fast völlig aus dem kollektiven Gedächtnis der Bibliothekare verschwundenen Themas Raub- und Beutebücher.

WE

\section{A 10}

Ein Beispiel für die Verdrängung des Bücherraubs in der Nachkriegszeit an der SUB Göttingen

Schreiben von Prof. Dr. Wilhelm Martin Luther

an den Kurator der Universität Göttingen, 10.9.1959.

SUB Göttingen: Bibl. Arch. D 1061 
Im August 1959 leitete der Senator für Finanzen (Sondervermögen und Bauverwaltung) in Berlin eine Anfrage an die Universität Göttingen weiter, die sich auf die Restitution von Büchern aus der Bibliothek des von den Nationalsozialisten gegründeten ehemaligen Reichsinstituts für die Erforscbung der Geschichte des neuen Deutschlands bezog, dessen Bestände gegen Kriegsende zum Teil nach Göttingen verlagert worden waren. Konkret ging es um Bücher von Michael M. Zagayski, der Vizepräsident des Vereins der jüdischen Kaufleute und Industriellen in Warschau gewesen war. Einige seiner Bücher waren in der Nachkriegszeit in einem Carnegie-Bookshop aufgetaucht und enthielten neben seinem Exlibris auch einen Besitzstempel der Bibliothek des Reichsinstituts. Prof. Dr. Wilhelm Martin Luther, Direktor der SUB Göttingen von 1958 bis 1962, bestätigt in seinem Schreiben an den Kurator, dass nach Kriegsende ca. 200 Bücher des Reichsinstituts der Göttinger Bibliothek überlassen worden waren, die mittlerweile nach Zustimmung des Bundesarchivs als Rechtsnachfolgerin des Reichsinstituts in den Bestand aufgenommen wurden. Dass sich darunter auch Bücher aus jüdischem Privatbesitz befinden könnten, negierte er: „Es scheint mir völlig ausgeschlossen, dass sich unter diesem Schrifttum Bücher aus dem Besitz des Herrn Michael M. Zagayski, Warschau, Malcezwskiego 17, befunden haben; zudem hätte die Bibliothek Stücke mit dem Exlibris eines Privatbesitzers niemals in Besitz genommen." Eine offene Frage ist, ob Luther, der 1942 als Referendar an der UB Göttingen in den Bibliotheksdienst aufgenommen wurde und 1958 Nachfolger von Hartmann geworden war, das Thema Raubgut bereits völlig verdrängt hatte oder bewusst jede Beteiligung der Universitätsbibliothek Göttingen abstritt.

WE

\section{A 11}

\section{Angeblich keine Bücher „aus Beständen der sozialistischen Büchereien“}

Schreiben von Prof. Dr. Karl Julius Hartmann vom 10.1.1948. Universitätsarchiv Göttingen, Kur. 1883

Nach einer Anfrage des niedersächsischen Kultusministers im Dezember 1947 war die Universitätsbibliothek Göttingen dazu aufgefordert worden, ihre Büchereingänge auf beschlagnahmte Bestände sozialistischer Büchereien hin zu überprüfen, die in der Zeit des Nationalsozialismus angeschafft worden waren. Nach Aussage des Direktors, Prof. Dr. Karl Julius Hartmann, der von 1935 bis 1958 die Universitätsbibliothek Göttingen leitete, waren - abgesehen von einer Ausnahme - „niemals Exemplare“ dieser Art in den Bestand der Bibliothek gelangt. Als einen Sonderfall bezeichnete er die ,nicht sehr große, genau nicht mehr feststellbare Anzahl von Werken" aus der Gewerkschaftsbücherei Winsen/Luhe. In seiner Stellungnahme gab Hartmann an, er habe die Bücher nach seinem Dienstantritt 
unbearbeitet vorgefunden. Daraufhin habe er sie „als ein Sonderdepot mit der Bezeichnung fremdes Eigentum " in Kisten gelagert. Im Zuge der Auslagerungsmaßnahmen seien diese 1944 ins Bergwerk Volpriehausen gelangt und bei der dortigen Explosion vernichtet worden. Nach unserem heutigen Wissen müssen die Behauptungen Hartmanns als unhaltbar gelten. Die systematische Überprüfung aller Büchereingänge von 1933 bis 1945 hat ergeben, dass es mehrere Lieferungen beschlagnahmter sozialdemokratischer Bücherbestände gab. Interessant ist auch, dass im Zugangsbuch der Universitätsbibliothek Göttingen von 1935 elf Bucheingänge des Bürgermeisters Winsen/Luhe festgehalten wurden. In dreien dieser Werke ist der Stempel des Gewerkschaftskartells Winsen a. d. Luhe zu finden.

\section{A 12}

\section{Aussage des Direktors durch Bücher widerlegbar}

Kurt Eisner:

Das Ende des Reichs.

Deutschland und Preußen im Zeitalter der großen Revolutionen.

Berlin: Buchhandlung Vorwärts, 1907.

SUB Göttingen: $8^{\circ}$ Hist. Germ. X, $61<2>$

Provenienz: Gewerkschafts-Kartell Winsen an der Luhe

(Bezug über das Bürgermeisteramt Winsen), 1935

Dieses Buch von Kurt Eisner wurde der Universitätsbibliothek Göttingen zusammen mit zehn weiteren Publikationen im September 1935 durch den Bürgermeister von Winsen an der Luhe als „Geschenk“ übergeben. Die Bürgermeisterämter waren Sammelstellen für beschlagnahmte Literatur aufgelöster Vereine und Gewerkschaften. Das Buch belegt die Unrichtigkeit von Hartmanns

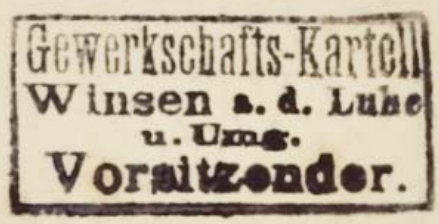

Aussage, die Winsener Bücher seien durch Kriegseinwirkungen vernichtet worden bzw. es seien erst gar keine Bücher aufgelöster sozialistischer Bibliotheken nach Göttingen gelangt. 


\section{A 13}

\section{Verlagerung und Rückgabe von ca. 33.000 Büchern der Universitäts- und Landesbibliothek Straßburg 1944-1946}

Schreiben von Prof. Dr. Karl Julius Hartmann

an den Kurator der Universität Straßburg,

Abwicklungsstelle Tübingen, MR Breuer, 17.7.1945.

SUB Göttingen: Bibl. Arch. D,

Sammlung ungeordneter Akten zur UB Straßburg

\section{Ich hatbe Ubrigens den Versuch genocht, die fronz"̈sischen}

offiziere hier devon zu uberzeugen, daB die hierher verbrecten Bïcher für Prsnkreich kein besonderes Interesse bithen; veil es sick in der rauptssche un deutsehe literetur hosdelt, die fir die Bedürnisse der deutsche Unterrichtsverwaltung angeschefft worden oint, wëhrerd, wie mir bekannt war, die französische Blbliotheksverwaltung in clermon:-Ferrand seit 1939 Eleich:slls ihre Bücherergünzung der Strabburger Bibliothek noct den f-anzčsischen Bedürenissen weitergefübrt hot. Die beidea ferrer schienen Verständnis

Prof. Dr. Karl Julius Hartmann hatte von 1941 bis 1945 neben der Universitätsbibliothek Göttingen auch kommissarisch die Universitäts- und Landesbibliothek Straßburg geleitet. Im September 1944 - einige Tage vor der Befreiung der Stadt durch die Alliierten - hatte er die in seiner Amtszeit erworbene monographische Literatur, ca. 33.000 Bände, aus Straßburg evakuieren und über Tübingen nach Göttingen verbringen lassen, wo er auch eine Ausweichstelle der Universitäts- und Landesbibliothek Straßburg einrichtete. Nach Kriegsende bereitete er zwar einerseits die Restitution der Bücher vor, versuchte aber zugleich noch, wie diese Akte zeigt, die französischen Offiziere, die die Bücher der Universitäts- und Landesbibliothek Straßburg in Göttingen inspizierten, davon zu überzeugen, die Bücher in Göttingen zu belassen - freilich ohne Erfolg. Im März 1946 wurden die Bücher von dem Direktor der Bibliothèque Nationale et Universitaire de Strasbourg, Dr. Ernest Wickersheimer, in Göttingen abgeholt und per Lastwagen nach Straßburg zurückgebracht. Im Bestand der SUB Göttingen sind deshalb bislang keine Bücher mit einem Straßburger Besitzstempel gefunden worden. Nur ein umfangreiches Kartenwerk enthält neben einem Besitzstempel der SUB Göttingen auch den der Universitäts- und Landesbibliothek Straßburg. 


\section{Wie findet man NS-Raubgut? - Die Projektarbeit an der SUB Göttingen}

Erst Anfang der 1990er Jahre begannen die ersten Bibliotheken, in ihren Beständen nach NS-Raubgut zu recherchieren. Nach der Washingtoner Erklärung von 1998 zum Umgang mit den von den Nationalsozialisten beschlagnahmten Kunstwerken (Objekt A 14) wurde das Thema NS-Raubgut intensiver von Bibliothekaren thematisiert und entwickelte sich zu einem neuen, anfangs nur zögerlich bestellten Feld der bibliothekarischen Provenienzforschung.

Seit Ende 2008 werden die Bestände der SUB Göttingen systematisch auf NSRaub- und Beutegut hin untersucht. Den Ausgangspunkt für die Recherchen bildeten die vollständig erhaltenen Zugangsbücher der SUB Göttingen aus den Jahren 1933 bis 1950. In diesem Zeitraum wurden ca. 100.000 Erwerbungen mit Angaben zu ihren Bezugsquellen in die Zugangsbücher eingetragen. Dadurch ergibt sich ein umfassender Überblick über die Erwerbungsvorgänge der damaligen Zeit. Bei allen Eintragungen wurde abgewogen, ob es sich um Raub- oder Beutegut handeln könnte. Bestand ein Anfangsverdacht, wurde der Titel in einer internen Arbeitsdatenbank erfasst. Wichtige Kriterien für die Auswahl waren zum einen der Autor und Titel des Buches. So wurden alle Titel registriert, die auf der nationalsozialistischen Verbotsliste (siehe Kapitel B 1) standen sowie auf kommunistische oder anderweitig parteifeindliche Inhalte schließen ließen. Zudem wurde auf jüdische bzw. hebräische Literatur geachtet, die sich aber so gut wie nicht fand. Zum anderen erwies sich die Bezugsquelle in den meisten Fällen als aussagekräftige Kategorie. Aus dem geschichtlichen Zusammenhang heraus ist bekannt, dass etwa Bürgermeister- und Landratsämter als Sammelstellen beschlagnahmter Bücher fungierten. Gleiches gilt für die Preußische Staatsbibliothek in Berlin, die zusammen mit anderen Institutionen wie der Reichstauschstelle, der Notgemeinschaft und dem Beschaffungsamt (alle in Berlin ansässig) Raub- und Beutegut auf die wissenschaftlichen Bibliotheken im Reich verteilten. Auch das Erscheinungsjahr und der Preis konnten Hinweise liefern, etwa wenn es sich um antiquarische Erwerbungen oder Verkäufe von Privatpersonen handelte (siehe hierzu Kapitel B 3).

Die Sichtung der Zugangsbücher erbrachte mehr als 8.000 vorläufig verdächtig erscheinende Bücher, die anschließend an ihrem Magazinstandort auf Provenienzmerkmale, sprich Herkunftshinweise hin untersucht wurden. Dabei ging es in erster Linie um das Auffinden von Stempeln, Exlibris, Autogrammen oder Widmungen, die Aufschluss über mögliche Vorbesitzer geben konnten. Die Ergebnisse wurden in der Arbeitsdatenbank festgehalten. Parallel dazu fanden Recherchen in Archiven statt, um die Hintergründe verdächtiger Erwerbungen anhand von Quellendokumenten aufzuklären. 
Als Ergebnis der zweieinhalbjährigen Projektarbeit konnten bislang in den Beständen der SUB Göttingen über 1.000 NS-Raub- und Beutegutfälle beziehungsweise Verdachtsfälle nachgewiesen und dokumentiert werden. Ein Buch wurde als eindeutiges Raub- bzw. Beutegut eingestuft, wenn die Erwerbungsumstände zweifelsfrei mit Hilfe von Quellenmaterial geklärt werden konnten. Ein Verdacht auf NS-Raub- bzw. Beutegut wurde für solche Fälle festgestellt, bei denen Analogieschlüsse sowie Literatur- und Quellenhinweise den Verdacht auf Raub- bzw. Beutegut zwar nahe legen, jedoch ein definitiver Beweis fehlt.

Die nachfolgenden Objekte und Fotos versuchen, die einzelnen Arbeitsschritte zum Auffinden von Raub- und Beutegut nachzuzeichnen.

\section{A 14}

\section{Anstoß durch Washingtoner Erklärung}

Wortlaut der „Grundsätze der Washingtoner Konferenz in Bezug auf Kunstwerke, die von den Nationalsozialisten beschlagnahmt wurden“ (sogenannte „Washingtoner Erklärung“" beziehungsweise „Washington Principles“), verabschiedet am 3.12.1998.

Im Dezember 1998 gab die Washingtoner Konferenz über Vermögenswerte aus der Zeit des Holocaust den entscheidenden Anstoß für die Provenienzforschung der letzten Jahre. Die in Washington zusammengekommenen Staaten, unter anderem Deutschland, kamen in den elf Artikeln überein, Anstrengungen zu unternehmen, um Kunstwerke aus dem Besitz von Opfern des Nationalsozialismus ausfindig zu machen und zurückzugeben.

Die Grundsätze sind rechtlich nicht bindend, enthalten jedoch eine moralische Selbstverpflichtung der Staaten, auf nationaler Ebene einen Rahmen zur Umsetzung der Erklärung zu schaffen. Dieser Maßgabe kam Deutschland in der ein Jahr später verabschiedeten „Gemeinsamen Erklärung der Bundesregierung, der Länder und der kommunalen Spitzenverbände zur Auffindung und zur Rückgabe NSverfolgungsbedingt entzogenen Kulturgutes, insbesondere aus jüdischem Besitz“ nach. Die deutsche Erklärung spricht nicht mehr ausschließlich von Kunstwerken, sondern allgemein von Kulturgütern, und bezieht öffentliche Einrichtungen wie Museen, Archive und Bibliotheken ein. Hier sollen für alle Kulturgüter die Besitzverhältnisse für den Zeitraum von 1933 bis 1945 überprüft werden. Öffentliches Interesse erregte die gemäß der „Washingtoner Erklärung“ erfolgte Restitution des Gemäldes „Berliner Straßenszene“ von Ernst Ludwig Kirchner im Jahr 2006. 


\section{A 15}

\section{Zugangsbuch der Universitätsbibliothek Göttingen von 1934}

SUB Göttingen: Bibl. Arch. Zugangsbuch 1934

Das Zugangsbuch zeigt am 4. Mai 1934 eine Eintragung von Büchern aus der Stadtbücherei Harburg-Wilhelmsburg. Unter der laufenden Nr. 2173 (siehe linke Seite oben) ist der Titel: „Nelli Auerbach, Marx und die Gewerkschaften, Berlin 1922“ aufgeführt. Im Jahr 1934 kamen insgesamt 157 Bücher aus der Stadtbücherei Harburg-Wilhelmsburg in den Bestand der Universitätsbibliothek Göttingen.

\section{A 16}

\section{Erzwungener Verzicht auf Marx}

Nelli Auerbach:

Marx und die Gewerkschaften.

Berlin : Vereinigung Internationaler Verlagsanstalten (VIVA), 1922.

SUB Göttingen: $8^{\circ}$ Pol. III, $7777 /$ bi

Provenienz: Stadtbücherei Harburg-Wilhelmsburg, 1934

Die Autorin Nelli Auerbach erörtert das Thema Gewerkschaften im Spiegel von Marx' Theorien und gibt einen Abriss über die deutsche Gewerkschaftsbewegung. Im selben Verlag erschien auch Die Internationale. Zeitschrift für Praxis und Theorie des Marxismus. Da Marx als ideologischer Feind eingestuft wurde, waren sämtliche Schriften von und über ihn seit 1933 verboten und mussten aus dem Verkehr gezogen werden. Das vorliegende Werk wurde namentlich 1938 in der Liste des schädli-

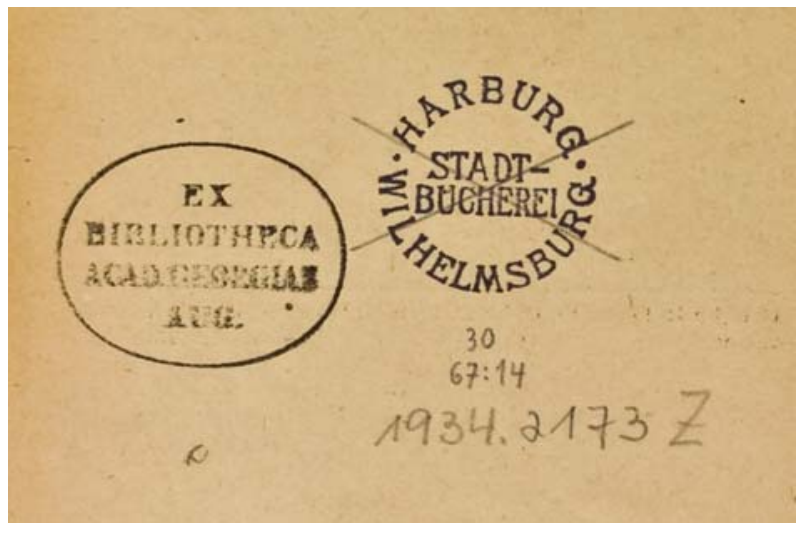
chen und unerwünschten Schrifttums indiziert. Auf dem Buchdeckel und Buchrücken sind noch Reste einer roten Markierung zu erkennen, mit der verbotene Bücher in der Universitätsbibliothek Göttingen gekennzeichnet werden mussten. 
A. NS-Raub- und Beutebücher und die Universitätsbibliothek Göttingen 1933-1945

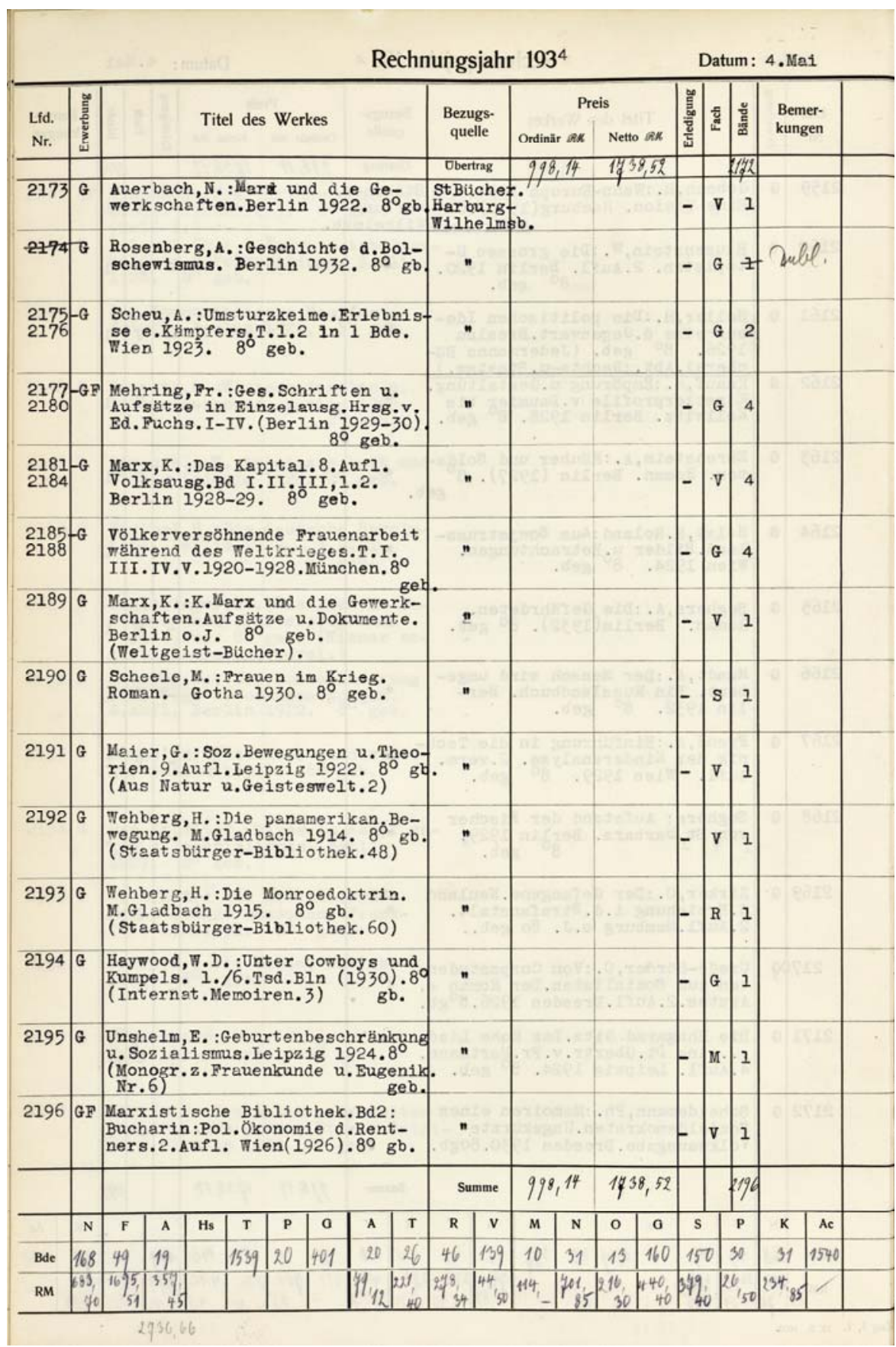

Abb.: Objekt $A 15$ 


\section{A 17}

\section{Der Alphabetische Bandkatalog der Universitätsbibliothek Göttingen}

Eintragung ,Auerbach, N.[elli]““ in:

Catalogus Alphabeticus Aue-Auf.

Alphabetischer Bandkatalog Band 46a, S. 192.

SUB Göttingen

Bis in die 1930er Jahre war der Alphabetische Bandkatalog der Hauptkatalog der Universitätsbibliothek Göttingen. Er nahm alle bis 1930 erschienenen Titel auf und wuchs auf insgesamt 1.056 Bände an. Die breite mittlere Spalte enthält den jeweiligen Autorennamen, eine Kurzform des Titels, die Auflage und den Erscheinungsvermerk (Ort, Verlag, Jahr). Für jeden Verfasser war grundsätzlich ein Blatt vorgesehen, um Raum für weitere Eintragungen vorzuhalten. In der linken Spalte „Catal.[ogus] Realis“ findet sich die Signatur des Werks von Nelli Auerbach ( $8^{\circ}$ Pol. III, 7777bi) und rechts unter „Access.[io]“ die Zugangsnummer 1934.2173.

HR

\section{A 18}

\section{Magazin der Zentralbibliothek der SUB Göttingen}

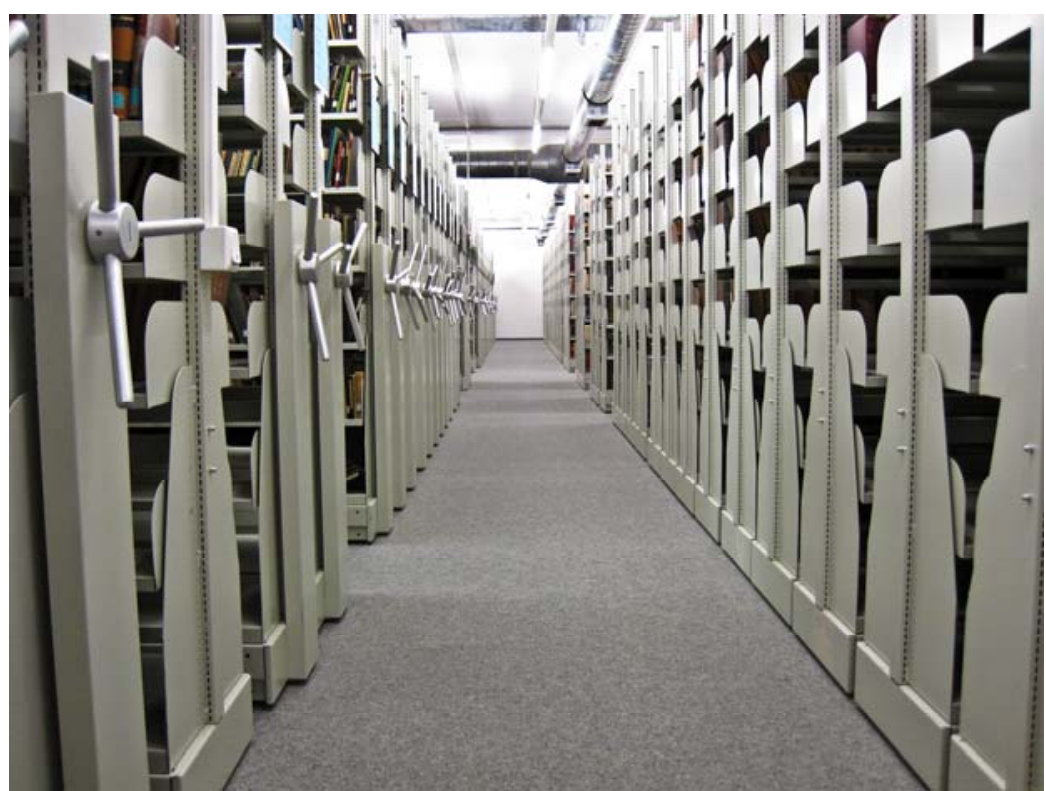


Im Magazin der Zentralbibliothek der SUB Göttingen werden heute die Bücher ab dem Erscheinungsjahr 1901 aufbewahrt. Hier wurden im Rahmen des Göttinger Forschungsprojektes etwa zwei Drittel der vorläufig als verdächtig eingestuften Bücher auf Provenienzmerkmale hin untersucht. Die restlichen überprüften Werke sind vor 1900 erschienen und im Magazin des Historischen Gebäudes der SUB Göttingen untergebracht.

NB

\section{A 19}

Nachweis über NS-Raubgut im Göttinger Universitätskatalog

Screenshot eines Buchbeispiels im Universitätskatalog Göttingen http://opac.sub.uni-goettingen.de

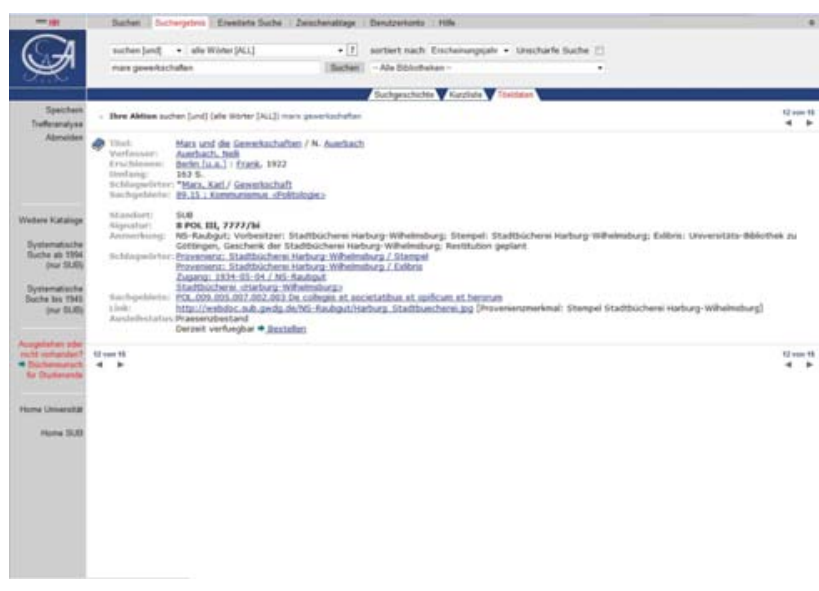

Die Überprüfung des Buches „Marx und die Gewerkschaften“ ergab, dass es sich um einen eindeutigen NSRaubgutfall handelt. Das Ergebnis ist im Göttinger Universitätskatalog dokumentiert (siehe auch Objekt F 4). Dabei werden folgende Angaben nachgewiesen: Vorbesitzer, Bezugsquelle, Provenienzmerkmale, auffällige Eintragungen, Zugangsdatum und Restitutionsvermerk. Das Buch ist nicht mehr ausleihbar, sondern befindet sich nun im Präsenzbestand der SUB Göttingen, wo es im Lesesaal eingesehen werden kann. 


\section{B. NS-Raubgut aus den Jahren 1933-1945}

\section{Verbotene Literatur aus Volksbüchereien und Leihbuchhandlungen}

Während der NS-Diktatur waren zahlreiche Schriftsteller und ihre Werke verboten. $\mathrm{Zu}$ den bekannten unter ihnen zählten etwa Heinrich und Thomas Mann, Franz Kafka und Karl Marx. Auf den Index-Listen der Nationalsozialisten standen jedoch viele, heute kaum noch geläufige Autoren wie Schalom Asch, Heinrich Eduard Jacob oder Upton Sinclair. Bücher verbotener Schriftsteller durften weder in Buchhandlungen verkauft noch in Leihbüchereien angeboten oder in sonst einer Form verbreitet werden. Sie mussten aus dem öffentlichen Leben verschwinden und durften nur noch in wissenschaftlichen Bibliotheken unter Verschluss gehalten werden. Hier waren sie nur zu Forschungszwecken einsehbar.

Die Index- bzw. Verbotslisten bildeten die Vorlage für die Aussonderung verbotener Werke aus öffentlichen und privaten Beständen. 1933 lag eine erste sogenannte „Schwarze Liste“ mit verbotenen Werken vor. Sie diente als Grundlage für die im Mai 1933 in der Aktion „Wider den undeutschen Geist" verbrannten Bücher und war der Vorläufer der seit 1935 von der Reichsschrifttumskammer herausgegebenen und in der Folgezeit immer wieder ergänzten „Liste des schädlichen und unerwünschten Schrifttums“ (Objekt B 5). Hier waren Autoren und Werke indiziert, „die das nationalsozialistische Kulturwollen gefährden“22 konnten, also in irgendeiner Weise der NS-Weltanschauung widersprachen. Zum „schädlichen und unerwünschten Schrifttum“ zählten die Nationalsozialisten neben Werken jüdischer Autoren Bücher über den Marxismus und Kommunismus, solche mit pazifistischer, liberaler oder demokratischer Tendenz, Werke von Emigranten und sogenannten „Landesverrätern“, Bücher zur Sexualkunde oder auch sogenannte „Asphalt- und Zivilisationsliteratur"“. ${ }^{23}$ Neben Einzelwerken war oftmals das Gesamtwerk eines Autors verboten.

\footnotetext{
22 Anordnung der Reichsschrifttumskammer über schädliches und unerwünschtes Schrifttum, $\mathbb{\int} 1$, 1.11.1933.

23 Siehe hierzu: Die Bücherei. Zeitschrift der Reichsstelle für das Büchereiwesen, Bd. 2, Heft 6, Leipzig 1935.
} 
Die vielerorts in Stadtbibliotheken oder Buchhandlungen ausgesonderten Bücher mussten an wissenschaftliche Bibliotheken abgegeben werden, wo sie nicht nur separat aufgestellt wurden - wie in Göttingen in einem mit einer Gittertür verschlossenen Raum -, sondern auch eine spezielle Kennzeichnung erhielten (Objekte B 1 - B 4).

Die Universitätsbibliothek Göttingen übernahm 1934 einen 177 Bücher umfassenden Bestand an sogenannter ,zersetzender Literatur" aus der Stadtbücherei Harburg-Wilhelmsburg, der als „Geschenk“ in das Göttinger Zugangsbuch eingetragen wurde. Unter den Büchern befinden sich unter anderem Werke von Karl Marx, Sigmund Freud und Max Barthel. 1946 bat die Verwaltung der Hansestadt Hamburg um die Rückgabe der Bücher der Harburger Stadtbücherei. ${ }^{24}$ Man erklärte, dass die Wiedereröffnung der Stadtbücherei geplant sei. Da das Theater und alle Lichtspielhäuser zerstört worden seien, wäre „das Lesen von Büchern gegenwärtig die einzige Entspannungsmöglichkeit der Harburger Bevölkerung““.25 Außerdem wolle man die „damals zwangsweise ausgeschiedenen Bücher“ deshalb zurückhaben, weil es an Büchern fehle, ,die geeignet sind, durch fortschrittlichen, freiheitlichen und sozialen Inhalt die national-sozialistischen Ideologien zu widerlegen". ${ }^{26}$

Der Direktor der Universitätsbibliothek, Prof. Dr. Karl Julius Hartmann, wies die Herausgabe der Literatur zurück, indem er auf juristisch-formaler Ebene argumentierte, es sei „zweifelsfrei [...] eine Eigentumsübertragung vorgenommen [worden], die ein Rückforderungstecht ausschliesst. [...] Nach der damaligen Sachlage war die Abgabe ein freiwilliger Akt." 27

Hartmann berief sich zudem auf die gebräuchliche Bibliothekspraxis: Es widerspräche „... allen Gepflogenheiten im Bibliotheksverkehr [...], Bücher, die einmal in sämtlichen Katalogen (Alphabetischer, Systematischer, Schlagwortkatalog, Spezialkataloge) verzeichnet sind, wieder zu streichen." 28 Ein solches Vorgehen würde zu einer „Verunstaltung“ der Kataloge führen. Dieser fadenscheinigen und aus heutiger Sicht unhaltbaren Argumentation schloss sich der Oberpräsident von Hannover $a^{29}{ }^{2}$, woraufhin der mit dem Fall beauftragte Kurator der Universi-

${ }^{24}$ Universitätsarchiv Göttingen, Kur. 1883, Schreiben der Kreisverwaltung der Hansestadt Hamburg an den Rektor der Universität Göttingen vom 4.7.1946.

${ }^{25}$ Ebda.

${ }^{26}$ Ebda.

27 Universitätsarchiv Göttingen, Kur. 1883, Schreiben des Direktors der Universitätsbibliothek, Prof. Dr. Karl Julius Hartmann, an den Kurator der Universität vom 23.7.1946.

28 Ebda.

${ }^{29}$ Universitätsarchiv Göttingen, Kur. 1883, Schreiben des Oberpräsidenten von Hannover, Abteilung Wissenschaft, Kunst und Volksbildung an den Kurator der Universität Göttingen vom 7.8.1946. 
tät am 12. August 1946 die Rückforderung der Bücher abschlägig beschied. ${ }^{30}$ Eine Restitution fand daraufhin nicht statt (Objekte B 6 und B 7).

Ein zweiter Fall: In den Jahren 1934 bis 1936 wurden der Universitätsbibliothek Göttingen immer wieder von Seiten der Preußischen Staatsbibliothek in Berlin größere Bestände an verbotenen Werken übergeben. In den meisten dieser Bücher finden sich keinerlei Hinweise auf ihre ursprüngliche Herkunft. Nur einige von ihnen enthalten Stempel von Berliner Buchhandlungen und Leihbüchereien (Objekte B 8 und B 9). Insgesamt handelt es sich bei den zugesandten Werken vornehmlich um neu verlegte, belletristische Literatur. Der Verdacht liegt nahe, dass die meisten dieser Bücher aus Beschlagnahmungsaktionen in Berliner Verlagen und Buchhandlungen stammen.

\section{B 1}

\section{Kennzeichnungspflicht für verbotene Werke}

Umlauf vom 13.12.1934.

SUB Göttingen: Bibl. Arch. C 2,4

Die Bibliotheksmitarbeiter werden in diesem Umlauf dazu angehalten, verbotene Schriften mit einem rautenförmigen roten Aufkleber zu kennzeichnen. Die Benutzung indizierter Werke war streng reglementiert und nur zu wissenschaftlichen Zwecken erlaubt. Noch heute befinden sich zahlreiche Bücher im Bestand der SUB Göttingen, auf deren Buchrücken oder vorderem Buchdeckel sich ein solcher

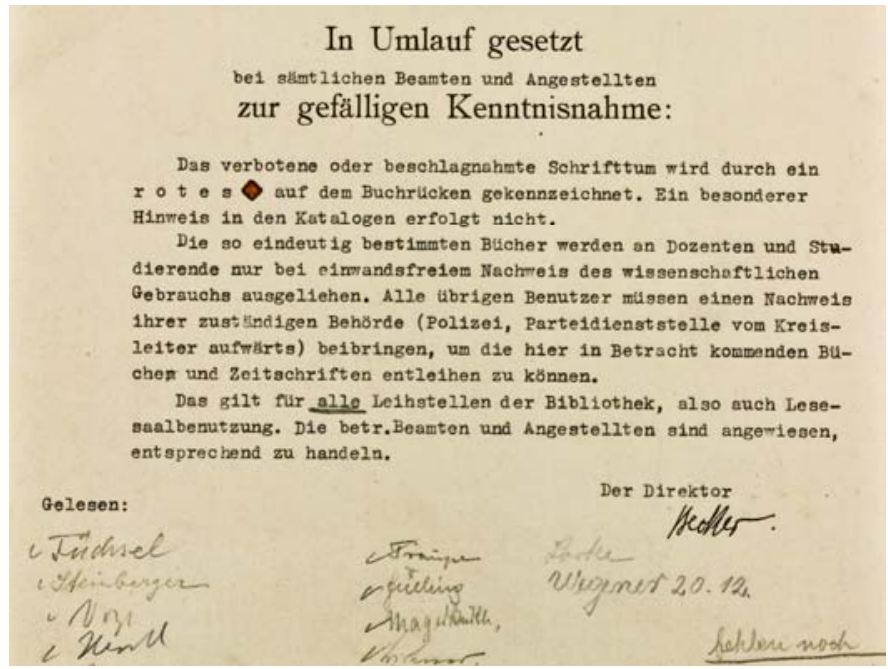
Aufkleber erhalten hat.

30 Universitätsarchiv Göttingen, Kur. 1883, Schreiben des Kurators der Universität Göttingen an die Kreisverwaltung Hamburg-Harburg vom 12.8.1946. 


\section{B 2}

\section{Achtung: Verboten!}

Wilhelm Dittmann:

Die Marine-Justiz-Morde von 1917 und die Admirals-Rebellion von 1918.

Berlin : Dietz, 1926.

SUB Göttingen: $8^{\circ}$ Hist. un. IX, 3231

Provenienz: SPD-Ortsverein Osterholz-Scharmbeck

(Bezug über das Landratsamt von Osterholz-Scharmbeck), 1935

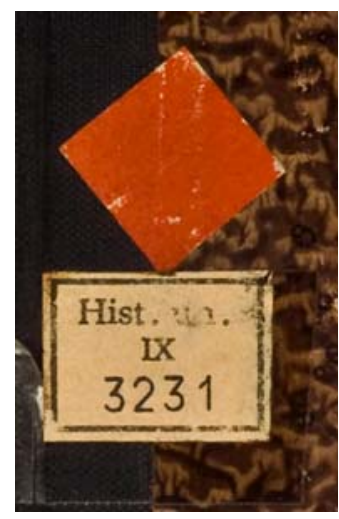

Zur äußeren Kennzeichnung dafür, dass es sich um ein verbotenes Werk handelte, wurde dieser Band von den Göttinger Bibliothekaren in den 1930er Jahren mit einem roten Streifen und einer roten Raute markiert. Die Universitätsbibliothek Göttingen erhielt das Buch im August 1935 vom Landratsamt Osterholz-Scharmbeck als „Geschenk". Zuvor hatte es sich laut Stempel in der Bibliothek des SPD-Ortsvereins Osterholz-Scharmbeck befunden und war nach der dortigen Beschlagnahmung an das Landratsamt weitergeleitet worden. Auf dem Titelblatt wurde das Buch außerdem mit dem Vermerk „V. L.“ als „verbotene Literatur“ gekennzeichnet.

\section{B 3}

\section{Kennzeichnung „V. L.“}

René Schickele:

Der Wolf in der Hürde (= Das Erbe am Rhein, 3).

Berlin : S. Fischer, 1931.

SUB Göttingen: $8^{\circ}$ Fab. VIII, 8753:3

Provenienz: unbekannt (Bezug über Preußische Staatsbibliothek), 1936

René Schickele (1883-1940) war Elsässer und bemühte sich als Schriftsteller, Journalist und Politiker zeitlebens um die Verbesserung der deutschfranzösischen Beziehungen. Literarisch trat er durch seine Romantrilogie „Das Erbe am Rhein“ (1925-1931) hervor. Die Reichsschrifttumskammer setzte Schickeles Gesamtwerk 1935 auf die „Liste des schädlichen und unerwünschten Schrifttums“. Dieses Buch ging im Mai 1936 als „Geschenk“ von der Preußischen Staatsbibliothek Berlin in den Bestand der Universitätsbibliothek Göttingen über. Es enthält keinerlei Vorbesitzermerkmale, weshalb seine ursprüngliche Herkunft nicht geklärt 


\section{RENÉ SCHICKELE

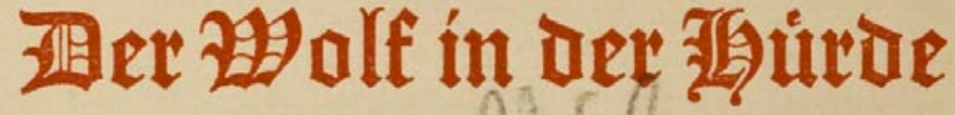

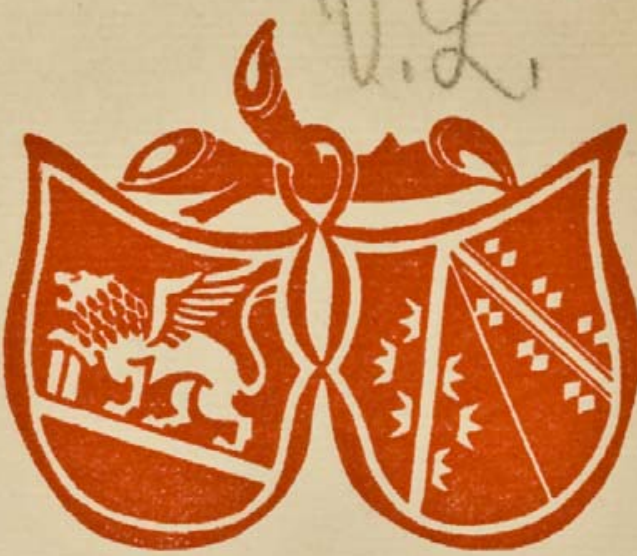

\section{玨as Cerbe am Zabrin}

\section{E R D R I T T E R O M A N}

Von dem hohen Standort, wo die weisesten Gedanken des Politikers, die liebsten Träume des Dichters und die Forderung einfacher Menschenvernunft eins sind, blickt Schickele in diesem Buche auf die Heimat an der Grenze zwischen Deutschland und Frankreich. Er erzählt uns von Männern und Frauen im rein verwalteten Erbe ihrer Natur und Schönheit und einer zauberisch leidenschaftlichen jungen Generation. Schickeles Elsa $\beta$ liegt mitten in der Welt und mitten im Menschenherzen.

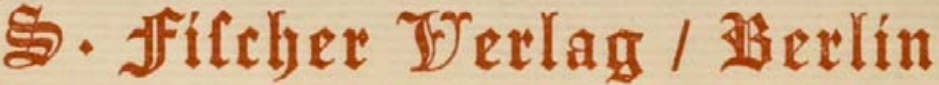


ist. Es könnte möglicherweise aus einer Beschlagnahmungsaktion in einer Buchhandlung oder in einem Verlag stammen. Der Vermerk „V. L.“ kennzeichnet das Buch als ,verbotene Literatur“. Der Vermerk ist in diesem Fall auf dem Titelblatt erhalten geblieben, wurde jedoch oftmals in der Nachkriegszeit ausradiert.

\section{B 4}

\section{Bücher hinter Gittern}

Schreiben vom 6.8.1936 zum Erwerb einer eisernen Gittertür.

SUB Göttingen: Bibl. Arch. C 13,2

Die in den wissenschaftlichen Bibliotheken aufbewahrte verbotene Literatur sollte laut ministerieller Anordnung aus dem regulären Bestand herausgenommen und unter Verschluss gehalten werden. Um diese Direktive umsetzen zu können, ließ der Direktor der Universitätsbibliothek Göttingen eine Gittertür anschaffen. Die verbotenen Bücher wurden in einem abgetrennten Raum im Handschriftenmagazin aufbewahrt.

\section{B 5}

\section{Der Index}

Liste des schädlichen und unerwünschten Schrifttums.

Leipzig, 1938.

SUB Göttingen: $8^{\circ}$ HLL III, 5661

Die von der Reichsschrifttumskammer erstellte „Liste des schädlichen und unerwünschten Schrifttums“ von 1935 enthält über 4.000 Einträge verbotener Werke und Autoren. Der Besitz und die Verbreitung der hier indizierten Bücher waren streng untersagt. Die Liste ging an alle Buchhandlungen, Verlage und Leihbüchereien, die ihren Bestand auf verbotene Literatur hin überprüfen und diese gegebenenfalls daraus entfernen mussten. Ein Vorläufer dieser Liste war die 1933 zur Bücherverbrennung herangezogene sogenannte „Schwarze Liste“. 


\section{B 6}

\section{Erzwungene Geschenke}

„Zurückgezogene und der Universitätsbibliothek Göttingen geschenkweise überlassene Werke“

Staatsarchiv Hamburg, 430-5, 1750-02, Schreiben vom 29.3.1934 mit beiliegender Liste aller nach Göttingen überwiesener Buchtitel

Wie alle nicht-wissenschaftlichen Bibliotheken war auch die Stadtbücherei Harburg-Wilhelmsburg als öffentliche Bücherei genötigt, sogenannte ,zersetzende“ Werke, die auf der Verbotsliste standen, aus ihren Beständen zu entfernen. Die Bücher wurden alphabetisch aufgelistet und nach Göttingen gesandt, wo sie laut Eintrag im Zugangsbuch im Mai 1934 in den Bestand der Universitätsbibliothek Göttingen eingearbeitet wurden.

\section{B 7}

\section{Besitzerwechsel}

Rudolf Abraham:

Die Theorie des modernen Sozialismus.

Berlin : Arbeiterjugend-Verlag, 1930.

SUB Göttingen: $8^{\circ}$ Pol. III, 6453/me <3>

Provenienz: Stadtbücherei Harburg-Wilhelmsburg, 1934

Rudolf Abrahams „Theorie des modernen Sozialismus“ steht an erster Stelle der Bücherliste. Das Werk trägt noch den durch Streichung ungültig gemachten Besitzstempel der Stadtbücherei Harburg-Wilhelmsburg. Auf den vorderen Einbanddeckel klebte die Universitätsbibliothek Göttingen ein Geschenkexlibris, um die Herkunft des Buches und seine Erwerbung als „Geschenk“ zu kennzeichnen. Der Vorgang zeigt, dass die Bücher aus Harburg-Wilhelmsburg wie ganz reguläre Zugänge behandelt und in den Bestand eingearbeitet wurden.

\section{B 8}

Buchhaus Friedenau muss auf „Die Zauberin von Kastilien“ verzichten

Schalom Asch:

Die Zauberin von Kastilien.

Berlin : Ladyschnikow, 1926. 
SUB Göttingen: $8^{\circ}$ Fab. I, 2936

Provenienz: Buchhaus Friedenau Berlin

(Bezug über die Preußische Staatsbibliothek Berlin), 1935

Schalom Asch, 1880 in der Nähe von Warschau geboren, war den Zeitgenossen als Verfasser zahlreicher Romane und Dramen mit teils historischen Inhalten bekannt. In seinen Werken schildert er oftmals die Lebenswelt der ostjüdischen Bevölkerung, die ihm aufgrund seiner Herkunft von klein auf vertraut war. Da Asch ein jüdischer Autor war, wurde sein Name von Anfang an auf dem Bücherindex der Nationalsozialisten geführt. Aus diesem Grund musste das Buchhaus Friedenau in Berlin, das Buchhandlung, Antiquariat und Leihbücherei zugleich war, den Titel aus dem Sortiment nehmen.

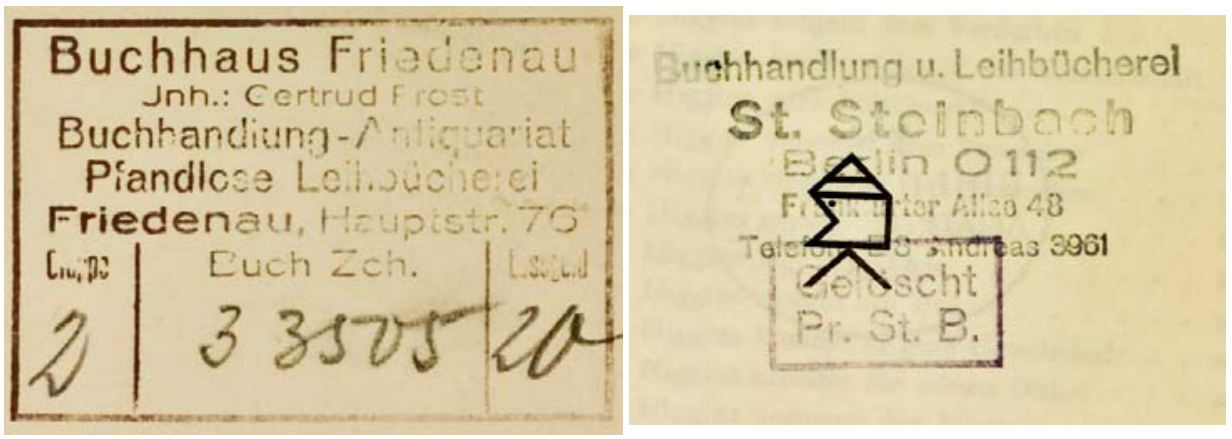

\section{B 9}

\section{Sinclair wird aussortiert}

Upton Sinclair:

Jimmie Higgins.

Berlin : Malik-Verlag, 1924.

SUB Göttingen: $8^{\circ}$ Fab. IX, 3544/h

Provenienz: Buchhandlung und Leihbücherei Steinbach Berlin

(Bezug über die Preußische Staatsbibliothek Berlin), 1934

Dieser Roman des sozialkritischen amerikanischen Autors Upton Sinclair wurde der Universitätsbibliothek Göttingen im Dezember 1934 als „Geschenk“ von der Preußischen Staatsbibliothek zu Berlin übersandt, wie das Geschenkexlibris zeigt. Es trägt einen Besitzstempel der Buchhandlung und Leihbücherei Steinbach in Berlin, in der sich das Buch ursprünglich befunden hatte. Da Sinclair zu den von den Nationalsozialisten verbotenen Autoren zählte, musste die Buchhandlung das 
Werk aussondern. Es gelangte in den Bestand der Preußischen Staatsbibliothek, die den Vorbesitzereintrag mit dem Stempel „Gelöscht Pr.St.B.“ ungültig machte.

\section{Bücher aus Arbeiterbibliotheken und sozialdemokratischen Vereinen}

In den Jahren zwischen 1934 und 1936 erhielt die Universitätsbibliothek Göttingen wiederholt Buchgeschenke von Bürgermeister- und Landratsämtern aus der Reichsprovinz Hannover. In der Mehrzahl handelte es sich um Werke von Autoren, die wegen ihrer demokratischen, humanistischen oder kommunistischen Gesinnung bzw. wegen ihrer jüdischen Herkunft von den Nationalsozialisten verboten worden waren. ${ }^{31}$

Der Umfang der zugesandten Bestände war sehr unterschiedlich: 135 Bücher übersandte der Bürgermeister aus Verden, 54 Bücher der Landrat aus Hann. Münden, während nur fünf Bücher vom Landrat aus Rotenburg i. Hann an die Bibliothek überwiesen wurden. ${ }^{32}$

Bei all diesen Zugängen stellt sich die Frage, wer die ursprünglichen Eigentümer der Bücher waren. In vielen dieser Werke ließ sich durch den Nachweis eines Stempels, einer Widmung oder eines Exlibris zunächst eine Spur aufnehmen. Durch weitergehende archivalische Forschungen konnte festgestellt werden, dass die Mehrzahl der Bücher aus kommunistischen und sozialdemokratischen Bibliotheken stammte. Anhand der Reichsgesetze über die „Einziehung kommunistischen Vermögens“ vom 26. Mai $1933^{33}$ und über die „Einziehung volks- und staatsfeindlichen Vermögens“" vom 14. Juli $1933^{34}$ hatten die Machthaber eine Legitimationsgrundlage, um an das Eigentum - darunter auch die Bücher - oppositioneller Parteien und der mit ihnen verbundenen Organisationen zu gelangen. Im Verlauf der kommenden Monate wurden zahlreiche Beschlagnahmungen vorgenommen, denen auch Arbeiter- und Gewerkschaftsbibliotheken zum Opfer fielen. Zum Teil haben sich die hierfür von den NS-Behörden eingeführten Vordrucke, wie die „Nachweisung über beschlagnahmtes Vermögen staatsfeindlicher

\footnotetext{
31 Bereits im Zuge der vom Hauptamt für Presse und Propaganda der Deutschen Studentenschaft initiierten Aktion „Wider den undeutschen Geist“, deren Höhepunkt die vielerorts durchgeführte Bücherverbrennung am 10.5.1933 bildete, wurden „Schwarze Listen“ für die Säuberung öffentlicher und privater Bibliotheken erstellt.

32 SUB Göttingen, Bibl.Arch. C Zugangsbücher von 1934 und 1935.

33 Reichsgesetzblatt 1933 I, S. 293.

34 Reichsgesetzblatt 1933 I, S. 479.
} 
Organisationen und Einzelpersonen“, in den Archiven erhalten, aus denen der Zeitpunkt und der Ort der jeweiligen Beschlagnahme bzw. der Umfang und die Art der eingezogenen Gegenstände hervorgehen (Objekt B 10).

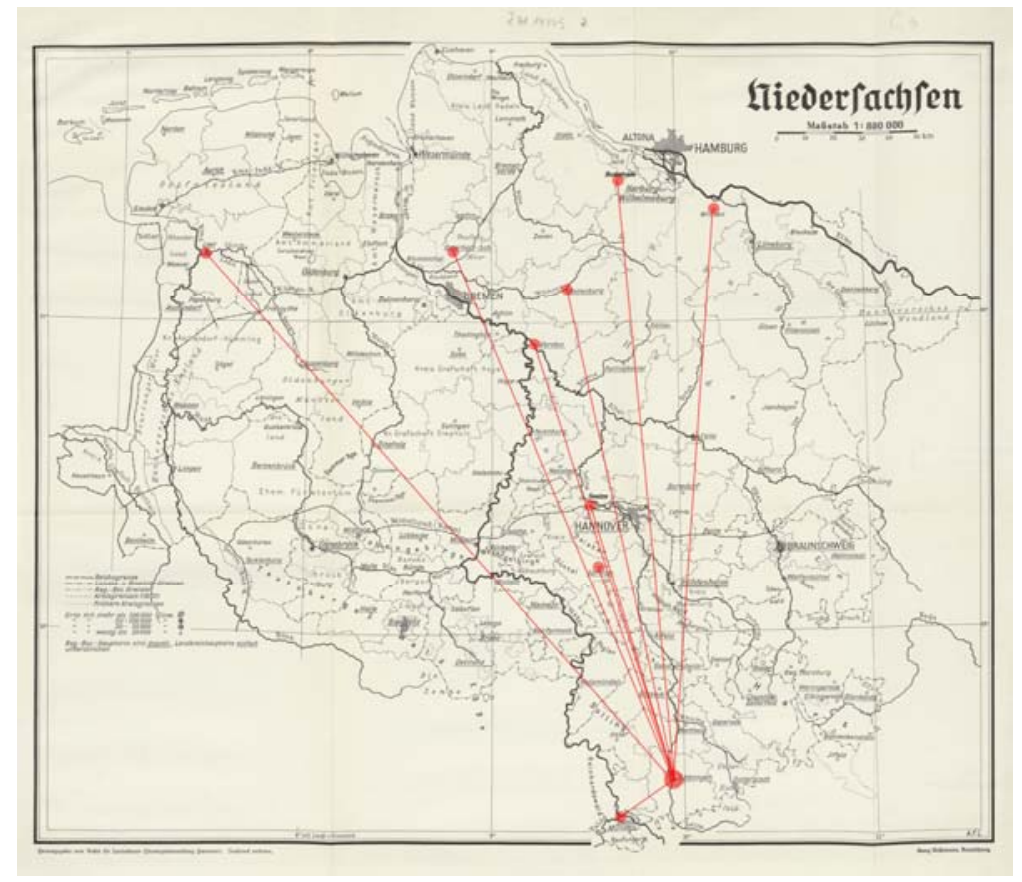

Abb.: Karte der Provinz. Hannover (mit Eintrag der Orte, aus denen Bücher an die UB Göttingen gelangten)

Ein Erlass des Preußischen Finanzministers vom 27. März 1934 legte schließlich fest, dass die beschlagnahmten Publikationen zunächst der Preußischen Staatsbibliothek in Berlin gemeldet werden sollten (Objekt B 11). In diesem Sinne wurden Verzeichnisse über die eingezogenen Bücher angefertigt, die anschließend nach Berlin gesandt wurden. Die Preußische Staatsbibliothek strich die gewünschten Werke an und sandte die Liste zurück. Dabei schien sie zuweilen stark beansprucht und bat beispielsweise den Landrat aus Hann. Münden um Geduld bei der Bearbeitung, da hunderte von Listen „von Gemeinden und Kreisen“ eingingen (Objekt B 12). ${ }^{35}$ Die für ihren Bestand unbrauchbaren Werke sollten anderen wissenschaftlichen Bibliotheken angeboten werden, so auch der Universitätsbibliothek Göttingen. Diese erhielt anschließend die Listen mit den beschlagnahmten Büchern, die - soweit ermittelbar - ausschließlich aus Bibliotheken der Pro-

\footnotetext{
35 Kreisarchiv Göttingen, LA HMÜ, 1081, Schreiben vom 11.5.1935.
} 
vinz Hannover stammten. ${ }^{36}$ Recht detailliert konnten die Verteilungswege im Fall der Bibliothek der SPD von Hann. Münden nachgezeichnet werden, da sich hierzu zahlreiche Dokumente im Stadtarchiv Hann. Münden und im Kreisarchiv Göttingen finden ließen.

Nach einer systematischen Überprüfung aller Bucheingänge aus der Zeit des Nationalsozialismus konnte festgestellt werden, dass die Universitätsbibliothek Göttingen mehr als 250 Bücher von Bürgermeister- und Landratsämtern erhalten hatte. Nahezu 200 von ihnen wurden als NS-Raubgut identifiziert. Unter Zuhilfenahme erhaltener Dokumente aus den einschlägigen Archiven und anhand von Provenienzhinweisen in den Büchern selbst ließ sich ihre Herkunft und Erwerbungsgeschichte in vielen Fällen genauer aufklären. Demgegenüber besteht bei etlichen Büchern der Verdacht, dass sie ebenfalls beschlagnahmt worden sind. Bei vielen der über die Landräte oder Bürgermeister eingegangenen Bücher handelt es sich um Werke von Autoren, die von den Nationalsozialisten verboten worden waren, wie beispielsweise die Publikationen von Maxim Gorki oder Leopold Kampf sowie um Schriften kommunistischen oder sozialdemokratischen Inhalts (Objekte B 14 und B 15).

\section{B 10}

\section{Vordrucke über die Nachweisung beschlagnahmten Vermögens}

Vordruck aus Rotenburg i. Hann. vom 10.9.1934 und Vordruck aus Verden vom 16.11.1934.

Staatsarchiv Stade, Rep. 180P, 1575 und 1577

Vordruck aus Hann. Münden o. D.

Stadtarchiv Hann. Münden, MR 1108

Die Beispiele von Vordrucken zeigen, dass bei einer Beschlagnahmung von Vermögen staatsfeindlicher Organisationen und Einzelpersonen stets die gleichen Angaben abgefragt wurden. Es wurde festgehalten, wann, wo und bei wem die Aktion stattfand und welche Gegenstände eingezogen wurden. Aus den aufgefundenen Dokumenten geht beispielsweise hervor, dass die Ortspolizeibehörde in Rotenburg i. Hann. am 30. April 1933 insgesamt 130 Bücher aus der Bibliothek des Bildungsausschusses des Ortsvereins der SPD beschlagnahmte.

${ }^{36}$ Vgl. Kreisarchiv Göttingen, LA HMÜ, 1081, Schreiben vom 18.12.1935. 


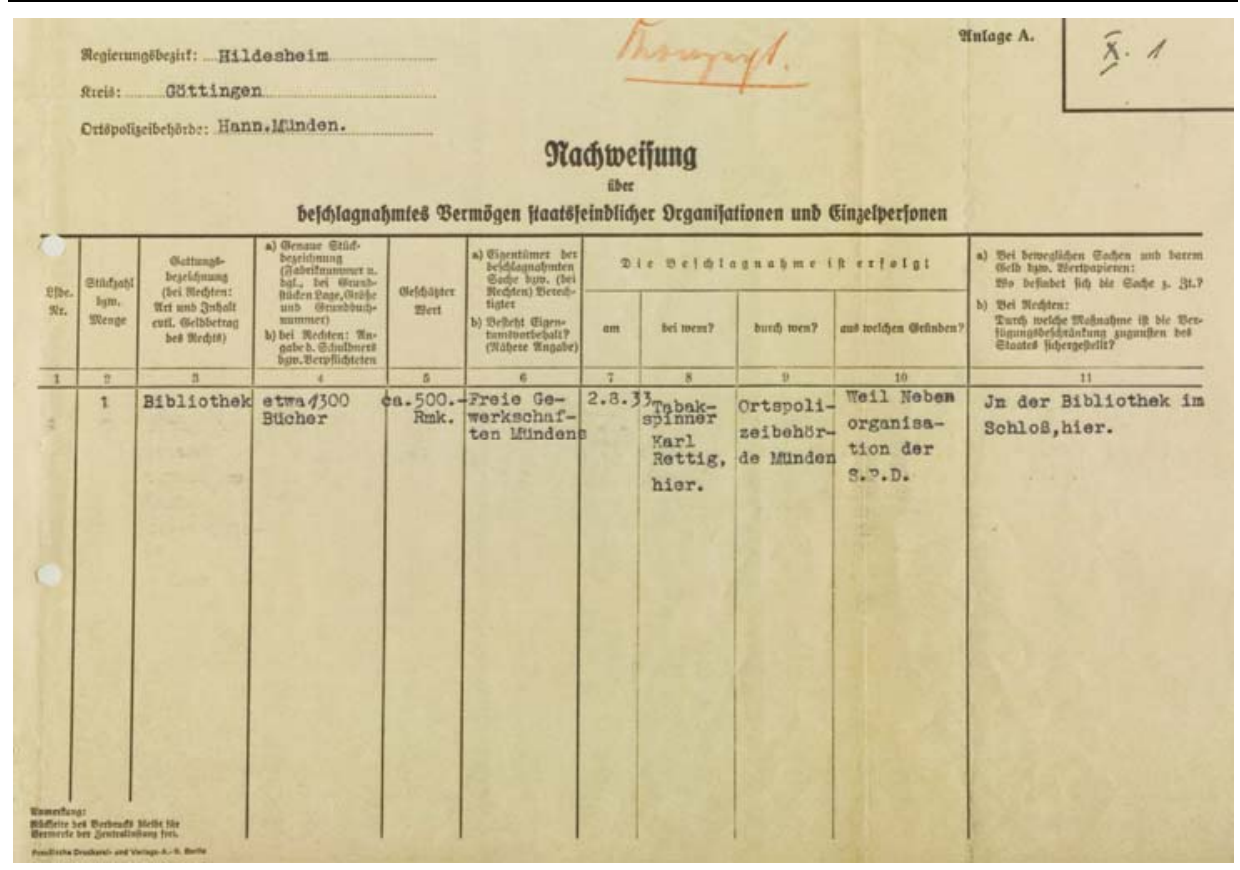

In Verden wurden am 12. Oktober 1934451 Bücher der Arbeiterzentralbibliothek bzw. des Sozialdemokratischen Wahlvereins und in Hann. Münden am 2. August 1933 rund 1.300 Bücher der örtlichen SPD eingezogen.

\section{B 11}

\section{Die Beschlagnahme der Bibliothek der SPD in Hann. Münden}

Schreiben des Landrats Hann. Münden vom 12.2.1935.

Stadtarchiv Hann. Münden, MR 1108

In einem Schreiben des Landrats Hann. Münden findet sich der Hinweis, die beschlagnahmten Bücher und Gegenstände seien Eigentum der „früheren SPD“ gewesen und wären „zu Gunsten des preußischen Staates“ eingezogen worden. Demgemäß sollte ein Verzeichnis über die noch vorhandenen Bücher „,in fünffacher Ausfertigung" nach einem vorgegebenen Muster erstellt werden. 


\section{B 12}

\section{Bücher aus Hann. Münden gehen an die Preußische Staatsbibliothek in} Berlin

Schreiben vom 18.12.1935.

Kreisarchiv Göttingen, LA HMÜ, 1081

Die Preußische Staatsbibliothek wünschte, je ein Exemplar aus dem Verzeichnis der beschlagnahmten Bücher zu erhalten, und zwar diejenigen, die mit Rotstift angestrichen waren. Die restlichen Bücher sollten „zunächst der Universitätsbibliothek Göttingen“" angeboten werden.

\section{B 13}

\section{Die Universitätsbibliothek Göttingen erhält Bücher aus Hann. Münden}

Schreiben vom 5.3.1936.

Kreisarchiv Göttingen, LA HMÜ, 1081

Nachdem die Preußische Staatsbibliothek für ihre Zwecke geeignete Titel aus der Liste der beschlagnahmten Bücher der früheren Arbeiterbibliothek Hann. Münden ausgewählt hatte, forderte die Göttinger Universitätsbibliothek ihrerseits 37 Titel für ihren Bestand an. In diesem Schreiben bedankt sich eine Mitarbeiterin der Zugangsabteilung der Universitätsbibliothek Göttingen beim Landrat Hann. Münden für den Empfang der Bücher.

\section{B 14}

Maxim Gorkis Roman „Drei Menschen“

Maxim Gorki:

Drei Menschen.

München : Wolf, 1923.

SUB Göttingen: $8^{\circ}$ Fab. X, 71721

Provenienz: Zentralbibliothek der organisierten Arbeiter Hann. Münden

(Bezug über das Landratsamt Hann. Münden), 1936

Der russische Schriftsteller Maxim Gorki (1868-1936) war in ärmlichen Verhältnissen aufgewachsen und hatte bereits in den späten 1880er Jahren Kontakte zu revolutionären Bewegungen im zaristischen Russland. In diesem frühen Roman 
(russische Erstausgabe 1900) schildert der Schriftsteller das Elend von scheiternden Menschen und ihre Hoffnung auf Besserung ihrer Lage. Das Buch stammt nach Ausweis des Besitzstempels auf dem Titelblatt aus der Zentralbibliothek der organisierten Arbeiter Hann. Münden; es wurde der Universitätsbibliothek Göttingen 1935 vom Landrat Hann. Münden als „Geschenk“ übergeben.

HR

\section{B 15}

\section{Ein Drama aus der russischen Revolution 1905}

Leopold Kampf:

Am Vorabend.

Berlin [u.a.] : Schuster \& Loeffler, 1906.

SUB Göttingen: $8^{\circ}$ Poet. Dram. III, 10094

Provenienz: Arbeiter-Zentral-Bibliothek Verden

(Bezug über das Bürgermeisteramt Verden), 1936

Der polnisch-österreichische Schriftsteller Leopold Kampf schildert in diesem

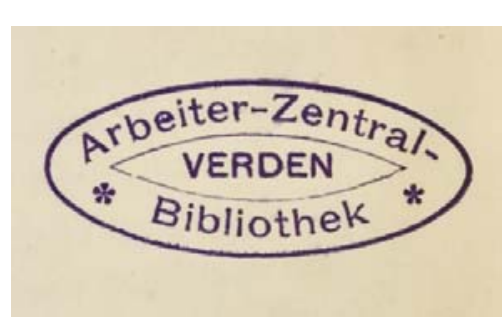
Drama die Stimmung unter den russischen Revolutionären kurz vor Beginn der Revolution des Jahres 1905. Nach zunächst friedlichen Demonstrationen für eine Verbesserung der Lebensverhältnisse sahen sich die Aktivisten zunehmenden Verfolgungen seitens der Regierung ausgesetzt, denen sie mit politischer und sozialer Gewalt begegneten. Das

Schauspiel war in der deutschen Kaiserzeit verboten. Besitzstempel weisen das Buch als Eigentum des Sozialdemokratischen Ortsvereins Verden bzw. der dortigen Arbeiter-Zentral-Bibliothek aus.

HR

\section{B 16}

\section{Porträt von Adolf Wittig}

Abbildung aus:

Dirk Sackmann / Geschichtswerkstatt Verden (Hg.):

„Ohne Schmuh ging es nicht“ - Zur Geschichte der Verdener Tabakarbeiterschaft.

Verden : Lührs \& Röver, 1991, S. 46. 
Der selbständige Zigarettenmacher Adolf Wittig geriet wegen seiner demokratischen Gesinnung und wegen des Abhörens von Feindsendern ins Visier der Nationalsozialisten. Am 1. April 1938 wurde er von der Gestapo in Verden verhaftet und anschließend in das Konzentrationslager Oranienburg-Sachsenhausen überführt. Erst nach knapp 13 Monaten wurde er am 20. April 1939 entlassen. Am 31. Mai 1943 schlossen die örtlichen Behörden seinen Betrieb wegen des Verdachts politischer Unzuverlässigkeit.

\section{Die Deutsche Arbeitsfront}

Die am 10. Mai 1933 gegründete Deutsche Arbeitsfront (DAF), geleitet von Robert Ley, war mit ca. 25 Millionen Mitgliedern die größte Massenorganisation im Nationalsozialismus. Sie trat zunächst an die Stelle der verbotenen Gewerkschaften, um die Arbeiter - später auch die Unternehmer - in einer einheitlichen, von der NSDAP kontrollierten Organisation zusammenzuführen. Schon bald kam es zu Konflikten zwischen Vertretern der DAF, die aus der Gruppe der Nationalsozialistischen Betriebszellenorganisation (NSBO) kamen, und Unternehmern. ${ }^{37}$ „Seit dem Sommer 1933 bemühte sich das Regime schrittweise um eine „Entgewerkschaftlichung der DAF ...“.38 Rasch fokussierte sie sich auf „Erziehungsund Betreuungsfunktion[en]"39. Aufgrund ihrer finanziellen Stärke gelang es ihr, nicht nur ein großes Wirtschaftsimperium aufzubauen, sondern auch zahlreiche Unterorganisationen zu errichten. Die heute noch bekannteste von ihnen war die „Kraft durch Freude“ (KdF). Zu den weniger bekannten Institutionen der Deutschen Arbeitsfront zählte das „Arbeitswissenschaftliche Institut“, das gleichsam als wissenschaftliche Denkfabrik für die Sozialpolitik der NSDAP dienen sollte. Für seine wissenschaftlichen Arbeiten wurde kraft einer Verordnung vom 4. Juli 1936 eine sozial- und volkswirtschaftliche Zentralbücherei gegründet, deren Grundstock 300.000 Bände bildeten, die aus beschlagnahmten Gewerkschaftsbüchereien übernommen worden waren. Aus diesem Bestand wurden 193780.000 Dubletten ausgesondert. ${ }^{40}$ Man kann davon ausgehen, dass diese Dubletten nicht nur Einrichtungen der Deutschen Arbeitsfront zur Verfügung gestellt wurden, sondern auch an wissenschaftliche Bibliotheken im Reich weitergegeben wurden. Von den 50 von der DAF an die damalige Universitätsbibliothek Göttingen über-

\footnotetext{
${ }^{37}$ Hans-Ulrich Thamer: Der Nationalsozialismus, Stuttgart 2002, S. $249 \mathrm{f}$.

${ }^{38}$ Ebd., S. 250.

${ }^{39}$ Ebd., S. 250.

40 Zentralblatt für Bibliothekswesen, Bd. 55, 1938, S. 88-90.
} 
sandten Büchern konnten 32 Bände mit Stempeln früherer Gewerkschaftsbüchereien nachgewiesen werden.

WE

\section{B 17}

\section{Böttcher, Küfer, Hilfsarbeiter}

August Bringmann:

Geschichte der deutschen Zimmererbewegung, Bd.1.

Hamburg : Fr. Schrader, 1909.

SUB Göttingen: $8^{\circ}$ Hist. Germ. II, 1471/ru [2]:1

Provenienz: Verband der Nahrungsmittel- u. Getränkearbeiter bzw.

Verband der Böttcher, Weinküfer und Hilfsarbeiter

(Bezug über die Deutsche Arbeitsfront), 1938

Die Stempel in diesem Buch verweisen auf zwei verschiedene Vorbesitzer. Ver-

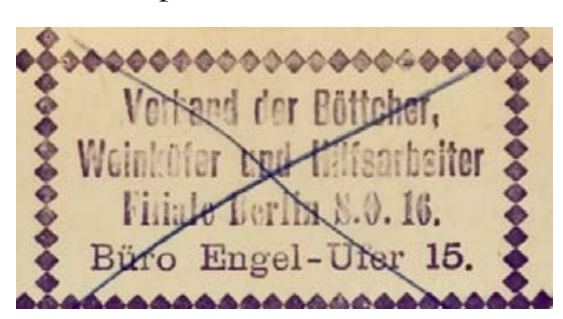
mutlich gehörte es vor der Zwangsauflösung der Arbeiterverbände dem Verband der Nahrungsmittel- und Getränkearbeiter in Berlin und davor dem Verband der Böttcher, Weinküfer und Hilfsarbeiter. Die Bücher der aufgelösten Arbeiterverbände gingen zunächst in den Bestand des Arbeitswissenschaftlichen Instituts der

Deutschen Arbeitsfront über (siehe Stempel mit Hakenkreuz). Die Deutsche Arbeitsfront erhielt aufgrund der Auflösung der Gewerkschaften zahlreiche Dubletten, die sie wissenschaftlichen Bibliotheken überwies. Auch die Universitätsbibliothek Göttingen profitierte davon und arbeitete Anfang 1937 und 1938 die unter der Erwerbungsart „Tausch“ in das Zugangsbuch eingetragenen Bände in ihren Bestand ein.

\section{B 19}

\section{Weibliche Handels- und Büroangestellte}

Joseph Jahn:

Markt und Mensch. Grundzüge der Volkswirtschaftslehre.

Hamburg : Hanseatische Verlagsanstalt, 1927.

SUB Göttingen: $8^{\circ}$ Pol. III, 4739/k

Provenienz: Verband der weiblichen Handels- u. Büroangestellten e.V. 
(Bezug über die Deutsche Arbeitsfront), 1938

Das Buch befand sich ursprünglich im Besitz des Verbandes der weiblichen Handels- und Büroangestellten e.V., der eine eigene Handbücherei besaß, um seine Mitglieder zu informieren.

\section{B 20}

\section{Nahrungsmittel- und Getränkearbeiter}

Bruno Schoenlank:

Sociale Kämpfe vor dreihundert Jahren.

Leipzig : Duncker \& Humblot, 2. Auflage, 1907.

SUB Göttingen: $8^{\circ}$ Hist. Bav. II, $3011<2>$

Provenienz: Verband der Nahrungsmittel- und Getränkearbeiter

(Bezug über die Deutsche Arbeitsfront), 1938

Auf dem Titelblatt findet sich ein Stempel des Verbandes der Nahrungsmittelund Getränkearbeiter. Der Autor des Buches, Bruno Schoenlank (1859-1901), trat während der Zeit des Kaiserreichs als sozialdemokratischer Politiker und Journalist hervor. Sein Name stand bereits auf der „Schwarzen Liste“ von 1933, die Mitte der 1930er Jahre zur wesentlich umfangreicheren „Liste des schädlichen und unerwünschten Schrifttums“ erweitert wurde.

\section{B 21}

\section{Transportarbeiter}

Hans Dreher:

Die ökonomischen Vorbedingungen und das Werden der Organisation.

Ein Ausschnitt aus der Geschichte der Handel-, Transport-

und Verkehrsarbeiter-Bewegung Deutschlands.

Berlin : Verlagsbuchhandlung Courier, 1907.

SUB Göttingen: $8^{\circ}$ Hist. Germ. II, 1452/e

Provenienz: Deutscher Transportarbeiter-Verband

(Bezug über die Deutsche Arbeitsfront), 1938

Vor der Abgabe des Buches an die Universitätsbibliothek Göttingen durch die Deutsche Arbeitsfront beziehungsweise das angegliederte Arbeitswissenschaftliche Institut (siehe Stempel links oben) befand es sich in der Bibliothek des Deutschen 
Transportarbeiter-Verbandes mit Sitz in Berlin. In der Bibliotheksordnung wird darauf hingewiesen, dass Bücher gegen „Vorzeigung des Mitgliedsbuches“ für vier Wochen kostenfrei entliehen werden dürfen. Im Krankheitsfall sollten Leser auf eine Ausleihe verzichten, um eine Ansteckung anderer Benutzer zu vermeiden.

\section{Bücher von politisch und rassisch Verfolgten: Walter Heise}

Am 25. April 1933 beschlagnahmte die Ortspolizeibehörde Münden in der Woh-

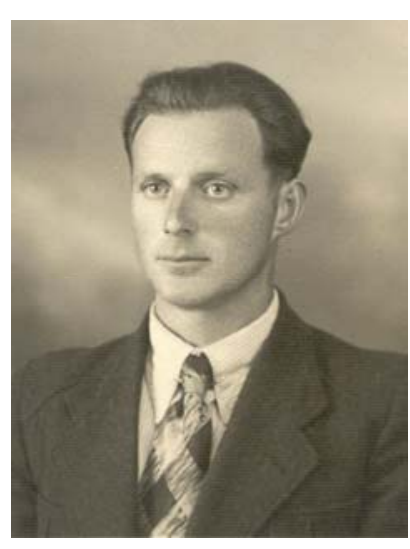
nung von Walter Heise 54 Bücher und einen Reisekoffer. In dem Vordruck Nachweisung über beschlagnahmtes Vermögen von Einzelpersonen (Objekt B 22) werden als Grund für die Sicherstellung der Gegenstände die KPD-Mitgliedschaft von Walter Heise und der marxistische Inhalt der Bücher genannt. Zu den eingezogenen Büchern zählte beispielsweise das 1929 erschienene Buch des tschechischen Schriftstellers Otto Katz, Neun Männer im Eis (Objekt B 28) oder das von Egon Erwin Kisch geschriebene Werk Paradies Amerika. Beide Autoren zählten zur oppositionellen Linken, bei Kisch kam noch dessen jüdische Abstammung hinzu, um von den Nationalsozialisten verboten und verfolgt $\mathrm{zu}$ werden.

Auch der Arbeiter Walter Heise geriet in den kommenden Jahren wiederholt ins Visier der Nationalsozialisten. Im Zuge einer von den Nationalsozialisten geplanten und durchgeführten, groß angelegten Razzia gegen die Kommunisten aus Hann. Münden wurde er am 8. Oktober 1935 zusammen mit vielen anderen örtlichen Oppositionellen in Haft genommen. ${ }^{41}$ In der Anklageschrift warf man ihm und seinen Weggefährten unter anderem hochverräterische Unternehmungen vor, die „durch illegale Zusammenkünfte, durch Sammlung, Hingabe und Weiterleitung von Geldbeträgen für die Zwecke der KPD und durch Kauf und Verteilung

${ }^{41}$ Gottfried Christmann / Dieter Kropp: Arbeiterbewegung in Hann. Münden von 1918 bis 1936, Göttingen 1984, S. 127. 
von Flugschriften“" gekennzeichnet waren. ${ }^{42}$ Dem ungeachtet blieb Walter Heise seiner politischen Gesinnung treu, was für ihn schwere Folgen haben sollte. Im Jahr 1939 erfolgte eine weitere Festnahme, bei der Walter Heise vermutlich an seine psychischen und physischen Grenzen stieß. Aus einer im Stadtarchiv Hann. Münden aufbewahrten Akte über diejenigen Einwohner Hann. Mündens, die den Freitod wählten, geht hervor, dass sich Heise - unmittelbar nach seiner Haftentlassung - am 19. Juli 1939 das Leben nahm (Objekt B 23). Der erst 33-jährige Walter Heise hinterließ seine Ehefrau und ihre Kinder aus erster Ehe.

Seine Bücher waren indessen in die Bestände der Universitätsbibliotheken Berlin und Göttingen aufgenommen worden. Eine Entschädigung für die Einziehung wurde nicht gewährt, da die 54 Bücher marxistischen Inhalts im Verdacht standen, „zur Förderung staatsfeindlicher Bestrebungen bestimmt“ $z u \operatorname{sein}^{43}$ und unter die Gesetze über die Einziehung kommunistischen sowie volks- und staatsfeindlichen Vermögens fielen. ${ }^{44}$

Nach einem Erlass des Preußischen Finanzministers vom 27. März 1934 sollte die zu Gunsten des Landes Preußen eingezogene Literatur der Preußischen Staatsbibliothek in Berlin gemeldet werden. Hierfür wurden Verzeichnisse mit den bibliographischen Angaben (Titel, Verfasser, Erscheinungsjahr usw.) angefertigt und an die dortige Erwerbungsabteilung gesandt. Die für die Staatsbibliothek nicht in Frage kommenden Werke wurden daraufhin anderen Universitäts- und Landesbibliotheken im Reich angeboten.

Gemäß der Satzung des neuen Erlasses wurde die Liste mit allen bei Walter Heise beschlagnahmten Buchtiteln zunächst an die Preußische Staatsbibliothek nach Berlin gegeben und danach der Universitätsbibliothek Göttingen zur Durchsicht angeboten (Objekt B 24). Die Berliner Staatsbibliothek markierte die für sie brauchbaren Titel und schickte die Liste mit den insgesamt 25 gewünschten Publikationen an den Landrat nach Hann. Münden zurück (Objekt B 25). AnschlieBend erhielt die Universitätsbibliothek Göttingen die Aufstellung der Titel, die von den verbliebenen Werken ihrerseits 17 erbat. ${ }^{45}$

Am 21. Januar 1935 wurden die Bücher „durch Postpaket“ nach Göttingen übersandt. ${ }^{46}$ Vier Tage später bestätigte die Zugangsabteilung der Universitätsbibliothek „mit verbindlichem Dank“ den Eingang der Bände aus Hann. Münden

42 Wilhelm Schumann: Ihr seid den dunkeln Weg für uns gegangen ... Skizzen aus dem Widerstand in Hann. Münden 1933-1939, Frankfurt a. Main 1973, S. 102 (aus der Anklageschrift „Vorbereitung eines hochverräterischen Unternehmens“, vom Generalstaatsanwalt Kassel, 28.1.1936).

43 Stadtarchiv Hann. Münden, MR 1108, Schreiben des Regierungspräsidenten in Hildesheim vom 5.10.1933. Hierin wird sich auf $₫ 7$ des Gesetzes vom 26.5.1933 berufen.

44 Reichsgesetzblatt I, S. 293, \ 1 des Gesetzes über die Einziehung kommunistischen Vermögens vom 26.5.1933 und Reichsgesetzblatt I, S. 479, Gesetz über die Einziehung volks- und staatsfeindlichen Vermögens vom 14.7.1933.

45 Kreisarchiv Göttingen, LA HMÜ, 1111, Schreiben der Universitätsbibliothek Göttingen (i. A. Kühn) vom 7.1.1935.

46 Kreisarchiv Göttingen, LA HMÜ, 1111, Schreiben des Landrats Hann. Münden vom 21.1.1935. 
(Objekt B 26). Die Titel der Neuzugänge wurden am 01. Februar 1935 im Zugangsbuch der Universitätsbibliothek Göttingen festgehalten. ${ }^{47}$ Bei einer Überprüfung der 17 in Göttingen verbliebenen Bücher fanden die Projektbearbeiterinnen in zwei Werken das handschriftliche Autogramm Walter Heises. Nach dem Wunsch der Erben sollen diese beiden Bücher in ihren Besitz übergehen, während die übrigen Werke im Bestand der Niedersächsischen Staats- und Universitätsbibliothek Göttingen bleiben sollen.

\section{B 22}

Nachweisung über beschlagnahmtes Vermögen von Einzelpersonen: Walter Heise

Dokument nach einem Vordruck über die Nachweisung beschlagnahmten Vermögens, ohne Datum.

Stadtarchiv Hann. Münden, MR 1108

Aus diesem Dokument geht hervor, dass die Ortspolizei Münden am 25. April 1933 „bei Durchführung einer Einzelaktion“ bei dem KPD-Anhänger Walter Heise 54 Bücher „marxistischen Inhalts“ und einen Reisekoffer beschlagnahmte. Der Wert der eingezogenen Gegenstände wurde auf insgesamt 80 Reichsmark geschätzt.

\section{B 23}

\section{Bücher bei Walter Heise beschlagnahmt}

Schreiben vom 5.10.1933.

Stadtarchiv Hann. Münden, MR 1108

In diesem Schreiben wird Walter Heise vom Regierungspräsidenten in Hildesheim darüber informiert, dass die seinerzeit beschlagnahmten Bücher marxistischen Inhalts dem Land Preußen zufallen, da sie der „Förderung staatsfeindlicher Bestrebungen" Vorschub leisten würden. Demzufolge war nicht daran gedacht, eine Entschädigung zu gewähren.

\footnotetext{
${ }^{47}$ SUB Göttingen Bibl.Arch. C Zugangsbuch vom Rechnungsjahr 1935.
} 


\section{B 24}

\section{Verzeichnis der beschlagnahmten Bücher Walter Heises}

Bücherliste, ohne Datum.

Kreisarchiv Göttingen, LA HMÜ, 1111

Von allen für das Land Preußen eingezogenen „staats- und volksfeindlichen“ Büchern sollten Verzeichnisse - meist in fünffacher Ausfertigung - nach einem bestimmten Muster angelegt werden. Darin waren der Buchtitel, der Verfasser, die Auflage und der Verlag vermerkt. Die Preußische Staatsbibliothek in Berlin wählte anhand dieser Listen die für sie brauchbaren Bücher aus. Anschließend wurden die Listen an andere wissenschaftliche Bibliotheken weitergereicht. Die mit „, “ gekennzeichneten Werke aus der Liste der Bücher Walter Heises wurden am 3. Januar 1935 nach Berlin abgegeben. Anschließend sollte die Universitätsbibliothek Göttingen eine Auswahl für ihre Bestandserweiterung treffen.

\section{B 25}

\section{Die Preußische Staatsbibliothek und die Universitätsbibliothek Göttingen erhalten Bücher aus dem Bestand Walter Heises}

Schreiben vom 5.1.1935.

Kreisarchiv Göttingen, LA HMÜ, 1111

Das Landratsamt in Hann. Münden forderte im Januar 1935 die Universitätsbibliothek Göttingen dazu auf, anhand der zugesandten Liste Bücher auszuwählen. Hierbei handelte es sich um die beschlagnahmte Literatur aus dem Hause Walter Heises. Die Preußische Staatsbibliothek hatte bereits am 4. Januar 1935 insgesamt 25 Werke dieses Bestandes „,mittels Postpaket“ erhalten. 
B. NS-Raubgut aus den Jahren 1933-1945

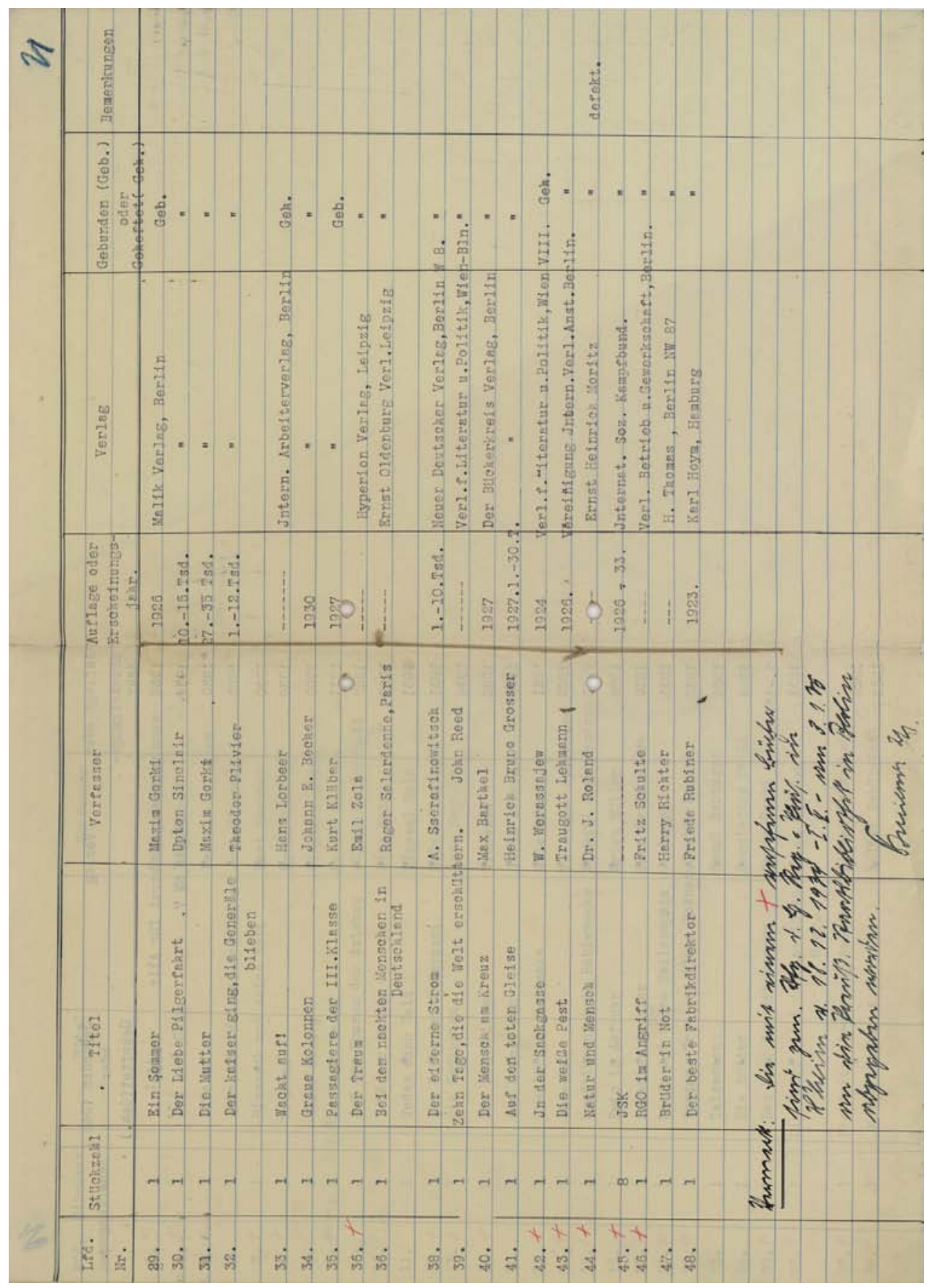

Abb.: Objekt B 24 


\section{B 26}

\section{Die Universitätsbibliothek Göttingen bestätigt den Eingang der Bücher} von Walter Heise

Schreiben vom 25.1.1935.

Kreisarchiv Göttingen, LA HMÜ, 1111

Am 25. Januar 1935 bestätigte die Zugangsabteilung der Universitätsbibliothek Göttingen dankend den Eingang der vom Landrat Hann. Münden übersandten Bücher. Das genaue Datum der Überweisung ist wegen einer Beschädigung des Dokuments nicht mehr lesbar.

\section{B 27}

\section{Walter Heise nimmt sich das Leben}

Anzeige über das Auffinden eines Leichnams, ohne Datum.

Stadtarchiv Hann. Münden, MR 1276

Am 19. Juli 1939 gegen 8 Uhr fanden der Stiefsohn und ein Freund des Opfers die Leiche von Walter Heise. Er hatte sich in seiner Wohnung erhängt. Walter Heise, geboren am 26. Juni 1906 in Mühlhausen, war zu diesem Zeitpunkt erst 33 Jahre alt. Mögliche Gründe, die Aufschluss über das Motiv dieser Handlung geben könnten, gehen aus dem Dokument nicht hervor.

\section{B 28}

\section{Per Luftschiff an den Nordpol - aus dem Besitz von Walter Heise}

Otto Katz:

Neun Männer im Eis : Dokumente einer Polartragödie.

Berlin : Universum-Bücherei für Alle, 1929.

Schriftenreihe: Universum-Bücherei für Alle ; 38

SUB Götttingen: $8^{\circ}$ Itin. I, 4900

Provenienz: Walter Heise Hann. Münden

(Bezug über das Landratsamt Hann. Münden), 1934

Der tschechische Schriftsteller Otto Katz (1895-1952) lebte seit Anfang der 1920er Jahre in Berlin, wo er in die KPD eintrat und als Kunstkritiker und Verleger arbeitete. In diesem Expeditionsbericht schildert er den gescheiterten Versuch 
des italienischen Luftschiffpioniers Oberst Umberto Nobile, mit dem Luftschiff „Italia“ den Nordpol zu bezwingen. Ein Teil der Mannschaft, darunter auch Nobile, wurde von der Besatzung eines sowjetischen Eisbrechers gerettet. Das Buch trägt einen eigenhändigen Besitzereintrag von Walter Heise.

HR

\section{Bücher von politisch und rassisch Verfolgten: Dr. Heinrich Troeger}

Am 4. Oktober 1933 schrieb der ehemalige Bürgermeister aus Neusalz (Schlesien), Dr. Heinrich Troeger, dem Direktor der Universitätsbibliothek Göttingen, Prof. Dr. Josef Becker, dass er der Bibliothek seine „Bücher marxistischer Tendenz“ schenken wolle. Troeger hob hervor, dass er auf diese Weise seinen Austritt aus der SPD zu unterstreichen und dem Verdacht, sich noch in diesem Sinne zu betätigen, zu begegnen versuchte (Objekt B 29). Der Direktor antwortete, dass er „,von dem freundlichen Angebot gerne Gebrauch“ machen wolle. ${ }^{48}$ Im darauffolgenden April wurden in das Zugangsbuch der Universitätsbibliothek Göttingen insgesamt 72 kommunistisch oder sozialdemokratisch ausgerichtete Titel als Geschenke Dr. Heinrich Troegers eingetragen ${ }^{49}$, wie beispielsweise Trotzkis Werk Die Lehren der Revolution (Objekt B 33) sowie etliche sozialpolitische Heftchen (Objekt B 34). In einigen dieser Werke befindet sich der Namenszug des Schenkers, häufig mit dem Datum des Erwerbs. ${ }^{50}$ Noch heute enthält jedes aus der Privatbibliothek Troegers stammende Buch ein Geschenkexlibris mit dem Vermerk: „Geschenk von Herrn Dr. Troeger, Berlin“.

48 SUB Göttingen Bibl.Arch. C 20,3, Schreiben vom 6. 10.1933.

49 SUB Göttingen Bibl.Arch. C Zugangsbuch vom Rechnungsjahr 1934, Eintragungen vom 27.4.1934.

${ }^{50}$ Interessant ist, dass als Absender eine Berliner Adresse angegeben worden ist, wobei Troeger in Neusalz gelebt hatte und in Breslau geboren war. Die Geschichte seines weiteren Werdegangs zeigt jedoch, dass der ehemalige Bürgermeister nach den polizeirechtlichen Verfolgungsmaßnahmen Schlesien den Rücken gekehrt hatte, um sich 1934 als freier Rechtsanwalt in Berlin niederzulassen. Die Übersendung der Bücher nach Göttingen nahm so auch einige Zeit in Anspruch. Während Troegers Inhaftierung war die Dienstwohnung gekündigt und seine schwangere Frau auf die Straße gesetzt worden, weshalb sich die Möbel und die Literatur übergangsweise und ungeordnet in einer leer stehenden Wohnung in Neusalz befanden. Troeger selbst erklärt in seinem Schreiben an den Bibliotheksleiter, dass er zurzeit nicht an die Bücher herankäme, aber die nächste sich bietende Gelegenheit nutzen wolle, um die versprochenen Bestände zu selektieren. Tatsächlich dauerte diese Durchsicht noch bis nach seinem Umzug nach Berlin. Archiv der Friedrich-Ebert-Stiftung in Bonn, Dr. Heinrich Troeger, Mappe 1, Lebenslauf des Ministerialdirektors Dr. jur. Heinrich Troeger, S. 2f; SUB Göttingen Bibl.Arch. C 20,3, Schreiben vom 4.10.1933. 
Aus heutiger Sicht stellt sich die Frage, welche tatsächlichen Beweggründe und welche Lebensumstände den Schenker dazu bewogen haben, seine Privatbücher wegzugeben. Dem glücklichen Umstand, dass Heinrich Troeger Zeit seines Lebens Tagebuch führte, ist es zu verdanken, dass die zeitgenössischen Vorkommnisse sehr gut nachgezeichnet werden können.

Anhand von Dokumenten - allen voran den Tagebuchaufzeichnungen - aus dem im Archiv der Friedrich-Ebert-Stiftung in Bonn verwahrten Nachlass Heinrich Troegers, ließen sich seine persönlichen Lebensumstände im Kontext zum gesellschaftlichen bzw. politischen Zeitgeschehen gut nachvollziehen. Darüber hinaus gibt sein im Jahr 1947 selbst verfasster Lebenslauf Aufschlüsse über den Werdegang und die politische Haltung Troegers in den Jahren des Nationalsozialismus (Objekt B 32). Dank dieser Quellen wird deutlich, dass Troeger in erster Linie aus Angst vor Übergriffen seitens der neuen Machthaber handelte. Die Bücherabgabe hatte demnach zum Ziel, den Nationalsozialisten keine Angriffsfläche mehr zu bieten (Objekt B 30).

Der promovierte Jurist Heinrich Troeger war bereits seit 1926 sozialdemokratischer Bürgermeister von Neusalz/Oder. ${ }^{51}$ Nach der Machtergreifung durch die Nationalsozialisten bekannte er sich weiterhin zur SPD und weigerte sich, der NSDAP beizutreten, woraufhin er ,,wegen nationaler Unzuverlässigkeit [...] ohne

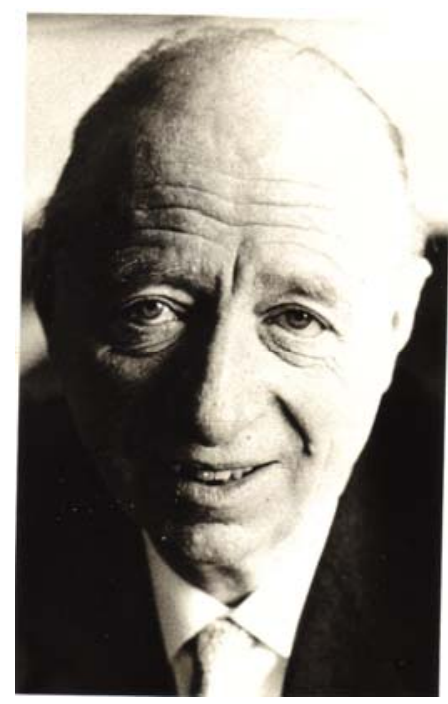

Pension aus dem Amt entlassen“wurde. Bereits im März 1933 wurde Troeger in „Schutzhaft“ genommen und erst wieder freigelassen, als er seine „Beurlaubung aus dem Dienst ohne zeitliche Beschränkung“" unterschrieben hatte. ${ }^{52}$ Es folgten ein Disziplinarverfahren und mehrere Strafverfahren. Am 4. Mai 1933 vertraute Troeger seinem Tagebuch an: „Die Zeit ist chaotisch und undurchsichtig. [...]. Aber wie weiter?"53 (Objekt B 30). Einen Höhepunkt der Verfolgungsmaßnahmen durch die Nationalsozialisten stellt seine Verhaftung im Juni 1933 dar. Auch diese Erlebnisse im Gerichtsgefängnis in Grünberg hielt er schriftlich fest. Hier machte Troeger wohl die Erfahrung, dass beschlagnahmte „staatsfeindliche“ Literatur als Druckmittel gegen ihre Eigentümer verwendet werden konnte. ${ }^{54}$ Er beschloss, in seiner Wohnung

51 Archiv der Friedrich-Ebert-Stiftung in Bonn, Dr. Heinrich Troeger, Mappe 1, Betr. politische Betätigung des Dr. jur. Heinrich Troeger, um 1946 (o. Datumsangabe).

52 Ebda., S. 1.

53 Archiv der Friedrich-Ebert-Stiftung in Bonn, Dr. Heinrich Troeger, Tagebuchblätter Bd. 4, S. 670.

${ }^{54}$ In den Aufzeichnungen wird nur der Nachnahme des Mitinhaftierten genannt: „Direktor Trebitz, 52 Jahre alt, still, verschlossen, niedergedrückt“. Dazu ebda., Tagebuchblätter Bd. 5, S. 695. 
„,noch einmal gründlich Nachschau“ zu halten (Objekt B 31).

Bereits kurz nach seiner Entlassung schrieb er den oben genannten Brief an Becker, den er vermutlich persönlich kannte, da dieser bis 1932 Leiter der Stadtbibliothek in Breslau gewesen war, wo Troeger einige Semester studiert hatte. Troeger starb - nach einer politischen Kariere als hessischer Finanzminister im Nachkriegsdeutschland - am 28. August 1975 in Bad Nauheim.

Dem Wunsch der Familie Dr. Troegers entsprechend, die von der SUB Göttingen über den Fund informiert wurde, hat die SUB Göttingen diese Bücher zum Nachlass Heinrich Troegers an die Friedrich-Ebert-Stiftung übergeben.

\section{B 29}

\section{Angebot einer Bücherschenkung von Heinrich Troeger}

Schreiben vom 4.10.1933.

SUB Göttingen: Bibl. Arch. C 20,3

In diesem Brief bietet Dr. Heinrich Troeger der Universitätsbibliothek Göttingen 72 Bücher „marxistischer Tendenz“ aus seiner Privatbibliothek als Geschenke an. „Es handelt sich“, so schreibt er dem Bibliotheksdirektor Prof. Dr. Josef Becker, „um eine ganze Reihe von Druckstücken“, die nicht besonders wertvoll, aber gut erhalten seien. Nach eigenen Aussagen wollte Dr. Heinrich Troeger mit diesem Schritt sein Ausscheiden aus der SPD untermauern und gleichzeitig ,jeden Anhaltspunkt für den Verdacht einer Fortsetzung“، seiner „früheren Betätigung vermeiden“.

\section{B 30}

\section{Heinrich Troeger gerät ins Visier der Nationalsozialisten}

Transkribierte Tagebucheintragung (Mai 1933).

Archiv der Friedrich-Ebert-Stiftung in Bonn,

Dr. Heinrich Troeger, 56, Tagebuchblätter, Band 4, S. 670.

Dr. Heinrich Troeger führte zeit seines Lebens Tagebuch. In seinen Aufzeichnungen hielt er politische und gesellschaftliche Umwandlungsprozesse fest und reflektierte seine private Lebenssituation. In einer scharfsinnigen und sehr persönlichen Weise erzählt er auch von seinen Erfahrungen im Jahr 1933. Troeger weigerte sich, der „Versuchung“ nachzugeben, , aus der SPD auszutreten, ja sich zum Eintritt in die NSDAP zu melden“. „Aber wie weiter?" Er beobachtete, dass „der 
Sturm auf die Gewerkschaftshäuser, die Auflösung der Gewerkschaften [...] erschreckende Zeichen des Kommenden" seien. Die überlieferten Tagebuchaufzeichnungen sind ein eindrucksvolles Dokument eines intellektuellen Zeitzeugen.

\section{B 31}

\section{Heinrich Troegers Erlebnisse im Gefängnis}

Transkribierte Tagebucheintragung (17.7.1933).

Archiv der Friedrich-Ebert-Stiftung in Bonn, Dr. Heinrich Troeger, 56, Tagebuchblätter, Band 5, S. 697-698.

Am Sonntagnachmittag des 25. Juni 1935 wurde Dr. Heinrich Troeger verhaftet und in die Gemeinschaftszelle 56a des Gerichtsgefängnisses in Grünberg gebracht. In seinen Tagebuchaufzeichnungen erinnert er sich, aus „der kahlen, feuchten Zelle" durch das Gitter geblickt zu haben. Er beobachtete, wie „[d]iensteifrige Polizeibeamte und SA-Hilfspolizisten“ eine „Reihe Waschkörbe mit Büchern und Akten“ abluden. Ein Mitgefangener glaubte, ,seine eigenen Bücher und Aktendeckel zu erkennen und war noch erregter und betroffener". Troeger selbst „rechnete nun mit Bestimmtheit mit einer neuen Durchsuchung seiner Wohnung“ und wollte „noch einmal gründlich Nachschau“ halten. Kurz nach seiner Entlassung bot er der Universitätsbibliothek Göttingen seine Bücher zum Geschenk an.

\section{B 32}

\section{Politische Betätigung von Heinrich Troeger}

Lebenslauf des Ministerialdirektors Dr. jur. Heinrich Troeger vom 16.4.1947. Archiv der Friedrich-Ebert-Stiftung in Bonn, Dr. Heinrich Troeger, 1.

Aus dem 1947 selbstverfassten Lebenslauf von Dr. Heinrich Troeger lassen sich viele Details seiner politischen Haltung in den Jahren des Nationalsozialismus entnehmen. Er berichtet unter anderem davon, dass er im Juli 1933 ,grundlos verhaftet und in das Gefängnis nach Grünberg überführt" worden war. Auch nach seiner anschließenden Übersiedlung nach Berlin 1934 wurde er von der Geheimen Staatspolizei ,wochenlang beobachtet und verfolgt““. 


\section{B 33}

\section{Trotzkis Analyse der russischen Revolution}

Leo Trotzki:

1917 : Die Lehren der Revolution.

Berlin : E. Laub, (1925).

SUB Göttingen: $8^{\circ}$ Hist. Russ. 414/57

Provenienz: Dr. Heinrich Troeger, 1934

Der russische Revolutionär und marxistische Theoretiker Leo Trotzki (1879-1940) veröffentlichte dieses Werk im Jahre 1924 als eine Analyse der Vorgänge in Russland seit der Machtübernahme durch die Bolschewiki im Oktober 1917.

Seit 1922 war Trotzki in einen Machtkampf mit Josef Stalin verwickelt, der 1926 mit seinem Ausschluss aus der KPdSU und 1928 mit seiner Verbannung nach Alma-Ata endete. Dr. Heinrich Troeger versah das Buch auf der Titelseite mit einem handschriftlichen Eintrag „Dr. Troeger 1925“. In der Universitätsbibliothek Göttingen erhielt das Buch im vorderen Deckel ein eingeklebtes Geschenkexlibris.

HR

\section{B 34}

\section{Politische Kleinschriften aus der Bibliothek Heinrich Troegers}

Unser Programm in Wort und Bild: das Programm der Sozialdemokratischen Partei Deutschlands (beschlossen zu Heidelberg am 18.9.1925).

Berlin : Dietz, 1931.

SUB Göttingen: $8^{\circ}$ Hist. Germ. II, 935/1

Deutscher Gewerkschaftsbund : (Verzeichnis der Arbeitnehmergewerkschaften). Berlin-Wilmersdorf, (1931).

SUB Göttingen: $8^{\circ}$ Hist. Germ. II, 1453/42

Herbert Dewald: Kampf dem Betriebs-Faschismus!

Berlin : Dietz, 1932.

SUB Göttingen: $8^{\circ}$ Hist. Germ. II, 1449/ad

Artur Mahraun:

Der Jungdeutsche Orden (Staatsbürger : 48).

Berlin : Jungdeutscher Verlag, [1932].

SUB Göttingen: $8^{\circ}$ Hist. Germ. II, 935/q 
Umbau der Wirtschaft: die Forderungen der Gewerkschaften.

Berlin : Allgemeiner Deutscher Gewerkschaftsbund, 1932.

SUB Göttingen: $8^{\circ}$ Hist. Germ. II, 1350/y

Bei der Mehrzahl der von Dr. Heinrich Troeger an die Universitätsbibliothek Göttingen übergebenen Bücher handelt es sich um politische Schriften. Zu den als Beispiele gezeigten Heften zählen das Heidelberger Programm der SPD von 1925, gewerkschaftliche Publikationen, aber auch die Schrift des antiparlamentarischen Schriftstellers Artur Mahraun über den von ihm gegründeten Jungdeutschen Orden. Alle Hefte wurden in der Bibliothek neu gebunden und mit einem Geschenkexlibris versehen, das Troegers Name trägt.

HR

\section{Bücher von politisch und rassisch Verfolgten: Dr. Friedrich Fischl und Dr. Hanns Fischl}

Es waren vor allem Juden, die unter der Herrschaft der Nationalsozialisten zu leiden hatten. Mit der Annexion Österreichs durch das Deutsche Reich im März 1938 verschlechterte sich die Lage der dort lebenden jüdischen Bevölkerungsgruppe massiv. Besonders schwer traf es die Juden in Wien, das als ein großes Zentrum jüdischer Kultur in Europa galt. Hier wie andernorts wurden wertvolle Kunstgegenstände, aber auch Bücher von den Nationalsozialisten geraubt oder mussten von ihren Eigentümern unter Zwang verkauft werden. Die Nutznießer waren neben nationalsozialistischen Institutionen auch staatliche Museen und wissenschaftliche Bibliotheken.

Bei den Untersuchungen zu den Literaturerwerbungen an der Universitätsbibliothek Göttingen im Dritten Reich sind verhältnismäßig wenige Bücher aus jüdischem Vorbesitz gefunden worden. Unter Zuhilfenahme des im Stadtarchiv befindlichen, vom Gemeindesteueramt Göttingen angefertigten „Judenverzeichnis“ vom August 1938 wurden die Namen aller hier genannten ortsansässigen Juden mit denen in den Zugangsbüchern der Universitätsbibliothek eingetragenen Lieferanten abgeglichen ${ }^{55}$ (Objekt B 35). Allerdings galt es zu berücksichtigen, dass zu diesem Zeitpunkt bereits viele Juden die Stadt verlassen hatten. Von den

55 Verzeichnis über das Vermögen von Juden nach dem Stand vom 27.4.1938. Hieraus gehen 101 Personennamen hervor. Siehe auch: Stadtarchiv Göttingen, Pol. C 157/6, Verzeichnis jüdischer Personen nach dem Stande vom 25.11.1938. 
Anfang 1933 noch vorhandenen 97 jüdischen Unternehmen existierten im November 1938 nur noch 19 Betriebe. ${ }^{56}$

Insgesamt konnten aus dem überlieferten Archivmaterial kaum Anhaltspunkte entnommen werden, die auf Erwerbungen von Büchern aus jüdischem Besitz schließen lassen, die an die Göttinger Universitätsbibliothek gingen. Vielmehr konnte festgestellt werden, dass der Bürgermeister der Stadt Göttingen der Ansicht war, „keine geeignete Handhabe“ zu besitzen, „um an die Bücherei der jüdischen Synagoge zu kommen“ (Objekt B 39). Auch bei der Novemberpogromnacht 1938 wurden ,keine jüdischen Bibliotheken sichergestellt“ (Objekt B 40).

Erst nach Beginn des Zweiten Weltkriegs erwarb die Universitätsbibliothek Göttingen einige Bücher von zwei Wiener Juden. Im März 1941 verkaufte ihr der Wiener Rechtsanwalt Dr. Friedrich Fischl neun Bücher für 31 Reichsmark. Vier Monate später veräußerte er erneut ein Werk, für das er 5,50 Reichsmark erhielt. Auch sein Bruder, Dr. Hanns Fischl, wandte sich mit dem Verkauf von drei Publikationen an die Göttinger Bibliothek. ${ }^{57}$ Bei ersterem Verkauf handelte es sich vornehmlich um antiquarische Bücher, die Johann Wolfgang Goethe zum Inhalt haben. ${ }^{58}$ Die von Hanns Fischl verkauften Bücher behandeln Themen wie die amerikanische Wirtschaftsgeschichte, die österreichische Heeresgeschichte oder das Luftfahrtsrecht (letzteres von ihm selbst verfasst). ${ }^{59}$

Es ist wahrscheinlich, dass die Veräußerung der Literatur den antijüdischen Maßnahmen durch die Nationalsozialisten, wie beispielsweise den steuerlichen Abgaben für Juden, geschuldet war. ${ }^{60}$ Dafür spricht unter anderem, dass auch das Historische Museum in Wien Gegenstände der Brüder Fischl erhielt. ${ }^{61}$ Dr. Hanns Fischl verkaufte den Städtischen Sammlungen zwischen Oktober 1940 und August 1943 seltene Ansichtskarten, Aquarelle, Fotografien, Grafiken, Ölgemälde und andere Kunstgegenstände zu auffallend niedrigen Preisen. Auch sein Bruder Dr. Friedrich Fischl soll im Herbst 1941 dem Museum Postkarten verkauft haben. ${ }^{62}$

\footnotetext{
${ }^{56}$ Cordula Tollmien: Nationalsozialismus in Göttingen 1933-1945, Diss., Göttingen 1998, S. 181.

${ }_{57}$ SUB Göttingen Bibl.Arch. C Zugangsbuch vom Rechnungsjahr 1941.

${ }^{58}$ Friedrich Fischl forschte auf dem Gebiet. ; Er hatte Goethe in Marienbad (Prag 1904) und Goethe und Graf Kaspar Sternberg (Leipzig 1932) geschrieben, die ebenfalls zu den verkauften Werken zählten.

59 Vgl. Hanns Fischl: Das österreichische Luftfahrtrecht, Wien 1929.

60 Österreichische Juden hatten ab dem 27.4.1938 ihr Vermögen anzumelden, wenn es den Wert von 5.000 RM überstieg. Nach den Untersuchungen des Historischen Museums in Wien ist zu vermuten, dass Dr. Hanns Fischl kein Vermögen über 5.000 RM besaß, da er in den Akten der Vermögensverkehrsstelle und des Bundesdenkmalamtes nicht auftaucht. Vgl. Die Restitution von Kunst- und Kulturgegenständen aus dem Besitz der Stadt Wien 1998-2001, hrsg. von Museen der Stadt Wien, Wiener Stadt- und Landesbibliothek (Historisches Museum), Dr. Hanns Fischl, 15.6.2000, S. 25.

${ }^{61}$ Ebda., Zusammenfassende Darstellung betreffend die Erwerbungen von Objekten aus der ehemaligen Sammlung von Dr. Hanns Fischl und von Dr. Friedrich Fischl durch die Städtischen Sammlungen, 15.6.2000, S. 25-27.
}

${ }^{62}$ Ebda., S. 25 u. 26. 
Der 1881 in Brünn geborene Dr. Friedrich Fischl wurde am 19. Oktober 1941 in das Ghetto nach Lodsch deportiert und am 27. Januar 1942 ermordet. Auch seine Frau Louise, geb. Glaser, wurde am 28. Oktober 1941 von den Nationalsozialisten nach Litzmannstadt gebracht, wo sie ebenfalls den Tod fand. Das Ehepaar war seit dem 30. April 1935 verheiratet; die Ehe blieb kinderlos. Der zwei Jahre jüngere Bruder Dr. Hanns Fischl ging nach den Aussagen seiner ,arischen“ Ehefrau Gertrude „am 9.10. 1943 über Vorladung der Gestapo [...] und ist seither nicht mehr zurückgekehrt" ${ }^{\circ 3}$ Nach Auskunft des Zentralmeldeamtes der Bundespolizeidirektion Wien wurde er am 16. Oktober 1943 in das KZ Auschwitz überstellt. ${ }^{64}$ Er soll zuletzt auf dem Todesmarsch im Januar 1945 nach Mauthausen gesehen worden sein. 1947 erklärte ihn seine Frau für tot.

Nach dem Willen der Tochter von Hanns Fischl, der Nichte von Friedrich Fischl, die Alleinerbin ist und von der SUB Göttingen über den Bücherfund informiert wurde, sollen die Bücher im Bestand der Niedersächsischen Staats- und Universitätsbibliothek Göttingen verbleiben.

\section{B 35}

\section{Verzeichnis über das Vermögen der Göttinger Juden}

Verzeichnis aller Juden aus Göttingen, Stand vom 27.4.1938.

Stadtarchiv Göttingen, Pol. C 157,6

Das Gemeindesteueramt der Stadt Göttingen fertigte am 25. August 1938 ein sogenanntes ,Judenverzeichnis“ an. Damit sollte geprüft werden, ob das Vermögen der aufgelisteten jüdischen Mitbürger 5.000 Reichsmark übersteige. Bereits im Frühjahr 1938 war eine „Verordnung über die Anmeldung des Vermögens von Juden" ergangen, der zufolge Juden bis Ende Juli ihr Vermögen zu deklarieren hatten, wenn dessen Wert höher als 5.000 Reichsmark war. Diese Verordnung war der Vorläufer des späteren Reichsgesetzes über die „Sühneleistung der Juden“ vom 21. November 1938 (RGBl I, S. 1638f), wonach alle jüdischen Bürger mit einem Vermögen von mehr als 5.000 Reichsmark 20 Prozent davon an das Finanzamt abführen mussten.

\footnotetext{
${ }^{63}$ Aussagen von Gertrude Fischl mit Antrag auf Einleitung des Verfahrens zur Beweisführung des Todes, in: Landesgericht für Zivilrechtssachen (LGfZRS) Wien, 48 T 2349/46 (2.7.1947), dargestellt in ebda., S. 26.

${ }^{64}$ Ebda.
} 


\section{B 36}

\section{Bücher von Hanns Fischl}

Zugangsbuch der Universitätsbibliothek Göttingen vom Rechnungsjahr 1941. SUB Göttingen: Bibl. Arch. Zugangsbuch 1941

Das Zugangsbuch vom Rechnungsjahr 1941 verweist auf den Eingang von drei Büchern, die von „T. Fischl Wien 19, Hardtg. 8“ stammen. Mit Hilfe der angegebenen Adresse konnte der Betroffene ermittelt werden: der Rechtsanwalt Dr. Hanns Fischl, der die Bände der Universitätsbibliothek Göttingen zum Verkauf angeboten hatte. Hierfür wurden ihm am 10. Juli 1941 insgesamt 14,95 Reichsmark überwiesen. Warum im Zugangsbuch die Namenseintragung „T. Fischl“ lautet, ist unbekannt. Es könnte sich um einen Schreibfehler oder um eine Abkürzung des Namens seiner Frau Gertrude Fischl (Traudel) handeln.

\section{B 37 \\ Mollinarys Memoiren}

Anton von Mollinary:

Sechsundvierzig Jahre im österreichisch-ungarischen Heere 1833-1879. Bd. 1. Zürich : Orell Füssli, 1905.

SUB Göttingen: $8^{\circ}$ Hist. Au. Germ. III, 8383:1

Provenienz: Dr. Hanns Fischl Wien, 1941

Die Autobiographie des österreichischen Generals Anton von Mollinary (18201904) beschreibt in zwei Bänden die militärische Laufbahn des Adligen, der 1833 als Kadett in die Armee eintrat, 1850 zum Oberst ernannt wurde und seine Karriere 1873 als Feldzeugmeister beendete, im österreichischen Heer der zweithöchste Generalsrang. Das Österreichische Biographische Lexikon 1815-1950 nennt die Memoiren „das gehaltvollste Erinnerungswerk eines kaiserlichen Offiziers aus der 2. Hälfte des 19. Jahrhunderts“. Das Buch stammt aus dem Besitz des jüdischen Rechtsanwalts Dr. Hanns Fischl in Wien, der es 1941 an die Universitätsbibliothek Göttingen verkaufte. 


\section{B 38}

\section{Goethes Faust aus englischer Sicht}

F. Melian Stawell und G. Lowes Dickinson:

Goethe and Faust : an interpretation, with passages newly translated into English verse.

London : Bell, 1928.

SUB Göttingen: $8^{\circ}$ Poet. Dram. III, 4415

Provenienz: Dr. Friedrich Fischl, Wien 1941

Florence Melian Stawell (1869-1936) war Dozentin für Klassische Philologie am Newnham College in Cambridge. Gemeinsam mit dem Historiker Goldsworthy Lowes Dickinson veröffentlichte sie das vorliegende Werk über Goethes „Faust“, in dem auch einige Originaltexte in neuer englischer Übersetzung präsentiert werden. Das Buch war ursprünglich im Privatbesitz des Präsidenten des Wiener Goethe-Vereins, Robert Franz Arnold. Aus seinem Nachlass gelangte es 1938 in die Bibliothek des Goethe-Vereins. Die Stempel bzw. Aufkleber, die auf diesen Vorbesitz verweisen, wurden durchgestrichen, als das Buch an den Sammler Dr. Friedrich Fischl veräußert wurde.

HR

\section{B 39}

\section{Bücher der jüdischen Synagogengemeinde in Göttingen}

Karl Julius Hartmann: Entwurf eines Briefes an den Kurator der Universität Göttingen.

Göttingen, 7.10.1938.

SUB Göttingen: Bibl. Arch. C 28,6

Durch einen ministeriellen Erlass waren alle öffentlichen und privaten Bibliotheken dazu angehalten, einen Bericht über den Umfang der Bücherbestände zur jüdischen und hebräischen Literatur abzugeben. Im Bereich der Universität Göttingen wurden Erhebungen insbesondere an den Seminarbibliotheken durchgeführt. Darüber hinaus wurde versucht, Informationen über die Göttinger Synagogenbibliothek einzuholen. In einem Briefentwurf des Bibliotheksdirektors Prof. Dr. Karl Julius Hartmann an den Kurator der Universität Göttingen erklärte dieser, dass der Bürgermeister der Stadt Göttingen, Albert Gnade (1886 bis nach 1945), „keine geeignete Handhabe besäße, um an die Bücherei der jüdischen Synagogengemeinde heranzukommen“. Über deren „Art und Umfang“ könnten demnach keine Aussagen gemacht werden. Darüber hinaus seien auch keine Pri- 
vatbibliotheken von Juden und ,Judenforschern" bekannt.

JD

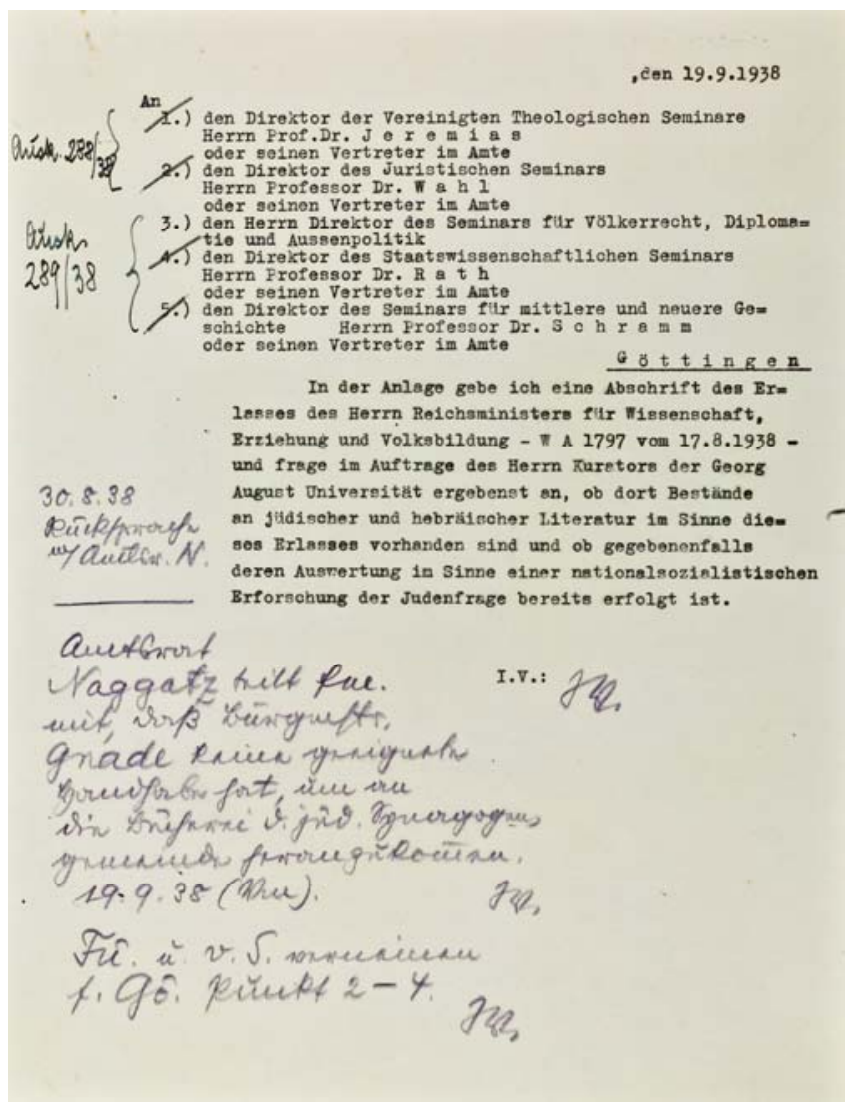

\section{B 40}

\section{Beschlagnahmung jüdischer Bibliotheken in Göttingen}

Schreiben der Geheimen Staatspolizei Hildesheim vom 22.3.1939.

Stadtarchiv Göttingen, Pol. C 157,6

In der vom nationalsozialistischen Regime gelenkten Reichspogromnacht vom 9. zum 10. November 1938 wurden unter anderem zahlreiche jüdische Einrichtungen zerstört oder geplündert. Später sollte eine nachträgliche Überprüfung der beschlagnahmten Bibliotheken eingeleitet werden. Im Zuge dessen forderte auch die Geheime Staatspolizeistelle in Hildesheim im März 1939 ihre Außendienststellen in Göttingen und Goslar dazu auf, eine Erfassung und Sichtung der beschlagnahmten Bibliotheken vorzunehmen. Laut einer handschriftlichen Randnotiz des Göttinger Kriminalobersekretärs Theodor Griethe waren jedoch in Göttingen „jüdische Bibliotheken nicht sichergestellt" worden. 


\section{NS-Beutebücher 1939-1945}

\section{Bücher aus deutschen Kriegsgefangenenlagern}

Das nationalsozialistische Deutsche Reich war während des Zweiten Weltkrieges in 21 Wehrkreise aufgeteilt, die mit römischen Ziffern von I bis XXI gekennzeichnet waren. Dementsprechend wurden auch die Kriegsgefangenenlager nummeriert und zusätzlich mit den Buchstaben A und B gekennzeichnet. Beispielsweise trug das Lager Lamsdorf in Schlesien die Nummer VIII-B. Bei den Lagern handelte es sich entweder um Stalags (Stammlager für Mannschaften und Unteroffiziere), Oflags (Offizierslager) und Dulags (Durchgangslager). Die Mehrzahl der Lager waren Stalags. ${ }^{65}$

Die Behandlung der Kriegsgefangenen wurde durch die Haager Landkriegsordnung von 1907 sowie die Genfer Konventionen von 1906 und 1929 geregelt. Hilfsorganisationen (Objekt C 3 und C 8) durften sich um die Belange der Gefangenen kümmern und Lebensmittel und andere Gegenstände in die Lager schicken, darunter auch Bücher. Während polnische und russische Kriegsgefangene in deutschen Lagern als Inhaftierte „Zweiter Klasse“ behandelt wurden, gestatteten die Deutschen den sogenannten „Westgefangenen“ Freizeitangebote zu organisieren und Bibliotheken (Objekt C 1) zu unterhalten. ${ }^{66}$ Neben Hilfsorganisationen wie das Rote Kreuz versorgten auch Angehörige die Gefangenen mit Büchern (Objekt C 4).

Bevor die Sendungen die Empfänger erreichten, wurden sie zunächst von den Lagerzensoren - oftmals mehr als 20 in einem Lager - auf verdächtige Inhalte hin überprüft (Objekt C 2). Wenn Bücher auf der vom Oberkommando der Wehr-

\footnotetext{
${ }^{65}$ Siehe: Angelo Spinelli / Lewis Carlson: Life behind barbed wire. The secret World War II photographs of prisoner of war Angelo M. Spinelli, New York 2004. Hier findet sich eine Karte mit Einzeichnung der Lagerstandorte.

${ }^{66}$ Siehe hierzu u. a.: Zur Geschichte des Kriegsgefangenenlagers Stalag VI A Hemer. Eine Begleitschrift für die Gedenkstätte und die beiden Friedhöfe, hrsg. v. Verein für Hemeraner Zeitgeschichte e. V., Hemer 2006, S. 13 ff.
} 
macht herausgegebenen Sperrliste standen und/oder Passagen mit deutschfeindlichen Äußerungen enthielten (Objekt C 4 und C 5), wurden sie beschlagnahmt und mit einem Vermerk wie Angehalten (Objekt C 6 und C 7) oder Zurückgehalten und einem Prüfstempel versehen (Objekt C 7). Vielfach markierten die Zensoren die zurückgehaltenen Werke auch mit einem roten $Z$ (zensiert, zurückgehalten) und strichen die Textstellen im Buch an (Objekt C 5). Gelegentlich schrieben die Zensoren auch den Namen desjenigen Kriegsgefangenen, für den das Buch mit der Post ins Lager geschickt wurde, auf das Vorsatzblatt (Objekt C 4).

Die vorstehenden Erkenntnisse ergaben sich aus der Untersuchung von Büchern, die im Juni 1943 vom Beschaffungsamt in Berlin an die UB Göttingen gesandt wurden. Das Beschaffungsamt war eine Institution, die zusammen mit dem Deutsch-Ausländischen Buchtausch ausländische Literatur für wissenschaftliche Bibliotheken besorgen sollte. Die Universitätsbibliothek Göttingen erhielt während der Kriegsjahre mehrere größere Lieferungen vom Beschaffungsamt, die generell als Geschenk in die Zugangsbücher eingetragen wurden, obwohl es sich um entzogenes Eigentum von Kriegsgefangenen handelte. Bei den im Juni 1943 überlassenen Büchern konnten 140 Bände ausfindig gemacht werden, die in verschiedenen Kriegsgefangenenlagern beschlagnahmt und an das Beschaffungsamt weitergeleitet worden waren. Es sind vorwiegend englischsprachige Romane von damals populären Autoren wie Edward Phillips Oppenheim oder Leslie Charteris.

\section{1}

\section{Lagerbücherei im Stammlager Fürstenberg}

Angelo Spinelli, Lewis Carlson:

Life behind barbed wire. The secret World War II photographs of prisoner of war Angelo M. Spinelli.

New York : Fordham University Press, 2004, S. 73.

SUB Göttingen: 2004 A 22379

Die Lagerbücherei im Stammlager (Stalag) III-B in Fürstenberg/Oder wurde von amerikanischen Kriegsgefangenen unterhalten. Nur den sogenannten „Westgefangenen" war das Recht eingeräumt worden, kulturelle und sportliche Freizeitangebote für sich zu organisieren. Dazu gehörte auch die über 10.000 Bände umfassende Bücherei im Stalag, die in einer eigenen Baracke untergebracht war. Sie setzte sich vor allem aus Spenden der YMCA und des Internationalen Roten Kreuzes zusammen. 


\section{2}

\section{Zensoren bei der Arbeit}

Baracke im Offizierslager X B bei Nienburg.

Provenienz: Museum Nienburg/Weser. Repro von Bildarchiv - Nr. 19290.

Das Foto zeigt die Innenansicht einer als Postprüfstelle dienenden Baracke im Offizierslager (Oflag) $\mathrm{X}-\mathrm{B}$, einem Lager für französische Kriegsgefangene im Offiziersrang in der Nähe von Nienburg. Soldaten der Abwehr sowie Zivilangestellte mit Fremdsprachenkenntnissen überprüfen die Kriegsgefangenenpost.

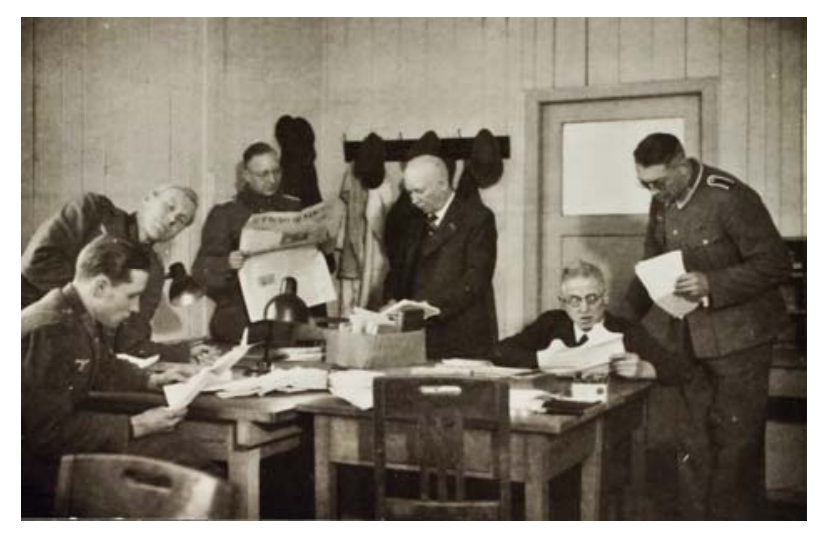

\section{3}

\section{Bücherhilfe für Kriegsgefangene}

Isaac Pitman:

Pitman's shorthand manual.

London : Sir Isaac Pitman \& Sons Ltd., London 1931.

SUB Göttingen: $8^{\circ}$ Art. illib. 1605

Provenienz: Stalag II-D Stargard (Bezug über das Beschaffungsamt), 1943

Sowohl das Britische Rote Kreuz als auch die YMCA Switzerland (siehe Stempel im Buch) beteiligten sich an der Sammlung von Buchspenden für Kriegsgefangene. Diese Einführung in Isaac Pitmans Stenographie wurde in das Stammlager (Stalag) II-D bei Stargard (Pommern) geschickt, wo sie zunächst von den Lagerzensoren geprüft wurde. Das Stalag II-D gehörte zu den ersten deutschen Kriegsgefangenenlagern und war 1939 für polnische Kriegsgefangene eingerichtet worden. 1940 kamen französische und belgische Gefangene hinzu, 1941 sowjetische Häftlinge, die während des sogenannten „Unternehmens Barbarossa“ in deutsche Gefangenschaft geraten waren. 1943 folgten italienische und ein Jahr später kanadische Gefangene. 


\section{4}

\section{Ein Buch für Private Thomas Nichol}

Leslie Charteris:

The Saint in Miami (= The Saint Books 21).

London : Hodder \& Stoughton, 1941.

SUB Göttingen: $8^{\circ}$ Fab. IX, 5485

Provenienz: Stalag Schildberg (Bezug über das Beschaffungsamt), 1943

Dieses Buch stammt aus dem Stammlager (Stalag) XXI-A in Schildberg (Polen). Es war für den Gefangenen Private Thomas Nichol mit der Gefangenennummer 2317 bestimmt. Das Werk kam allerdings nicht von einer Hilfsorganisation, sondern wurde privat durch eine Miss F. G. Jackson geschickt. Es erreichte seinen Adressaten allerdings nicht, da es „zurückgehalten“ wurde. Ein Zensor namens Bull schrieb eine ausführliche Begründung für seine Entscheidung auf das Vorsatzblatt des Buches: Es sei ,voller Beleidigungen gegen unseren Führer und das Deutsche Volk. Es ist ein Hetzbuch gegen Deutschland, den Nationalsozialismus und unseren Führer“. Entsprechende Belegstellen für seine Begründung gibt er auf der rechten Seite an.

\section{5}

\section{Verboten: "German gangster with cold blue eyes"}

Grierson Dickson:

Gun Business.

London : Hutchinson \& Co., 1939.

SUB Göttingen: $8^{\circ}$ Fab. IX, 5811

Provenienz: unbekanntes Stammlager (Bezug über das Beschaffungsamt), 1943

In der rot angestrichenen Textstelle dieses Romans wird sein deutscher Protagonist Eitel abwertend charakterisiert. Auf dem Vorsatzblatt des Buches weist ein Zensor namens Grundel auf diese Seite hin. Im Bestand der SUB Göttingen befinden sich insgesamt zwölf von Grundel zensierte Bücher aus Stammlagern; jedoch gibt es in keinem der Bände einen Besitzstempel. Deshalb kann das Kriegsgefangenenlager, aus dem das Buch über das Beschaffungsamt in die Universitätsbibliothek Göttingen gelangte, nicht mehr lokalisiert werden. Das Vorgehen Grundels entspricht dem in den deutschen Stammlagern üblichen Verfahren, weshalb von einer Herkunft aus einem Stammlager ausgegangen wird. 


\section{6}

\section{„Eckstein. Jude!“}

Gustav Eckstein:

Canary. The history of a family.

London : Faber \& Faber, 1937.

SUB Göttingen: $8^{\circ}$ Fab. IX, 5448

Provenienz: Stalag VIII-B Lamsdorf

(Bezug über das Beschaffungsamt), 1943

Das Buch des österreichischen Sozialdemokraten Gustav Eckstein (1875-1916) stammt aus dem Stammlager (Stalag) VIII-B in Lamsdorf (Schlesien), das bereits vor dem Zweiten Weltkrieg existierte. Der Roman wurde von den Lagerzensoren geprüft und „angehalten“, wie sich an der Eintragung des Zensors feststellen lässt. Als Grund wird die jüdische Abstammung des Autors genannt.

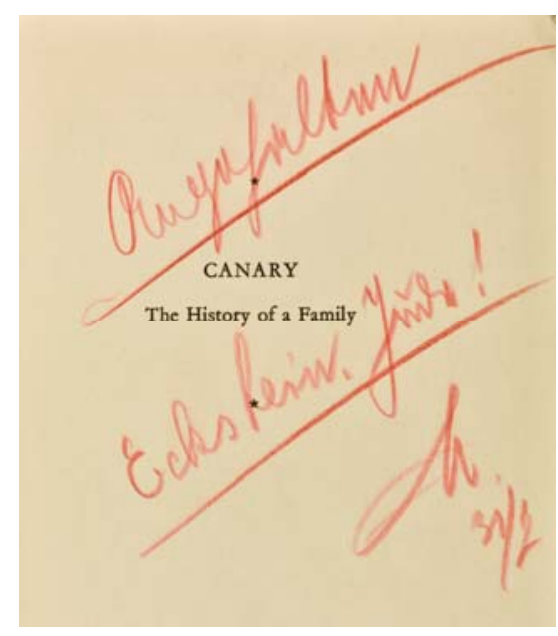

\section{7}

\section{"Letters from Iceland"}

W. H. Auden, Louis Macneice:

Letters from Iceland.

New York : Random House, 1937.

SUB Göttingen: $8^{\circ}$ Itin. II, 1676

Provenienz: Stalag VIII-B Lamsdorf (Bezug über das Beschaffungsamt), 1943

W. H. Auden trug mit einer Reisebeschreibung, Briefen und Hinweisen für Touristen wesentlich zum Erfolg dieses zusammen mit Louis Macneice verfassten Buches bei. Diese Erstausgabe wurde im Stammlager (Stalag) Lamsdorf (Schlesien) vom Zensor Falz (Prüfstempelnummer 28) hinsichtlich seines Einflusses auf die Kriegsgefangenen als bedenklich eingestuft. Seine Begründung: „Angehalten wegen beleidigender Äußerungen gegen

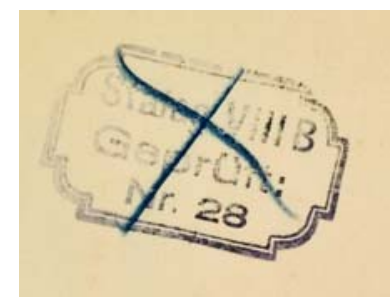
das Deutsche Reich“. 


\section{8}

\section{Bücherwege: Stalag - Beschaffungsamt - UB Göttingen}

Martin Joseph Freeman:

The murder of a midget.

London : Eldon Press, 1935.

SUB Göttingen: $8^{\circ}$ Fab. IX, 5354

Provenienz: Stalag Schubin (Bezug über das Beschaffungsamt), 1943

Das Kriegsgefangenenlager Stalag XXI-B befand sich ursprünglich in Schubin

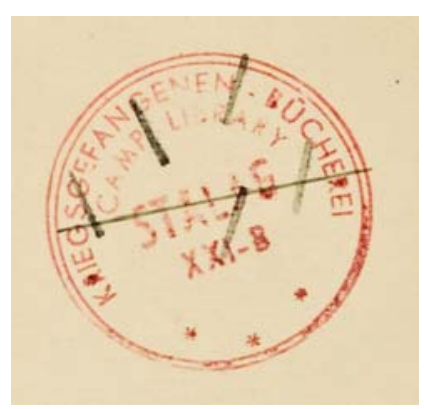
(Posen), wurde aber während des Zweiten Weltkrieges mehrfach verlegt. Dieses Buch trägt einen Zensur- bzw. Prüfstempel, wurde aber nicht zurückgehalten, sondern an die „Camp Library“ weitergegeben.

Die Bücherei des Kriegsgefangenenlagers profitierte dabei von einer Spende des Dänischen Roten Kreuzes (siehe Stempel im Buch). Es bleibt ungeklärt, unter welchen

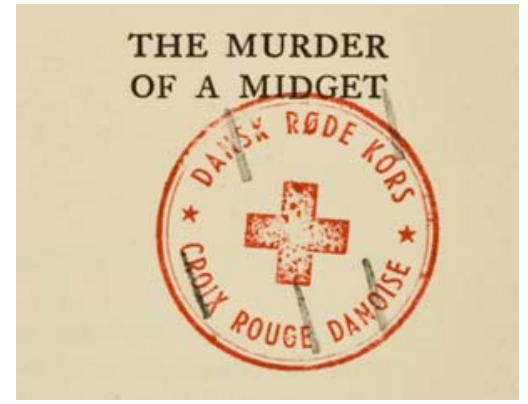
Umständen das nicht zensierte und daher auch nicht sofort beschlagnahmte Buch der Bücherei wieder entzogen wurde und in den Besitz des Beschaffungsamtes gelangte.

\section{Bücher aus den besetzten Gebieten}

Mit dem Ausbruch des Zweiten Weltkrieges begann in den besetzten Gebieten ein im großen Stil organisierter Kulturgutraub, dem viele Buchhandlungen, Antiquariate, Verlage und Bibliotheken verfolgter Organisationen, aber auch Bibliotheken von Privatpersonen zum Opfer fielen. An solchen Beschlagnahmungen beteiligt waren verschiedene NS-Organisationen, aber auch die Wehrmacht oder das Auswärtige Amt. Bücher, die sie nicht für ihre eigenen Zwecke gebrauchen konnten, wurden auch an bei der Preußischen Staatsbibliothek angesiedelte Einrichtungen wie die Reichstauschstelle, das Beschaffungsamt oder den Deutsch-Ausländischen 
Buchtausch weitergegeben. Diese personell miteinander verflochtenen und für den allgemeinen Schriftenaustausch verantwortlichen Institutionen verteilten die Literatur wiederum an wissenschaftliche Bibliotheken im Deutschen Reich.

Vor allem die Reichstauschstelle wuchs zu einer der wichtigsten Verteilereinrichtungen für Beutebücher heran. Im Jahr 1943 erhielt sie die zusätzliche Aufgabe, die Buchbestände der zerstörten deutschen Bibliotheken wieder aufzustocken. $\mathrm{Zu}$ diesem Zweck bekam sie Mittel in Millionenhöhe, mit denen sie unter anderem alle greifbaren Bibliotheken im Ausland, darunter auch Privatbibliotheken aufkaufen sollte (Objekt C 13). ${ }^{67}$

Auch die Universitätsbibliothek Göttingen profitierte von diesen Aktionen. Da die Bücher über den regulären Tauschverkehr hereinkamen, kann man freilich nur bei den Büchern, die noch Provenienz- bzw. Besitzeinträge enthalten, erkennen, dass es sich um Beutegut handelt. Auffällig sind zum Beispiel knapp 40 Bücher, die einen Dublettenstempel der Universitätsbibliothek Posen enthalten. In der von den deutschen Besatzern übernommenen und 1941 neu eröffneten Staats- und Universitätsbibliothek Posen wurden zahlreiche beschlagnahmte Bücher gesammelt und Dubletten an Bibliotheken im Reich verteilt. ${ }^{68}$

Insgesamt 28 Titel kamen Ende 1940 und Anfang 1941 aus einem Beutelager der Wehrmacht in der Weender Landstraße 59 in Göttingen in die Universitätsbibliothek (Objekte C 9 und C 10). In einigen der Bücher konnten Besitzstempel öffentlicher Bibliotheken in den Niederlanden (Arnhem, Enschede etc.) nachgewiesen werden.

Wie hoch die Eigeninitiative der Bibliothekare bei der Beschaffung erbeuteter ausländischer Literatur war, lässt sich nur schwer beurteilen. Bislang konnte nur ein Brief gefunden werden, in dem der Direktor der Universitätsbibliothek Göttingen, Prof. Dr. Karl Julius Hartmann, einen im Ausland stationierten Kollegen darum bat, „Umschau zu halten“ und sich dafür einzusetzen, „dass bereits beschlagnahmte Literatur" für die Zwecke der Bibliothek zur Verfügung gestellt werde (Objekt C 14).

JD/HR

${ }^{67}$ Cornelia Briel: Die Preußische Staatsbibliothek und die Reichstauschstelle als Verteilerinstitutionen beschlagnahmter Literatur. Strukturen. Hypothesen. Beispiele. In: Regine Dehnel (Hrsg.): NS-Raubgut in Bibliotheken. Suche. Ergebnisse. Perspektiven. Drittes Hannoversches Symposium, Frankfurt/Main 2008, S. 29-43.

${ }^{68}$ Aus einem Schreiben eines Angestellten der Dublettenstelle in Posen geht hervor, dass der „reiche Bestand an polnischen Doppelstücken [...] bestehende Lücken in den Beständen mancher Bibliothek des Altreichs“ füllen sollten. Die Doppelstücke sollten auf die „,bekannten Dublettenzettel der Reichstauschstelle [...] umgeschrieben und in Umlauf gesetzt werden" Bundesarchiv Berlin, R 4901, 13658, Bl. 128 (,Zweieinhalb Jahre Staats- und Universitätsbibliothek Posen“). 
C 9

Bücher aus dem Göttinger Beutelager

Zugangsbuch der Universitätsbibliothek Göttingen vom Rechnungsjahr 1940.

SUB Göttingen: Bibl. Arch. Zugangsbuch 1940

Im Zugangsbuch vom Rechnungsjahr 1940 sind unter den laufenden Inventarnummern 2.480, 2.481 und 3.137 bis 3.162 Büchereingänge aus dem Göttinger Beutelager der Wehrmacht festgehalten. Der Großteil der Werke ist auf Niederländisch verfasst; einige wurden auch in Frankreich verlegt. Bei allen Titeln ist unter der Rubrik „Erwerbung“ ein „G“ vermerkt, d.h. sie wurden als Geschenke in den Bestand der Universitätsbibliothek Göttingen aufgenommen.

\section{10}

\section{Empfangsbestätigung für die Bücher aus dem Göttinger Beutelager}

Briefbuch (2. Teil) der Universitätsbibliothek Göttingen, Bezugsnummer: 9.11.1940.

SUB Göttingen: Bibl. Arch. C 1,9.2

Im Bibliotheksarchiv Göttingen sind zwei Briefbücher (1. Teil: 1933-1938 / 2. Teil: 1938-1942) überliefert, in die vom Sekretariat der Universitätsbibliothek Göttingen alle dienstlichen Briefeingänge und -ausgänge stichpunktartig eingetragen wurden. Im zweiten Briefbuch ist unter der Bezugsnummer vom 9. November 1940 eine Empfangsbescheinigung über 21 Bücher aus dem Beutelager der Wehrmacht in Göttingen festgehalten. Der überwiegende Teil der Eintragungen in den Briefbüchern befasst sich mit Personalangelegenheiten. 


\section{11}

\section{H. W. Heuvels Heimatskizzen}

Hendrik Willem Heuvel:

Uit den Achterhoek : Schetsen van Land en Volk.

Deventer : Æ. E. Kluwer, 1929.

SUB Göttingen: $8^{\circ}$ Hist. Holl. IV, 1113

Provenienz: Beutelager der Wehrmacht in Göttingen, 1941

Der Historiker und Schriftsteller Hendrik Willem Heuvel (1864-1926) war als Lehrer in der kleinen Stadt Borculo im holländischen Gelderland tätig, bevor er sich der Geschichte und Kultur seines bäuerlichen Umfeldes auch als Schriftsteller widmete. Das Buch stammt aus der öffentlichen Bibliothek der Stadt Enschede, wie der Besitzstempel auf dem Titelblatt verrät. Das vordere Vorsatzblatt enthält 16 Datumsstempel mit Ausleihen vom 28. Mai 1937 bis zum 25. Mai 1940 sowie die Signatur der Bibliothek in Enschede (88 C 12). Alte Signaturschilder sind offenbar vom Buchrücken entfernt worden. Der Band gelangte über das Beutelager Göttingen 1941 in die Universitätsbibliothek Göttingen.

HR

\section{12}

\section{Selma Lagerlöfs Kindheitserinnerungen}

Selma Ottilia Lovisa Lagerlöf:

Herinneringen van een kind.

Amsterdam : H. J. W. Becht, 1931.

SUB Göttingen: $8^{\circ}$ Hist. lit. biogr. VIII, 55801

Provenienz: Willem Lion Marinus Ernest van Leeuwen (Bezug über das Beutelager Göttingen), 1941

Selma Lagerlöf (1858-1940) ist die wohl berühmteste schwedische Schriftstellerin des 20. Jahrhunderts. Sie erhielt 1909 als erste Frau den Nobelpreis für Literatur. Zu ihren bekanntesten Werken zählt das Kinderbuch „Die wunderbare Reise des kleinen Nils Holgersson mit den Wildgänsen“. Bei dem vorliegenden Werk handelt es sich um die holländische Übersetzung des zweiten Teils von Lagerlöfs Autobiographie, in der sie von ihren Kindheitserlebnissen auf dem elterlichen Gutshof berichtet. Das Buch wurde im Original 1930 unter dem Titel „Ett barns memoarer“ (wörtlich: „Memoiren eines Kindes“; Titel der deutschen Übersetzung: „Aus meinen Kindertagen“) veröffentlicht. Wie dem eingeklebten Exlibris 
auf dem Vorsatzblatt zu entnehmen ist, stammt es aus der Bibliothek des niederländischen Schriftstellers und Literaturkritikers Willem Lion Marinus Ernest van Leeuwen (1895-1972).

$\mathrm{CF}$

\section{13}

\section{Die Reichstauschstelle beansprucht riesige Büchermengen}

Schreiben vom 17.6.1944.

Universitätsarchiv Göttingen, Kur. 1833

Für den Ankauf von Buchbeständen zum Aufbau der im Zweiten Weltkrieg zerstörten Bibliotheken erhielt die Reichstauschstelle Mittel in Millionenhöhe. Damit kaufte sie im Inland und im besetzten Ausland große Mengen von Verlagsbeständen, von antiquarischen Büchern sowie Privatbibliotheken auf. Zudem griff sie auf bereits beschlagnahmte Bücher zurück. Mit diesem Schreiben versuchte die Reichstauschstelle in den Besitz von Professorenbibliotheken zu kommen. Vornehmlich warb sie um Buchbestände verstorbener oder gefallener sowie emeritierter Hochschullehrer.

\section{14}

\section{Umschau nach Büchern im Ausland}

Schreiben vom 8.10.1940.

SUB Göttingen: Bibl. Arch. C 13,2

Anfang Oktober 1940 schrieb der Direktor der Göttinger Universitätsbibliothek, Prof. Dr. Karl Julius Hartmann, einen Brief an den in Frankreich stationierten Professor für Mittlere und Neuere Geschichte, Prof. Dr. Percy Ernst Schramm. Darin bat er seinen Kollegen, sich nach bereits beschlagnahmten Büchern für den Bestand der Bibliothek umzusehen. Schramm war später im Oberkommando der Wehrmacht (OKW) für die Führung des Kriegstagebuchs verantwortlich. Bei der Überprüfung seiner Büchergeschenke an die Universitätsbibliothek Göttingen konnten jedoch keine Auffälligkeiten, also keine Hinweise auf bedenkliche Provenienzen festgestellt werden. 


\section{15}

\section{Zwei Dubletten aus der Universitätsbibliothek Posen}

Henri Gadeau de Kerville:

Les animaux et les yégétaux lumineux.

Paris, 1890.

SUB Göttingen: $8^{\circ}$ Zool. III, 4034

Provenienz: Biblioteka Vloclavskago Real'nago Učilišča (russ. = Bibliothek der Realschule von Włocławski) (Bezug über die Reichstauschstelle Berlin), 1941

Jacques Matha:

L'Instructions du peuple.

Paris : Morel, 1848.

SUB Göttingen: $8^{\circ}$ Pol. IV, 5772

Provenienz: Biblioteka Szkoły Nar[odowej] w Batignolles (poln. = Bibliothek der Volksschule in Batignolles) (Bezug über die Reichstauschstelle Berlin), 1941

Diese beiden Bücher wurden von der Universitätsbibliothek Posen zunächst der Reichstauschstelle in Berlin zur Verfügung gestellt, da es sich bei beiden um Dubletten handelte, die bereits in der Universitätsbibliothek Posen vorhanden waren.

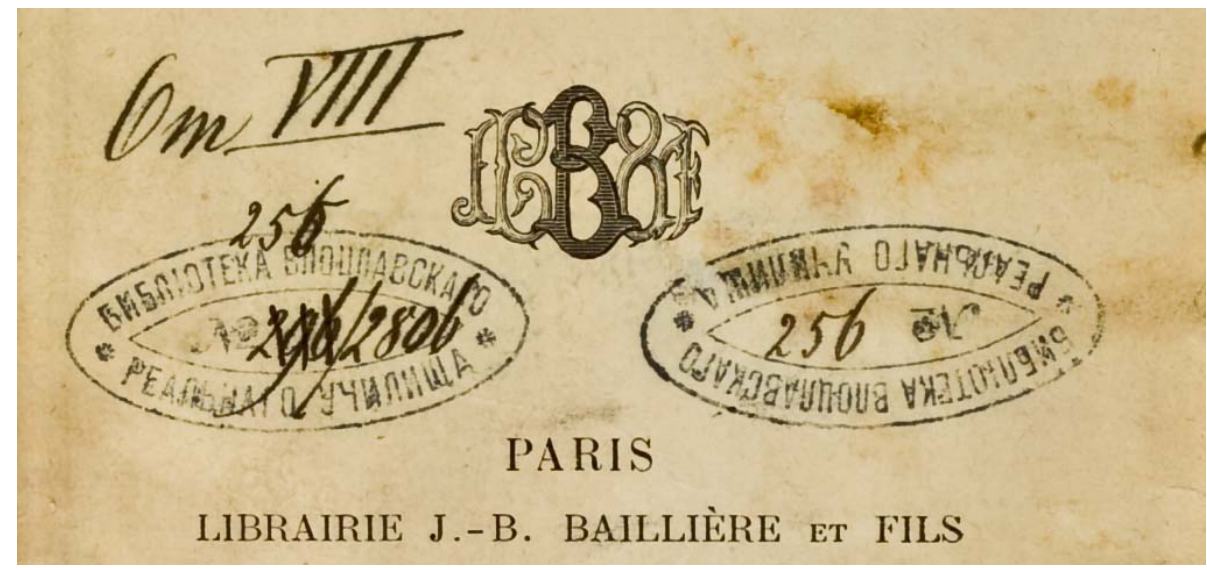

Die Universitätsbibliothek Posen selbst hatte die Exemplare aus zwei verschiedenen Bibliotheken erhalten, die ihre Bücher aus ungeklärten Gründen, möglicherweise unter den Zwängen der deutschen Besatzungsmacht, abgegeben hatten. Da die Universitätsbibliothek Posen als Sammelstelle für die in den Ostgebieten eingezogenen Bücher fungierte, kann von einem Verdacht auf Beutegut ausgegangen werden. 


\section{16}

\section{Das Beutelager der Wehrmacht in Göttingen}

Stadtplan von Göttingen.

Göttingen : E Kelterborn, 1939.

SUB Göttingen: $8^{\circ}$ Hist. Hann. V, 199

Auf diesem Stadtplan aus dem Jahr 1939 ist der Standort des ehemaligen Beutelagers der Wehrmacht in Göttingen gekennzeichnet. Das Grundstück gehörte ursprünglich der jüdischen Unternehmerfamilie Hahn, die eine Rohhäute- und Fellgroßhandlung und die Gallus Schuhfabrik GmbH besaß. Auf dem großen Gelände befanden sich zwei weitere Firmen jüdischer Unternehmer. Im Zuge der „Arisierung" erlitten die Betriebe zusehends Umsatzeinbußen und mussten schließlich aufgegeben werden. 


\section{Verdachtsfälle und ungeklärte Fälle: Unlösbarkeiten bei der Suche nach NS-Raub- und Beutegut}

Nicht immer lassen sich bei der Suche nach NS-Raub- und Beutebüchern im Bestand der SUB Göttingen die Erwerbungsumstände verdächtiger Fälle aufklären. Die Gründe für diesen Umstand können je nach Zugang sehr unterschiedlich sein. Vielfach verhindert die schlechte Quellenlage eine mögliche Klärung, wie und warum ein Buch in den Bestand der SUB gelangt ist. Nicht selten gingen Akten in den Kriegswirren verloren, wurden durch Bombentreffer vernichtet oder bewusst beseitigt.

Ein Fall, der bisher nicht aufgeklärt werden konnte, ist ein Zugang aus den letzten Kriegsmonaten. Der Rechtsanwalt Dr. Robert Schneider hatte der Universitätsbibliothek Göttingen im Januar 1945 eine Fachbibliothek von rund 1.500 Bänden verkauft (Objekte D 1-3). ${ }^{69} \mathrm{Im}$ Zugangsbuch wurde diese umfangreiche Erwerbung entgegen dem sonst üblichen Verfahren in einem Sammeleintrag festgehalten, d.h. die Titel sind nicht einzeln aufgeführt. Daher ist der Inhalt dieses Bestandes heute nur schwer rekonstruierbar. Die Bände wurden je nach Themenschwerpunkt den einzelnen Systemstellen zugeordnet und so verstreut im Magazin aufgestellt. Durch einen glücklichen Zufall konnte eine dieser Systemstellen ausfindig gemacht und die darin aufgestellten Bücher anhand der Zugangsnummer identifiziert werden. Bei den unter der Systemstelle „Historia Universalis III“ gefundenen Büchern handelt sich um Literatur zum Thema Freimaurerei.

Zumeist waren in diesen Büchern Tilgungen (rausgekratzt, übermalt, ausgeschnitten) vorgenommen worden, weshalb nur vereinzelt Rückschlüsse auf die jeweiligen Vorbesitzer gezogen werden konnten. Soweit ermittelbar, stammten viele Bücher dieses Bestandes aus dem Besitz ehemaliger Logen, wie beispielsweise der Loge der „Freunde zur Eintracht“ in Mainz, der „Loge zu Alzey“ oder der Loge der „Vereinigten Freunde an der Nahe“.

In Deutschland waren unter den Nationalsozialisten die Logenhäuser geschlossen und das Inventar - darunter auch der Buchbesitz - beschlagnahmt wor-

69 SUB Göttingen Bibl.Arch. C Zugangsbuch vom Rechnungsjahr 1944. 
den; viele Freimaurer wurden verfolgt. Am 17. August 1935 gab Innenminister Wilhelm Frick schließlich das endgültige Verbot der Freimaurerei in Deutschland bekannt. ${ }^{70}$ Insofern besteht der Verdacht, dass hier NS-Raubgutfälle vorliegen könnten. Allerdings ist eine endgültige Bewertung aufgrund fehlender oder widersprüchlicher Überlieferungen über diesen Vorgang und die Person Dr. Robert Schneider bislang nicht möglich. Nach dem derzeitigen Stand der Untersuchungen kann dieser Fall nur pauschal als verdächtig eingestuft werden.

Ein anderes Problem stellt die zum Teil schlechte Lesbarkeit der Bucheintragungen dar. Darüber hinaus erschweren häufig auftretende Zunamen wie Meier, Schulze oder Hansen aus dem norddeutschen und skandinavischen Raum (Objekt D 11) eine Zuordnung von Büchern in erheblichem Maße. Insbesondere bei Literatur aus Antiquariaten, die ihre Bücher aus verschiedenen Quellen bezogen, bleiben die Angaben im Buch die einzige Spur. Hier sind die Umstände des Verkaufs zumeist nur sehr schwer nachzuvollziehen und ohne einen Hinweis im Werk selbst nicht mehr zu ermitteln.

Zudem ist es vielfach schwierig, biographische Informationen zu den Personen zu erlangen, deren Exlibris, Namen oder Stempel in den Büchern ermittelt werden konnten, und etwas über ihre Lebensumstände herauszubekommen. Im Laufe der vergangenen Untersuchungen zeigte sich, dass Hintergrundinformationen häufig nur über Menschen aus dem öffentlichen Leben ermittelt werden konnten, da diese zumeist in Personendatenbanken oder in Archivakten aufgeführt sind. Als hilfreich erwies es sich, wenn Angaben über den Wohnort vorlagen, da hierüber eine Lokalisierung und somit Einschränkung des infrage kommenden Personenkreises möglich wurde (Objekte D 8-10).

Rückblickend ist die Personenrecherche - mehr noch als die Suche nach Institutionen wie Vereinen oder Verbindungen - ein sehr zeitaufwendiger Arbeitsprozess, der häufig zu keinerlei Ergebnissen führt. Und auch wenn der entsprechende Vorbesitzer identifiziert werden konnte, bleiben in fast allen Fällen die genauen Umstände der Erwerbung im Dunklen. Es ist deutlich geworden, dass eine gründliche Recherche in den regionalen und überregionalen Archiven unabdingbar ist, um bestimmte zeitgeschichtliche Umstände sowie lokale Besonderheiten in Erfahrung bringen und somit in den Gesamtzusammenhang einordnen zu können. Häufig ist erst dann endgültig zu beurteilen, ob ein NS-Raub- bzw. Beutegutfall vorliegt.

Neben dem Problem der Personenrecherche sind auch der Suche nach möglichen Rechtsnachfolgern Grenzen gesetzt, wie das Beispiel des an der Universität Göttingen ehemals tätigen jüdischen Anglistiken Prof. Dr. Hans Hecht zeigt (Objekte D 4-6). Dieser hatte der Universitätsbibliothek Göttingen unmittelbar nach seiner Zwangsentlassung 59 englischsprachige Bücher für einen Pauschalbetrag

\footnotetext{
${ }^{70}$ Helmut Neuberger: Freimauerei und Nationalsozialismus, Bd. II, Hamburg 1980, S. 105.
} 
von 245,- RM verkauft. ${ }^{71}$ Der Anglist und Robert-Burns-Forscher Hans Hecht, der mit einer „Nichtjüdin“ verheiratet war, überlebte die Zeit des Nationalsozialismus im Berliner Untergrund. Er verstarb - vermutlich geschwächt durch die entbehrungsreichen und leidvollen Jahre - am 8. Februar 1946 in Ostberlin. ${ }^{72}$ Aus einem Schreiben vom 9. Juli 1946 geht hervor, dass seine vier Kinder Deutschland verlassen hatten. ${ }^{73}$ Trotz aufwendiger Recherchearbeiten konnten bislang keine Auskünfte über ihren Verbleib oder den anderer Familienmitglieder ermittelt werden.

\section{1}

\section{Robert Schneiders Fachbibliothek zur Freimaurerei}

Zugangsbuch der Universitätsbibliothek Göttingen von 1944.

SUB Göttingen: Bibl. Arch. Zugangsbuch 1944

Am 23. Januar 1945 wurde im Zugangsbuch des Rechnungsjahres 1944 summarisch der Erhalt einer Fachbibliothek zur Freimaurerei vermerkt, die der Rechtsanwalt Dr. Robert Schneider der Universitätsbibliothek Göttingen für 3.500 Reichsmark verkauft hatte. Insgesamt umfasst dieser Bestand 1.500 Bände, die anscheinend „,nach vorgelegten Katalogen“ ausgewählt wurden.

\section{2}

\section{Robert Schneider vorübergehend in Göttingen wohnhaft}

Einwohnermeldekarte

Stadtarchiv Göttingen, Einwohnermelderegister

Auch nach gründlichen Recherchearbeiten konnte kaum etwas über den Rechtsanwalt Dr. Robert Schneider (1891-1960) in Erfahrung gebracht werden. Laut der im Stadtarchiv Göttingen überlieferten Einwohnermeldekarte lebte Schneider nur vorübergehend in Göttingen; als weitere Wohnorte sind Hamburg und Karlsruhe angegeben. Er war Mitglied in der Karlsruher Loge „Leopold zur Treue“, bevor er

\footnotetext{
${ }^{71}$ SUB Göttingen Bibl.Arch. C Zugangsbuch vom Rechnungsjahr 1935; dazu auch: Die Universität Göttingen unter dem Nationalsozialismus, hrsg. von Heinrich Becker u.a., 2. Aufl., München 1998, S. 405; Ute Schäfer-Richter / Jörg Klein: Die jüdischen Bürger im Kreis Göttingen: 19331945, Göttingen, Hann. Münden, Duderstadt. Ein Gedenkbuch, 2. Aufl., Göttingen 1993, S. 92.

72 Schäfer-Richter / Klein: Die jüdischen Bürger, S. 92.

${ }^{73}$ Universitätsarchiv Göttingen, Personalakte: Dr. Hans Hecht, Schreiben vom 9.7.1946.
} 
sich kritisch gegenüber der Freimaurerei äußerte. Die Schriften Schneiders sind nationalistisch und logenfeindlich überzeichnet. Die von ihm an die Universitätsbibliothek Göttingen verkauften Bücher haben die Freimaurerei zum Thema; viele von ihnen stammen - soweit es trotz entfernter Stempel ermittelbar ist - aus Logenbibliotheken.

\section{3}

\section{Die Wissenschaft der Freimaurerei}

Carl Nicolai Starcke:

Die Freimaurerei, ihre geschichtliche Entwicklung und kulturelle Bedeutung bei den verschiedenen Völkern. Hamburg : Rademacher [1913].

SUB Göttingen: $8^{\circ}$ Hist. un. III, 5905/c

Provenienz: Dr. Robert Schneider, 1945

Bei diesem Werk handelt es sich um die deutsche Übersetzung des 1911 in dänischer Sprache erschienenen Buches „Frimureriet, dets

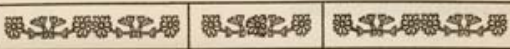

\section{Dir Strimnutterti}

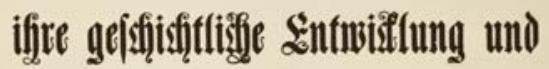

fulfurefle sedeutung

fiei den berifigiedenen \&öffertn. Oprindelse og Udvikling“. Sein Autor, der Kopenhagener Philosoph und Soziologe Carl Nicolai Starcke (1858-1926), war Mitglied der Freimaurerloge "Christian til Palmetræet" und besaß umfassende Kenntnisse über die Geschichte und die Organisationsstruktur der Freimaurerlogen. 1914 erschien noch eine weitere dänische Auflage der vergleichend angelegten Studie, die 1926 in das Schwedische übersetzt wurde.

\section{4}

\section{Hans Hecht - Anglistikprofessor}

Portrait von Prof. Dr. Hans Hecht

SUB Göttingen: Sammlung Voit: Hecht, Hans 
Prof. Dr. Hans Hecht (1876-1946) kam 1922 als ordentlicher Professor für englische Philologie an die Universität Göttingen. Als Frontkämpfer im Ersten Weltkrieg blieb er von der ersten Entlassungswelle 1933 zunächst verschont. Allerdings bekam er die Abneigung der nationalsozialistisch gesinnten Kollegen und Studenten wegen seiner jüdischen Abstammung zu spüren. Hecht reichte 1935 ein Urlaubsgesuch ein. Unmittelbar nach seiner Entlassung zum 1. Januar 1936 ging er nach Berlin. Er überlebte, geschützt durch seine Ehe mit einer „Arierin“ und zum Teil versteckt im Untergrund, das nationalsozialistische Regime. Im Februar 1946 starb er, durch die entbehrungsreichen Jahre geschwächt. Die 54 Bücher, die Hecht der Universitätsbibliothek Göttingen verkaufte, wurden im April 1935 in das Zugangsbuch aufgenommen. Vermutlich waren Geldsorgen der Grund für die Abgabe dieser Bücher. Im Juni 1936 bot er der Universitätsbibliothek zusätzlich seine rund 6.000 Bände umfassende Privatbibliothek zum Verkauf an. Diese Bücher sind jedoch nie in den Bestand aufgenommen worden.

\section{5}

\section{Hans Hecht: Emeritierung und Wegzug aus Göttingen}

Brief vom 23.6.1936.

Universitätsarchiv Göttingen, Kur. 1883

Der jüdische Anglistikprofessor Prof. Dr. Hans Hecht stellte im März 1935, nachdem es in seinen Veranstaltungen wiederholt zu Übergriffen seitens der Studenten und zu Anfeindungen einiger Kollegen gekommen war, einen förmlichen Antrag auf Emeritierung. Zunächst beurlaubt, erfolgte die offizielle Entlassung zum 1. Januar 1936. Hecht zog noch im selben Jahr nach Berlin. Dem Kurator der Universität Göttingen schrieb er in einem Abschiedsbrief: „Allen Schwierigkeiten zum Trotz bin ich entschlossen, meinen Weg fortzusetzen“.

\section{6}

\section{Essays über Schottlands Sprache und Literatur}

James Logie Robertson:

Furth in Field : A volume of essays on the life, language and literature of old Scotland by Hugh Haliburton [pseud]. London : T. Fisher Unwin, 1894.

SUB Göttingen: $8^{\circ}$ Hist. Brit. part. II, 4120/i

Provenienz: Prof. Dr. Hans Hecht, 1935 


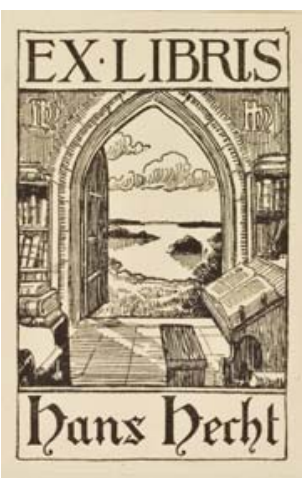

Nach seiner Ausbildung an der Universität in Edinburgh unterrichtete James Logie Robertson (1846-1922) an verschiedenen Colleges in Schottland. Er war ein eifriger Förderer der schottischen Literatur und Kultur und verfasste Beiträge für den „Scotsman“ und andere Zeitschriften. Unter dem Pseudonym Hugh Haliburton, angeblich ein Schäfer auf den Ochil Hills bei Stirling, publizierte er seit 1881 Gedichte und Essays. In diesem Buch ist das eindrucksvolle Exlibris des Göttinger Anglisten Prof. Dr. Hans Hecht erhalten geblieben, das den Blick aus einer Bibliothek auf eine Flusslandschaft zeigt.

HR

\section{7}

\section{Siegfried Ohnstein, ein Jude aus Berlin}

Thomas Scholz:

Chronik der Stadt Haynau in Schlesien.

Haynau : Selbstverlag, 1869.

SUB Göttingen: $8^{\circ}$ Hist. Sil. 5737

Provenienz: Siegfried Ohnstein Berlin

(Bezug über das Antiquariat W. Mueller, Berlin-Fried.), 1944

Siegfried Ohnstein wurde 1866 in Haynau (Schlesien) geboren und starb im Juli 1942 durch Freitod in Berlin. Sein Name steht im „Gedenkbuch für die Opfer der Verfolgung der Juden“, welches vom Bundesarchiv geführt wird. Das aus seinem

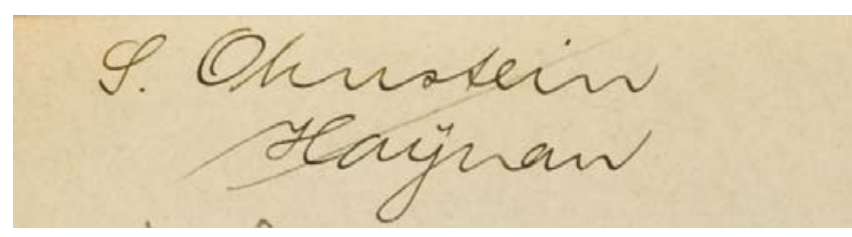
Besitz stammende Buch über die Geschichte seiner Geburtsstadt Haynau wurde von der Universitätsbibliothek Göttingen im Sommer 1944 über das Berliner Antiquariat W. Müller erworben. Das Autogramm Ohnsteins findet sich zweimal in dem Buch. 


\section{8}

\section{Hugo Heimann, Mäzen der Arbeiter}

Robert Hunter:

Socialists at work.

New York : Macmillan, 1908.

SUB Göttingen: $8^{\circ}$ Pol. III, 6409/ao

Provenienz: Hugo Heimann Berlin (Bezug über das Antiquariat Messow Berlin), 1944

Hugo Heimann (1859-1950) entstammte einer jüdischen Kaufmannsfamilie aus Westpreußen. Nach einer Buchhandelslehre hielt er sich für längere Zeit in England auf. In den 1890er Jahren führte er die Guttentagsche Verlagsbuchhandlung in Berlin, deren Verkauf ihn zu einem reichen Mann machte. Mit seinem Vermögen unterstützte er unter anderem die Arbeiterbewegung und stiftete die erste Volksbibliothek im Stadtteil Kreuzberg. Als Sozialdemokrat war er sowohl in der Berliner Stadtverordnetenversammlung als auch im Reichstag politisch aktiv. Der enge Vertraute Bebels ging kurz nach der Machtergreifung in die Emigration: zunächst nach Großbritannien, später nach New York, wo er im Jahre 1950 90jährig verstarb. Das Buch mit seinem Exlibris kaufte die Universitätsbibliothek Göttingen im Juli 1944 über das Antiquariat Messow in Berlin ein.

NB

\section{9}

\section{Benno Karpeles, jüdischer Sozialdemokrat aus Wien}

John Alfred Spender:

Life, journalism and politics, Vol. II.

New York : Frederick A. Stokes Company, 1927.

SUB Göttingen: $8^{\circ}$ Hist. Brit. un. III, 8499:2

Provenienz: Dr. Benno Karpeles Wien (Bezug über das Antiquariat Wolf, Wien), 1940

Benno Karpeles wurde 1868 in einer jüdischen Wiener Familie geboren, die durch die Speditionsfirma seines Vaters finanziell abgesichert war. Dieser großbürgerliche Hintergrund erlaubte es Karpeles, sich zeit seines Lebens sozialpolitisch zu engagieren. Als studierter Jurist und Ökonom war er in den 1890er Jahren Mitarbeiter der Arbeiter-Zeitung. Einige Jahre später beteiligte er sich maßgeblich am Aufbau des SPD-nahen Konsumvereins Vorwärts und der Großeinkaufsgesellschaft genossenschaftlicher Consumvereine GöC in Wien. Um seine Partei finanziell zu unterstützen, gründete er 1909 die Hammerbrotwerke. Unter dem Ein- 
druck der Schrecken des Ersten Weltkrieges gab er 1918 die pazifistische Wochenschrift „Der Friede“ heraus, ein Jahr später die linksintellektuelle Tageszeitung „Der Neue Tag“. Ein religiöses Erweckungserlebnis veranlasste ihn, einige Jahre vor seinem Tod zum Katholizismus überzutreten.

Dieses Buch mit dem Exlibris von Benno Karpeles kaufte die Universitätsbibliothek Göttingen im Herbst 1940 im Wiener Antiquariat Wolf. Es ist nicht bekannt, unter welchen Umständen das Buch in den Antiquariatshandel gelangte. Karpeles starb 1938, also im Jahr des „Anschlusses“ Österreichs an das Deutsche Reich, so dass auch hier die Repressionsmaßnahmen gegen Juden zu greifen begannen. Viele Juden sahen sich genötigt, ihren Besitz zu veräußern und zu emigrieren. Das Schicksal der Familie von Benno Karpeles konnte bisher nicht geklärt werden. Möglicherweise hätte sie die Bibliothek als Erbe eines verstorbenen Angehörigen auch unter anderen politischen Verhältnissen verkauft.

\section{10}

\section{Dresdner Jesuiten}

Anton Philipp Segesser:

Studien und Glossen zur Tagesgeschichte : Der Kulturkampf.

Bern : K. J. Wyß, 1875.

SUB Göttingen: $8^{\circ}$ Hist. Germ. XII, 554

Provenienz: Jesuitenpfarrei Sankt Petrus Dresden (Bezug über das Antiquariat J. Baumgarten, Dresden), 1942

Das Thema dieses Buches ist der Kulturkampf im Deutschen Kaiserreich während der 1870er Jahre, als dessen Folge auch die Gesellschaft Jesu verboten wor-

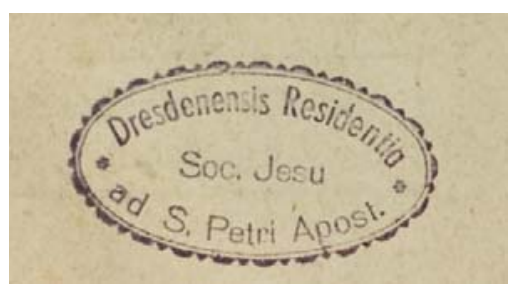

Konzentrationslagern inhaftiert.

Das Werk stammt aus dem Dresdner Antiquariat J. Baumgarten und wurde den war. Erst 1917 wurde der Orden in Deutschland wieder zugelassen. Im Dresdner Stadtteil Strehlen betreuten die Jesuiten seit 1930 die Pfarrei Sankt Petrus. Auch hier wurden während der Zeit des Nationalsozialismus Beschlagnahmungen durchgeführt. Angehörige des Jesuitenordens wurden verfolgt und in

\footnotetext{
Mitte 1942 in den Bestand der Universitätsbibliothek Göttingen aufgenommen.
Der Stempel trägt die Inschrift: „Dresdenensis Residentia Soc. Jesu ad S. Petri

Mitte 1942 in den Bestand der Universitätsbibliothek Göttingen aufgenommen.
Der Stempel trägt die Inschrift: „Dresdenensis Residentia Soc. Jesu ad S. Petri Apost."
} 


\section{11}

\section{Erschwerte Ermittlungen}

Joseph Sinel:

The sixth sense: A physical explanation of clairvoyance, telepathy, hypnotism, dreams and other phenomena usually considered occult.

London : Laurie, 1927.

SUB Göttingen: $8^{\circ}$ Phil. IV, 9785/i

Provenienz: H. J. Hansen (Bezug über das Antiquariat Häntzschel, Göttingen), 1942

Im Gegensatz zu den mit eindrucksvollen Exlibris versehenen ausgestellten Büchern weist dieses Buch lediglich ein mit Bleistift eingetragenes Autogramm „H. J. Hansen" auf. Auch wenn Hansen ein Datum und die Initialen der Vornamen hinzugefügt hat, reichen diese spärlichen Angaben nicht aus, um eine konkrete Person zu identifizieren. Der Eintrag sowie die Tatsache, dass das Antiquariat Häntzschel, von dem die Universitätsbibliothek Göttingen das Buch 1942 bezog, mit ausländischen Titeln aus dem skandinavischen Raum handelte, legen zwar die Vermutung nahe, dass es sich bei Hansen um eine Person aus dem Norden Europas handelt. Da der Name dort allerdings weit verbreitet ist und beispielsweise eine Ortsangabe oder Berufsbezeichnung fehlen, lässt sich die Suche nicht eingrenzen, weshalb H. J. Hansen für die Provenienzforschung eine anonyme Person bleibt.

Ein Ankauf des Buches vor der Besetzung Dänemarks und Norwegens im Jahr 1940 hätte das Buch völlig unverdächtig erscheinen lassen; zur Zeit der deutschen Besatzung aber ist zumindest ein Verdachtsmoment dafür gegeben, dass die Abgabe des Buches im Zusammenhang mit den politischen Verhältnissen gestanden haben könnte.

Dieser Fall steht exemplarisch für eine große Anzahl von Büchern, die während des Forschungsprojektes untersucht worden sind und für die nach Abschluss der Arbeiten kein eindeutiger Befund vorliegt.

In vielen Fällen ist ein Eintrag nicht mehr oder kaum noch lesbar beziehungsweise die Lesart unsicher, da mehrere Varianten in Frage kommen. Auch wenn ein Name lesbar ist, so führen Nachforschungen oftmals ins Leere, wenn die Person in keiner Personendatenbank geführt wird. Weiterführende Recherchearbeiten mit Hilfe archivalischer Quellen sind zumeist nur mit erheblichem Zeit- und Personenaufwand zu realisieren. 


\section{E. Raubgut am Seminar für Deutsche Philologie der Universität Göttingen}

Auch in den Institutsbibliotheken der Universität Göttingen gibt es Bestände aus NS-Raub- und Beutegut. Ein von der Arbeitsstelle für Provenienzrecherche/forschung am Institut für Museumsforschung der Staatlichen Museen zu Berlin und der Stiftung Niedersachsen gefördertes Forschungsprojekt widmet sich seit 2009 den Bibliotheken des Seminars für Deutsche Philologie, des Skandinavischen und des Sprachwissenschaftlichen Seminars. Die ermittelten Bestände werden derzeit in den Göttinger Universitätskatalog eingepflegt; die Untersuchung weiterer Teilbibliotheken steht bevor (die Arbeit in der Bibliothek des Seminars für Mittlere und Neuere Geschichte hat im August 2011 begonnen).

Anders als die Universitätsbibliothek Göttingen profitierten die Institute nicht direkt von Lieferungen der Preußischen Staatsbibliothek Berlin oder Abgaben durch NS-Dienststellen. Wolfgang Krause (1895-1970), ab 1938 Direktor der Abteilung für Nordische Philologie, leitete gleichzeitig die „Zentralstelle für Runenforschung des Ahnenerbe e.V.“, der Heinrich Himmler unterstehenden Abteilung der SS, deren Aufgabe es war, die ,geistige Weltherrschaft des arischen Germanentums“ „wissenschaftlich“ zu untermauern. Das „SS-Ahnenerbe“ sorgte für den zügigen Ausbau der Bibliothek, besonders durch skandinavische und runologische Literatur. Gelegentlich kamen täglich um 100 antiquarische Bücher in die Bibliothek - zumeist ohne erhaltene Kaufbelege.

Zum heutigen Zeitpunkt scheint es fast unmöglich zu sein, die Erwerbungspolitik der Jahre zwischen 1933 und 1945 beweiskräftig zu dokumentieren; die Direktoratsakten sind mutmaßlich bereits vor Kriegsende von belastendem Material „gesäubert“ worden. Das älteste erhaltene Zugangsbuch umfasst die Jahre ab 1937. Zumeist wurde weder Lieferant noch Kaufpreis notiert; die dafür vorgesehene Spalte blieb leer. Aus diesem Grunde ist es notwendig, jedes einzelne Buch autoptisch auf Verdachtsmomente wie Exlibris, Stempel fremder Bibliotheken, handschriftliche Namenseinträge usw. zu überprüfen. Bei der Durchsicht der Bücher stößt man vielfach auf durch Überklebung, Ausschnitt oder Radierung unkenntlich gemachte Vorbesitzervermerke (siehe Objekte E 3 - E 7). Viele der vor 1945 in die Bibliothek gelangten Bücher erhielten weder eine Inventarnummer 
noch wurden sie im Zugangsbuch verzeichnet. Gerade in solchen Bänden finden sich oftmals Indizien, die auf eine problematische Provenienz hindeuten.

Große Bestände der Skandinavistik und Sprachwissenschaft, besonders aber der „Abteilung für Runenforschung“, kamen aus den von der Wehrmacht besetzten Gebieten Frankreichs, Hollands, Belgiens und Dänemarks.

\section{E 1}

\section{Leerstellen I}

Bücher-Inventar-Verzeichnis

des Seminars für Deutsche Philologie [ca. 1938-1960]

Im ältesten erhalten Bücher-Inventar-Verzeichnis beziehungsweise Zugangsbuch des Seminars für Deutsche Philologie blieb die vorgesehene Spalte für Lieferdatum und Herkunft der Bücher in aller Regel leer; nur bei ca. 0,5 \% der (überwiegend antiquarischen) Zugänge wurde sie ausgefüllt.

Erst ab Mai 1944 wurden die Zugangsdaten, ab Januar 1945 dann auch regelmäßig die Lieferanten vermerkt. Die notierten Zugänge betreffen ab 1938 fast ausschließlich skandinavische Literatur. Diejenigen Bücher der deutschen Literatur, die ausweislich der Stempel zwischen 1933 und 1945 in die Bibliothek des Seminars für Deutsche Philologie gelangt sein müssen, finden sich zumeist nicht im Bücher-Inventar-Verzeichnis und erhielten auch keine Zugangsnummer - über Zeitpunkt des Eingangs und Lieferanten lassen sich keine Aussagen treffen.

FM

\section{E 2}

\section{Leerstellen II}

Akzessionsbuch des

Instituts für Runenforschung [1938-1947]

Das dem Seminar für Deutsche Philologie angegliederte Institut für Runenforschung, eine „Dienststelle der Reichsführung SS“ und gefördert durch das „SSAhnenerbe e.V.“, bezog nach der Besetzung Dänemarks durch die Wehrmacht im April 1940 große Lieferungen antiquarischer skandinavischer Bücher beim Kopenhagener Antiquar Ejnar Munksgaard, die durch die Buchhandelshäuser C. Boysen (Hamburg) und Harrassowitz (Leipzig) ausgeliefert wurden.

Die im Zugangsbuch für den Kaufpreis und das Bezahlungsdatum vorgesehen Spalte des Akzessionsbuchs blieb dabei stets leer. 
Viele Bibliotheken im Deutschen Reich waren höchst interessiert daran, ihre Bestände an „germanischer" Literatur aus Skandinavien auszubauen. Im Jahre 1943 strebte die „Abteilung Wissenschaft“ des bei Kriegsbeginn durch den Reichsführer-SS Heinrich Himmler gegründete Reichssicherheitshauptamtes in Berlin deshalb eine Kooperation mit dem Kopenhagener Buchhandelshaus Munksgaard an, wie aus einem Schreiben des SS-Sturmbannführers Dr. Ernst Turowski hervorgeht:

„Den Vorgang germanische Literatur habe ich weiter verfolgt und [...] ein gutes Stück vorwärts bringen können. Etwa Mitte nächster Woche ist eine erneute Besprechung im Reichswirtschaftsministerium angesetzt [...]. Allerdings wird der gesamte skandinavische Literaturbestand nicht mit einmal übernommen werden können, da die zur Verfügung stehenden Devisenmittel für Kopenhagen äußerst beschränkt sind. [...] Vielleicht ist es jetzt schon zweckmäßig, wenn Sie Herrn Munksgaard in Kopenhagen gelegentlich wissen lassen, daß der Vorgang nunmehr in ein akutes Stadium überwechselt und in der nächstfolgenden Zeit mit dem Abruf der Bücher begonnen werden würde." (Bundesarchiv, R 58/7135, Bl. 26)

Weitere Dokumente zu diesem „Vorgang“, den Details dieses angestrebten „Abrufs des gesamten skandinavischen Literaturbestandes“ und der Munksgaard dabei zugedachten Rolle haben sich weder in Berlin noch in Kopenhagen finden lassen.

FM

\section{E 3}

\section{Abgestempelt}

Iwan Goll:

Germaine Berton, die rote Jungfrau

Reihe: Außenseiter der Gesellschaft - Die Verbrechen der Gegenwart / hrsg. von Rudolf Leonhard ; 5.

Berlin : Verlag Die Schmiede [1925].

Seminar für Deutsche Philologie: W-GO 50 4/15

Provenienz: Nationalsozialistische Deutsche Arbeiterpartei Kreisschulungsleitung Hildesheim

Iwan Goll (1891-1950), bedeutender Dichter des Expressionismus und frühen Surrealismus, charakterisierte sich selbst als „durch Schicksal Jude, durch Zufall in Frankreich geboren, durch ein Stempelpapier als Deutscher bezeichnet“. Als Pazifist war er 1914 nach Frankreich emigriert, um nicht Soldat werden zu müssen. Bei Ausbruch des Zweiten Weltkriegess floh er mit seiner Frau, der Schriftstellerin Claire Goll, nach New York. Am 10. Mai 1933 war sein gesamtes Werk als ,jüdi- 
sche Zersetzungsliteratur“ auf dem Scheiterhaufen der Bücherverbrennung gelandet und verboten worden.

\section{E 4}

\section{Ausgeschnitten}

Max Brod:

Rëubeni. Fürst der Juden. Ein Renaissanceroman.

München : Kurt Wolff Verlag, 1925.

Signiertes und nummeriertes Exemplar

der Erstausgabe, Nr. 180 von 200.

Seminar für Deutsche Philologie:

W-BR 65 4/26 Mag.

Provenienz: Leihbücherei „Das neue Buch“, Berlin W 15, Pariserstr. 39/40

Max Brod (1884-1968): jüdischer Schriftsteller, seit 1933 verboten; auch in Leihbüchereien durften seine Werke nicht mehr angeboten werden. Auf dem Titelblatt und an zwei anderen Stellen dieses Buches wurden Vorbesitzervermerke ausgeschnitten; lediglich auf der letzten Seite ist der Stempel der Leihbücherei „Das neue Buch“ offenkundig übersehen worden. „Das neue Buch“ existierte lediglich von 1941 bis 1943; die Besitzerin hieß Helene Lutz. Ihr Schicksal nach 1943 ist unbekannt.

FM

\section{E 5}

\section{Aberkannt, geschwärzt}

Ruth Koplowitz:

Hölderlin als Briefschreiber. Inaugural-Dissertation, Frankfurt am Main 1931.

Augsburg : Heinrich Heber 1932.

Seminar für Deutsche Philologie: V-HO 20 7/30

Provenienz: unbekannt

Dissertation von Ruth Koplowitz (geboren 1906), verheiratete Heinrichsdorff, später verheiratete Blatt. Die jüdische Kommunistin und aktive NS-Gegnerin emigrierte 1933 nach England und lebte später als Sprachlehrerin in Melbourne, Australien. 1936 wurde ihr der Doktortitel der Universität Frankfurt/Main wegen „Hochverrats“ entzogen. Auf dem Umschlag des Bandes wurde der akademische Titel übermalt, auf dem Vorsatzblatt das Datum der Promotion (27. Juli 1931) 


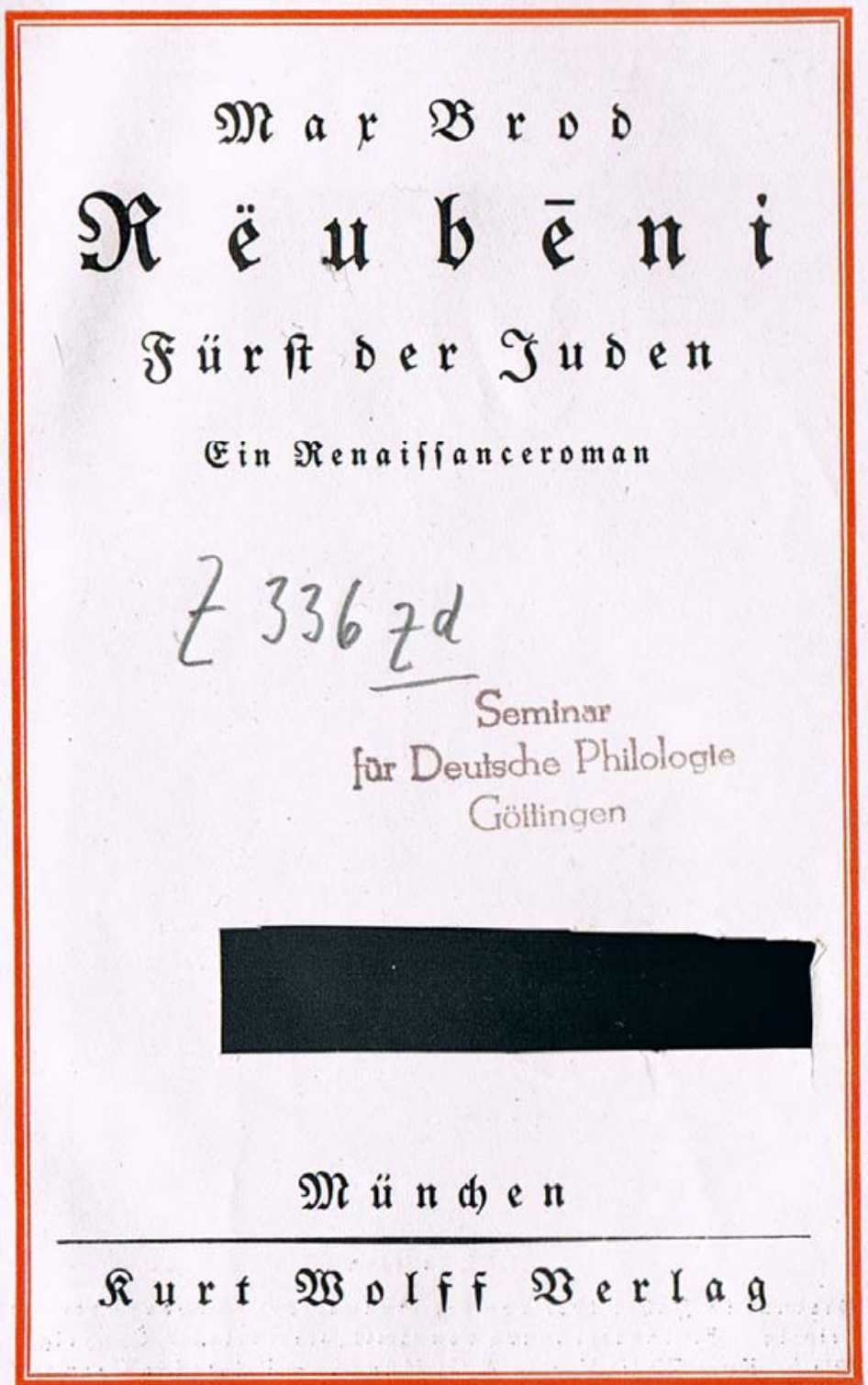

Abb.: Objekt E 4 
geschwärzt. Ruth Koplowitz war die Schwester des Germanisten Oskar Seidlin (1911-1984), der 1933 zunächst in die Schweiz, dann 1938 in die USA emigrierte. Wann der Band in das Seminar für Deutsche Philologie gelangte, ist unbekannt.

E 6

FM

\section{Abgekratzt}

Franz Werfel:

Der Gerichtstag in fünf Büchern.

München : Kurt Wolff Verlag, 1919.

Seminar für Deutsche Philologie: W-WE 75 4/9

Provenienz: unbekannt

Franz Werfel (1890-1945): jüdischer Schriftsteller, seit 1933 verboten. An drei Stellen des Bandes wurden Vorbesitzerstempel sorgsam abgekratzt; auch mit technischer Hilfestellung lassen sich nur noch die Worte „Arzt“ und „Berlin SW $23^{\text {" }}$ entziffern.

FM

\section{E 7}

\section{Überklebt}

Georg Brandes:

Henrik Ibsen. (Reihe: Die Literatur. Sammlung illustrierter Einzeldarstellungen, herausgegeben von Georg Brandes, Band 32).

Berlin : Bard Marquardt, ohne Jahr [um 1905].

Seminar für Deutsche Philologie: G-5 9/13

Provenienz: Albert Alsberg

Georg Brandes (1842-1927): jüdischer Schriftsteller aus Kopenhagen. Der handschriftlich eingetragene Name des Vorbesitzers wurde mit braunem Packpapier überklebt und überstempelt, lässt sich im Gegenlicht aber entziffern.

Das Buch gehörte Albert Alsberg, geboren am 14. April 1866 in Münster, wohnhaft in Berlin. Albert Alsberg wurde am 10. Juli 1942 nach Theresienstadt deportiert und kam dort am 17. Juni 1943 ums Leben. Theresienstadt diente ab Januar 1942 auch als „Altersghetto“ für alle „Reichsjuden“ mit einem Alter ab 65 Jahren. Ihnen wurde angemessene Unterbringung, ärztliche Versorgung und Verpflegung versprochen, im Gegenzug für so genannte „Heimeinkaufsverträge“, die oftmals komplette Vermögensübertragungen zugunsten des Deutschen Reichs bedeuteten. Die nach der Deportation im Reich verbliebenen Eigentümer wurden 
zum „staats- und volksfeindlichen Vermögen“ erklärt, beschlagnahmt und verkauft. Überlebende Nachfahren Albert Alsbergs konnten bislang nicht ermittelt werden. 


\section{F. Restitutionen und die Provenienzforschung an der SUB Göttingen nach Abschluss des Projektes}

Die systematische Auswertung der Zugangsbücher der Universitätsbibliothek Göttingen von 1933 bis 1950 hat es ermöglicht, wesentliche Fälle unrechtmäßiger Erwerbungen der Bibliothek zur Zeit des Nationalsozialismus zu ermitteln. Dennoch muss davon ausgegangen werden, dass es noch weitere, bislang nicht entdeckte und dokumentierte Fälle von NS-Raub- und Beutegut in den Beständen der SUB Göttingen gibt. Im Wesentlichen können diese Fälle zwei Gruppen zugeordnet werden:

Zum einen wurde unter den Erwerbungen bis 1950 eine Reihe von Verdachtsfällen ermittelt, bei denen es aufgrund fehlender Quellen bislang nicht möglich ist, eindeutig und verlässlich festzustellen, ob es sich tatsächlich um NS-Raubgut handelt (siehe Kap. D). Zum anderen muss davon ausgegangen werden, dass bei antiquarischen Erwerbungen bis in die 1980er Jahre hinein auch - in diesem Fall unwissentlich - NS-Raubbücher erworben wurden. Hinzu kommt, dass kleinere Restbestände der Zugänge vor 1945 erst in den 1950er und 1960er Jahren in den Bestand eingearbeitet wurden.

Angesichts der umfassenden Erwerbungen der Universitätsbibliothek Göttingen seit den 1950er Jahren ist es ausgesprochen schwierig, diese Fälle zu ermitteln. Im Zweifelsfall müssten ca. 1,5-2 Millionen Einträge in den Zugangsbüchern durchgesehen werden, um daraus antiquarische Erwerbungsvorgänge zu ermitteln, die dann wiederum autoptisch am einzelnen Buch auf Provenienzeinträge untersucht werden müssten.

Auch wenn für die Erwerbungen der Nachkriegszeit mithin eine vollständige und systematische Recherche nach NS-Raubgutfällen kaum möglich ist, wird die Recherche nach NS-Raubgut auch weiterhin eine Aufgabe der Bibliothekare der SUB Göttingen sein. Wenn in der Benutzung Bücher mit verdächtigen Provenienzeintragungen auffallen, müssen diese genauer untersucht werden. Sollte sich ein Verdacht auf NS-Raubgut erhärten, werden diese Angaben, ebenso wie die bereits ermittelten Raubgutfälle, im Göttinger Universitätskatalog (Objekt F 4) dokumentiert und an die Datenbank LostArt (Objekt F 3) weitergegeben. Doch nicht nur neue Verdachtsfälle können in den nächsten Jahren auftauchen. Es kann 
durchaus sein, dass auch zu ,alten“ Verdachtsfällen, zu denen es bislang keine ausreichenden Informationen gab, um sie sicher als NS-Raubgut oder zumindest als begründeten NS-Raubgutverdachtsfall einstufen zu können, neue Erkenntnisse gewonnen werden können. Da zurzeit auch an anderen Bibliotheken einschlägige Provenienzforschungsprojekte durchgeführt werden, ist es durchaus möglich, dass dort neue Informationen zu Büchern mit spezifischen Besitzeinträgen und Exlibris gefunden werden, die dann wiederum dazu führen können, dass bisherige Verdachtsfälle in Göttingen eindeutig geklärt werden können. Provenienzforschung mit Schwerpunkt auf den Erwerbungen von NS-Raub- und Beutebüchern wird somit in den kommenden Jahren eine Daueraufgabe der SUB Göttingen bleiben, auch wenn sie natürlich nicht mit derselben personellen Intensität wie im Rahmen des Projektes in den Jahren 2009 bis 2011 durchgeführt werden kann.

Die Recherche kann sich nicht nur darauf beschränken, Raubgutfälle zu dokumentieren. Wenn die Aussicht besteht, den legitimen Rechtsnachfolger des früheren Eigentümers zu ermitteln, muss dies versucht werden, um eine Restitution der Bücher anbieten und durchführen zu können, wie es während des Projektes zum Beispiel mit den Büchern von Heinrich Troeger geschah (Objekt F 1).

WE

\section{F 1}

\section{Die Bücher von Heinrich Troeger werden restituiert}

Foto von der Restitutionsveranstaltung in der Friedrich-Ebert-Stiftung, Bonn, am 14.4.2011

1934 schenkte der SPD-Politiker und Gegner der nationalsozialistischen Diktatur Dr. Heinrich Troeger der Universitätsbibliothek Göttingen 72 Bücher marxisti-

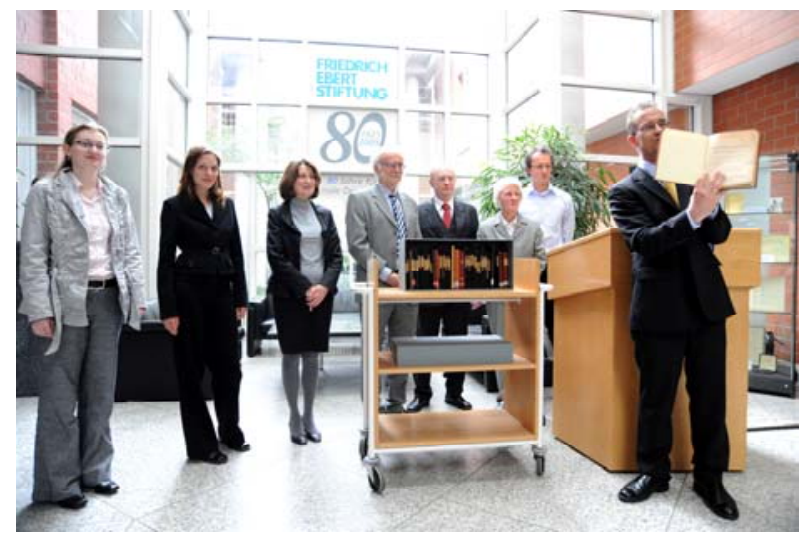
schen Inhalts aus seiner Privatbibliothek. Drohende

Verfolgungsmaßnahmen gegen ihn und die Beobachtung, dass verbotene Bücher von den Nationalsozialisten beschlagnahmt und als Druckmittel missbraucht werden konnten, hatten ihn zu diesem Schritt bewogen. Auf Wunsch der Familie Troeger, die von der SUB Göt- 
tingen über diesen Vorgang informiert worden war, wurden die Bücher der Bibliothek der Friedrich-Ebert-Stiftung in Bonn zugeführt. Die Friedrich-EbertStiftung, die eine Aufbewahrungsstätte von Dokumenten und Büchern mit dem Sammelschwerpunkt Geschichte der Arbeiterbewegung, der Sozialdemokratie und der Gewerkschaften ist, verwahrt bereits seit längerem den Nachlass Heinrich Troegers. Am 14. April 2011 wurde mit der feierlichen Übergabe der Bücher der Nachlass Troegers um die 1934 nach Göttingen abgegebene Literatur erweitert. Die SUB Göttingen hat die betreffenden Bücher aus ihrem Bestand gestrichen. Die Titel der Publikationen mit Anmerkungen zur Bucherwerbung als „NSRaubgut" sind jedoch zur Dokumentation des Vorgangs im Göttinger Universitätskatalog verblieben.

\section{F 2}

\section{Bericht über beschlagnahmte Bücher aus Verden in der Verdener Aller- Zeitung}

Artikel der Verdener Aller-Zeitung vom 25.3.2010.

(s. auch http://www.kreiszeitung.de/nachrichten/landkreis-

verden/verden/buecher-goettingen-aufgetaucht-689703.html)

Bei der Suche nach geraubter und erbeuteter Literatur im Bestand der SUB Göttingen wurden insgesamt 135 Bücher der Arbeiter-Zentralbibliothek und des Sozialdemokratischen Wahlvereins, Ortsgruppe Verden, entdeckt, die 1934 von den Nationalsozialisten beschlagnahmt worden waren. Dieser Vorgang wurde auf einer Informationsveranstaltung der SUB Göttingen im Jahr 2009 zum Göttinger Forschungsprojekt thematisiert. Interessiert an den genauen Umständen dieser Erwerbung, nahm der Verein Geschichtswerkstatt Verden Kontakt zu den Projektmitarbeitern auf und reiste nach Göttingen, um die relevanten Archivquellen und einige Buchbeispiele zu sichten. Im Anschluss verfassten die Verdener einen Artikel für ihre Lokalzeitung, in dem sie das Schicksal der Bücher darstellten.

\section{F 3}

Die internationale Suche nach NS-Raub- und Beutegut im Internet

Screenshot der Startseite der Internet-Datenbank für Kulturgutdokumentation und Kulturgutverluste „Lost Art“

http://www.lostart.de/Webs/DE/Start/Index.html 
Die im Internet zugängliche Datenbank Lost Art (www.lostart.de) wird von der Koordinierungsstelle Magdeburg betrieben, einer Einrichtung des Bundes und der Länder der Bundesrepublik Deutschland für Kulturgutdokumentation und Kulturgutverluste. Die Datenbank dient der Erfassung von Kulturgütern, die in der Zeit des Nationalsozialismus geraubt oder erbeutet wurden. In diesem Sinne untergliedert sich die Datenbank in Such- und Fundmeldungen. Ein Ziel des Forschungsprojektes „Ermittlung und Restitution von NS-Raubgut an der Niedersächsischen Staats- und Universitätsbibliothek Göttingen“ ist die Übermittlung aller entdeckten NS-Raubgut- und Verdachtsfälle an Lost Art.

Die Bekanntmachung dieser Kulturgüter im Internet erlaubt eine weltweite Suche nach geraubten oder erbeuteten Objekten und Ermittlung ihrer Verlustumstände, so dass Opfer oder deren Rechtsnachfolger bzw. Erben über Lost Art gezielt nach verlorenen Büchern suchen können.

\section{F 4}

\section{Die Dokumentation von NS-Raubgut im Universitätskatalog Göttingen}

Screenshot eines Buchbeispiels im Universitätskatalog Göttingen http://opac.sub.uni-goettingen.de

Der Göttinger Universitätskatalog verzeichnet in elektronischer Form die Medien der SUB Göttingen, ihrer Bereichsbibliotheken sowie von Instituts- und Seminarbibliotheken. Hier sind die aktuellen Ergebnisse des Forschungsprojektes dokumentiert, d.h. diejenigen Bibliotheksbestände, die sich als unrechtmäßige Erwerbungen herausgestellt haben, als auch diejenigen Eingänge, bei denen nach dem gegenwärtigen Stand der Recherchen ein solcher Verdacht besteht. Dabei sind die Katalogdaten (Autor, Titel, Körperschaft, Verlag etc.) durch zusätzliche Erläuterungen und Links erweitert.

Übergreifend werden NS-Raubgutfälle von Verdachtsfällen („Verdacht auf NS-Raubgut") unterschieden. Unter der Rubrik „Anmerkungen“ sind sämtliche Provenienzmerkmale (Stempel, Exlibris, Autogramm etc.) verzeichnet, die im Buch entdeckt wurden. In der Regel wird auch eine Abbildung davon erstellt und als Link eingefügt. Darüber hinaus steht dem Nutzer ein Hintergrundtext über den jeweiligen Bucheingang zur Verfügung. Eine Schnellsuche aller an der SUB Göttingen gefundenen Raub- und Beutebücher sowie aller Verdachtsfälle ist durch die Eingabe der Suchbegriffe „NS-Raubgut and erj<1945“ möglich. 


\section{Autoren}

Nicole Bartels, M.A.: Wissenschaftliche Hilfskraft im Projekt „Ermittlung und Restitution von NS-Raub- und Beutebüchern im Bestand der SUB Göttingen“ (bartels@sub.uni-goettingen.de)

Dr. Juliane Deinert: Wissenschaftliche Mitarbeiterin im Projekt „Ermittlung und Restitution von NS-Raub- und Beutebüchern im Bestand der SUB Göttingen“ (deinert@sub.uni-goettingen.de)

Dr. Wilfried Enderle: Fachreferent für Geschichte und Koordinator der Abteilung Informations- und Literaturversorgung Geistes- und Gesellschaftswissenschaften (wiss. Fachreferate, DFG-Sondersammelgebiete) der SUB Göttingen (enderle@sub.uni-goettingen.de)

Dr. Christian Fieseler: Stellv. Leiter der Abt. Spezialsammlungen und Bestandserhaltung der SUB Göttingen (fieseler@sub.uni-goettingen.de)

Prof. Dr. Frank Möbus: apl. Prof. für neuere deutsche Literaturwissenschaft an der Universität Göttingen; Leiter des Projektes NS-Raubgut an der Bibliothek des Seminars für Deutsche Philologie (frank.moebus@phil.uni-goettingen.de)

Dr. Helmut Rohlfing: Leiter der Abt. Spezialsammlungen und Bestandserhaltung der SUB Göttingen (rohlfing@sub.uni-goettingen.de) 
Bücher unter Verdacht - so lautete der Titel einer Ausstellung der NiederB sächsischen Staats- und Universitätsbibliothek Göttingen, bei der Beispiele von NS-Raub- und Beutebüchern aus ihren Beständen präsentiert wurden. Der Ausstellungskatalog dokumentiert nicht nur alle gezeigten Objekte, sondern gibt in kurzen Einführungen auch Informationen zum historischen Hintergrund. Wohl fast alle wissenschaftlichen Bibliotheken haben während des Dritten Reiches Bücher in ihre Bestände aufgenommen, die aus beschlagnahmten Bibliotheken von Arbeitervereinen und anderen Organisationen stammten, die bei Razzien in Buchhandlungen und Verlagen von den Nationalsozialisten entwendet und an Bibliotheken weitergegeben wurden, die Privatpersonen unter Zwang abgeben mussten oder die während des Krieges in den besetzten Gebieten geraubt wurden. Viele weitere Beispiele ließen sich nennen. Der vorliegende Ausstellungskatalog gibt einen Einblick in die zeitgenössische Praxis einer Universitätsbibliothek beim Umgang mit NS-Raub- und Beutebüchern, wie sie heute genannt werden. 